Daniel Makoto Tokunaga

\title{
TÉCNICAS DE RECONSTRUÇÃO E RENDERIZAÇÃO DE VÍDEO-AVATARES PARA EDUCAÇÃO E JOGOS ELETRÔNICOS
}




\title{
Daniel Makoto Tokunaga
}

\section{TÉCNICAS DE RECONSTRUÇÃO E RENDERIZAÇÃO DE VÍDEO-AVATARES PARA EDUCAÇÃO E JOGOS ELETRÔNICOS}

\author{
Dissertação apresentada à Escola Politécnica \\ da Universidade de São Paulo para obtenção \\ do Título de Mestre em Engenharia Elétrica.
}




\title{
Daniel Makoto Tokunaga
}

\section{TÉCNICAS DE RECONSTRUÇÃO E RENDERIZAÇÃO DE VÍDEO-AVATARES PARA EDUCAÇÃO E JOGOS ELETRÔNICOS}

\author{
Dissertação apresentada à Escola Politécnica \\ da Universidade de São Paulo para obtenção \\ do Título de Mestre em Engenharia Elétrica. \\ Área de concentração: \\ Sistemas Digitais \\ Orientador: \\ Prof. Livre-Docente Romero Tori
}


Este exemplar foi revisado e alterado em relação à versão original, sob responsabilidade única do autor e com a anuência de seu orientador.

São Paulo, 06 de julho de 2010.

Assinatura do autor

Assinatura do orientador

FICHA CATALOGRÁFICA

Tokunaga, Daniel Makoto

Técnicas de reconstrução e renderização de vídeo-avatares para educação e jogos / D.M. Tokunaga. -- ed. rev. -- São Paulo, 2010.

$107 \mathrm{p}$.

Dissertação (Mestrado) - Escola Politécnica da Universidade de São Paulo. Departamento de Engenharia de Computação e Sistemas Digitais.

1. Renderização 2. Computação gráfica 3.Realidade virtual 4. Jogos eletrônicos I. Universidade de São Paulo. Escola Politécnica. Departamento de Engenharia de Computação e Sistemas Digitais II. t. 
Dedico este trabalho aos meus pais, a todos que me apoiaram todo este tempo e ao futuro brilhante de todos. 


\section{AGRADECIMENTOS}

Agradeço ao meu orientador Prof. Dr. Romero Tori por ter orientado este trabalho e proposto diferentes ideias, ajudando o desenvolvimento deste trabalho e o meu desenvolvimento pessoal. Agradeço também a todos do Interlab, Profa. Dra. Fatima L. S. Nunes, Prof. Dr. Ricardo Nakamura, Ana Cláudia, Alexandre Tomoyose, Cléber Gimenez Corrêa, Daniel Callife, Fabio M. Carmo, Fernando Tsuda, João L. Bernardes, Lucas Padovane Trias, Roberto Cezar Bianchini, Silvio Ricardo R. Sanches, Valdinei Freire da Silva, que me ajudaram no desenvolvimento deste trabalho, me deram ideias, geraram debates e principalmente me aturaram por todo este tempo.

Também agradeço os alunos de graduação da POLI, Fábio Luiz Picchi, Anderson J. C. Cunha e André Uyeda, pelo auxílio na criação de aplicativos e na aplicação de testes. Os alunos de graduação do curso de design da FAU, Bruno S. Viana, Carina Missae B. Costa, Heloisa Yoshioka, Pedro G. Câmara e Samuel Henrique Sabadine da Cruz, por auxiliarem nos trabalhos de design e modelagem dos objetos 3D utilizados neste trabalho.

Esta dissertação não teria sido possível sem o apoio das instituições CAPES, pelo apoio com a bolsa, e FAPESP, com projeto Tidia que deu origem a este trabalho e auxiliou com as ferramentas utilizadas ao longo do trabalho.

Por fim, agradeço todos aqueles que me ajudaram diretamente ou indiretamente e que não listei aqui. E também, todos aqueles que não ajudaram, pois acredito que minimamente tiveram a boa vontade. 


\section{RESUMO}

Propiciar uma boa experiência de imersão ao usuário, quando este interage com conteúdos ou ambientes virtuais, é um dos principais desafios dos desenvolvedores e pesquisadores de tecnologias interativas, com destaque para realidade virtual e aumentada. Em especial nas áreas de educação e entretenimento, nas quais o engajamento do usuário e a significância dos conteúdos são cruciais para o sucesso da aplicação, é comum a busca por uma experiência que se aproxime de uma "imersão total" do participante. Quando as atividades envolvem interações a distância, um possível meio de se obter maior imersão são os chamados sistemas de "telecomunicação imersiva". Tais sistemas oferecem compartilhamento de um ambiente virtual e troca de informações entre participantes remotos, além da interação desses com o ambiente. Um componente importante desses sistemas é o "vídeo-avatar", uma representação visual do participante dentro do ambiente, baseado em sua captura de vídeo em tempo-real.

Este trabalho apresenta novas propostas de reconstrução geométrica e renderização para a geração e apresentação de um vídeo-avatar. Inicialmente, um modelo teórico para se modularizar as técnicas de reconstrução e renderização existentes foi proposto. Por meio desse modelo foi criada uma nova técnica de reconstrução geométrica e renderização, denominada "Video-based Microfacet Billboarding". Essa técnica emprega uma reconstrução e renderização em tempo-real que possibilita a representação de detalhes e melhora a percepção de integração com o ambiente. É também proposta neste trabalho o conceito de "non-photorealistic video-avatar", que visa aplicar um estilo não fotorrealístico único sobre toda a cena, a fim de melhorar a integração do avatar com o ambiente e, por sua vez, aumentar a imersão do usuário. Os resultados obtidos através da implementação do vídeo-avatar com essas técnicas e testes preliminares com usuários dão fortes indícios de que é possível a geração de uma representação visual que possua todos os requisitos do sistema iLive, sistema de telecomunicação imersiva voltado a educação e jogos eletrônicos em desenvolvimento pelo Laboratório de Tecnologias Interativas (Interlab) da Escola Politécnica da Universidade de São Paulo. 


\begin{abstract}
Providing good immersion experiences for users interacting with virtual contents or an environment is one of the main challenges for developers and researchers in interactive technologies, mainly virtual and augmented reality. Especially in areas of education and entertainment, in which the engagement of the user and the significance of content are of crucial importance for the success of the application, the search for experiences that approximate to one of a "total immersion" of the participant is common practice. When interaction at distance is necessary, one way to provide better immersion experiences is the use of a solution called "Immersive Telecommunication System". This kind of system can provide the sharing of the virtual environment among participants, information exchange among them, and also their interaction with the virtual environment. One of the most important component of these systems is the "video-avatar", the representation of the participant in the virtual environment based on a video of the participant captured in real-time.

This work presents new approaches of geometric reconstruction and rendering for the creation of a video-avatar. First, a theoretical model to modularize the existing reconstruction and rendering approaches was proposed. Based on this model, a new approach of geometric reconstruction and rendering, called "Video-based Microfacet Billboarding", was conceived. This approach uses a technique of real-time reconstruction and rendering that enables the representation of the object details and improves the integration of the avatar in the virtual environment. In this work, it is also proposed the concept of "non-photorealistic video-avatar", that aims to apply a non-photorealistic style over all the scene to improve the avatar integration with the environment, and with this, to enhance the user's immersion. The results obtained by the implementation of a video-avatar with these approaches, as well as preliminary users tests, gives us strong evidences that we could create a user representation that attends all the requisites of the iLive system, an immersive telecommunication system for education and gaming purposes, in development by the Interactive Technologies Laboratory (Interlab) of Escola Politécnica da Universidade de São Paulo.
\end{abstract}


内容梗概

インタラクティブテクノロジーの分野、とくに仮想現実と拡張現実の分野においての 主要な挑戦の一つとして、ヴァーチャルコンテンツと対話するユーザーのより一層の 没入体験の提供が挙げられる。特に教育やエンターテイメントなどユーザーのヴァー チャルコンテンツの捉え方がその体験の成功を左右する分野では、ユーザーの “完全 没入”を目的とする探求が行われている。ユーザ一同士の遠隔対話が必要とされる場 合、この没入間を得る方法として “Immersive Telecommunication System”を用い る事が出来る。この類のシステムでは仮想空間の共有、ユーザー同士の遠隔的な情報 交換、そしてこのユーザー達の仮想空間とのインタラクションが可能とされる。これ らのシステムで重要な要素として、仮想空間内でのリアルタイム現実映像を基にした ユーザーの表現方、“Video-Avatar”がある。

本論分ではこの Video-Avatar の生成のための新たな 3 次元形状復元\&レンダリン グ方のアプローチを提唱、実装化する。まず、これら 3 次元形状復元\&レンダリング 方をいくつかの断片にモジュール化出来る理論モデルが作られ、それを基にした新た な 3 次元形状復元\&レンダリング方、“Video-Based Microfacet Billboarding”が作ら れた。この技法は、実物体のディテールの表現、作り出されたアバターと仮想空間の より一層の統合が得られるリアルタイム復元\&レンダリングを可能とする。本論分で はさらに、仮想物体、復元物体の一つのノンフォトリアリスティック画風での統一に よって得られるアバターと仮想空間のより一層の統合、それによってユーザーの更な る没入が得られる、“Non-Photorealistic Video-Avatar” の概念を提唱する。これらの アプローチの実装や初期ユーザーテストによって得られた成果からは、Laboratório de Tecnologias Interativas (Interlab) da Escola Politécnica da Universidade de São Paulo によって開発中の教育用、エンターテイメント用 Immersive Telecommunication シス テム、iLive に必要な特徴を持った Video-Avatar を生成することが出来たと言う強い 確証が見て取れる。 


\section{LISTA DE FIGURAS}

1.1 Conceito de um sistema de telecomunicação imersiva . . . . . . . . . . . . . . 16

2.1 Virtual Reality continuum (MILGRAM et al., 1994) . . . . . . . . . . . . . 22

3.1 Proposta da detecção de fundo proposta por Bergh e Lalioti (1999) . . . . . . 29

3.2 Fluxograma do processo de remoção de fundo porposto no trabalho Sanches, Sementille e Tori (2009) . . . . . . . . . . . . . . . . . . . . 30

3.3 Técnica de switching planes. . . . . . . . . . . . . . . . . . . . 31

3.4 Avatar planar com o uso de estereoscopia (SISCOUTTO; TORI, 2004). . . . . . 32

3.5 A profundidade D correspondente a um ponto I da imagem . . . . . . . . . 33

3.6 Arranjo para imageamento estéreo (NAKAMURA, 2008). . . . . . . . . . . 33

3.7 Deformação de malhas triangulares por mapa de alturas (NAKAMURA, 2008). . 35

3.8 Switching Depth Model(OGl et al., 2001) . . . . . . . . . . . . . . . 35

3.9 Cálculo de coloração na técnica de splats . . . . . . . . . . . . . . 37

3.10 Simplificação de splats proposta por Naef (NAEF; STAADT; GROSS, 2004) .. 38

3.11 Reconstrução geométrica por visual hull . . . . . . . . . . . . . . . . . . . 38

3.12 Ambiente de captura utilizado por Matusik (MATUSIK et al., 2002) . . . . . . . 40

3.13 Microfacet Billboarding (YAMAZAKI et al., 2002) . . . . . . . . . . . . . . . 41

4.1 Representação visual do modelo teórico proposto . . . . . . . . . . . . . . . . 46

4.2 Possíveis transições de informações propostas . . . . . . . . . . . . . . . . . . . . 48

4.3 Técnica de Visual Hull (LAURENTINI, 1994; MATUSIK; BUEHLER; MCMILLAN, 2001) descrita segundo o modelo proposto. . . . . . . . . . . . . . . . . . . . 49

4.4 Técnica de Opacity Hull (MATUSIK et al., 2002) descrita segundo o modelo proposto. . . . . . . . . . . . . . . . . . . . . 50 50 
5.1 Técnica de Video-Based Microfacet Billboarding (VBMB) descrita segundo o modelo teórico proposto. . . . . . . . . . . . . . . . . . . . . . . . . 54

5.2 Conceito base da técnica VBMB . . . . . . . . . . . . . 56

5.3 Falha da reconstrução devido ao tamanho do micro-billboard . . . . . . . . . 57

5.4 Limitação da técnica de mapa de alturas f . . . . . . . . . . . . . . . . . . . 58

5.5 Algoritmo para renderização do vídeo-avatar. . . . . . . . . . . . . . . . . . . 59

5.6 Controle de nível de detalhe na técnica VBMB . . . . . . . . . . . . 60

5.7 Cálculo da: 5.7(a) normal de cada pixel e 5.7(b) normal de cada face . . . . . 60

5.8 Algoritmo para geração do mapa de normais através do mapa de alturas. . . . 61

5.9 Algoritmo para renderização do avatar com a coerência com a iluminação virtual, utilizado no pixel shading da placa gráfica. . . . . . . . . . . . . . . . 62

5.10 Quinas da imagem ao longo da imagem geradas pelo erro de posicionamento de cores. . . . . . . . . . . . . . . . . . . . . . . 62

5.11 Técnica de splats aplicada ao VBMB . . . . . . . . . . . . . . 63

5.12 Procedimento de renderização dos objetos virtuais utilizado para a geração do estilo "sombrio".

5.13 Algoritmo de cel shading modificado para a renderização dos objetos virtuais, utilizado no pixel shading da placa gráfica. . . . . . . . . . . . . . . . . . . 67

5.14 Procedimento de renderização do avatar utilizado para a geração do estilo "sombrio".

5.15 Algoritmo de cel shading modificado para a renderização do vídeo-avatar, utilizado no pixel shading da placa gráfica.

6.1 Renderização por microfacet billboarding à direita e à esquerda, imagem plana renderizada por um billboard para comparação

6.2 Comparação das reconstruções por VBMB e deformação de malhas triangulares 73

6.3 Vídeo-avatar dentro de um ambiente virtual . . . . . . . . . . . . . . . . . . . . . 74

6.4 Vídeo-avatar com iluminação em diferentes posições . . . . . . . . . . . . . . 74

6.5 Aplicação de iluminação tangível . . . . . . . . . . . . . . . . . . 75 
6.6 non-photorealistic video-avatar em ambientes virtuais . . . . . . . . . . . . 76

6.7 Comparação entre o non-photorealsitic video-avatar e o vídeo-avatar realista em ambientes realistas e não fotorealistas . . . . . . . . . . . . . . . . . . . . 77

6.8 Resultado da renderização utilizando-se a técnica de splats sobre o VBMB. . . 77

6.9 Comparação entre o a técnica de splats+VBMB e VBMB convencional . . . . 78

6.10 Função "Big Head", que pode ser utiliza para se gerar o caricatured video-avatar 78

6.11 Gráfico FPS $\times$ Subdivisão de imagem $(10$ à 100$) \ldots$. . . . . . . . . . . . . 80

6.12 Gráfico FPS × Subdivisão de imagem (30 à 300) . . . . . . . . . . . . . . . . 80

6.13 Comparação das técnicas VBMB e mesh render na reconstrução de um objeto detalhado . . . . . . . . . . . . . . . . . . . . . 83

6.14 Comparação das técnicas VBMB e mesh render na reconstrução de um avatar 84

6.15 Qualidade visual do avatar X Valor de Subdivisões . . . . . . . . . . . . . . . 85

6.16 Comparação da integração do vídeo-avatar com o ambiente, ambos em diferentes estilos . . . . . . . . . . . . . . . . . . . . . . . . . 86

6.17 Comparação da integração do vídeo-avatar em um ambiente de jogo, com ou sem o estilo do ambiente. . . . . . . . . . . . . . . . . . . . . . . . . . 87

6.18 Arquitetura do sistema iLive . . . . . . . . . . . . . . . . . . . . . . . . 88

7.1 Imagem conceito de um jogo de poker utilizando vídeo-avatares. . . . . . . . . 94 


\section{LISTA DE TABELAS}

3.1 Técnicas de reconstrução $X$ características . . . . . . . . . . . . . . . . 43

4.1 Fluxo de dados de técnicas de reconstrução geométrica descritas segundo o modelo proposto . . . . . . . . . . . . . . . . . . . 52

5.1 VBMB e outas técnicas de reconstrução X características . . . . . . . . . 55 


\section{SUMÁRIO}

1 Introdução 16

1.1 Objetivos . . . . . . . . . . . . . . . . . . . . . . . . . . . . . . . . 18

1.2 Motivação e Justificativa . . . . . . . . . . . . . . . . . . . . . . . . . 18

1.3 Requisitos do Trabalho . . . . . . . . . . . . . . . . . . . . . . . . . . . . 19

1.4 Contribuições . . . . . . . . . . . . . . . . . . . . . . . . . . . . . . . . . . . . . . . . . . . . . . 19

1.5 Metodologia . . . . . . . . . . . . . . . . . . . 20

1.6 Organização do Texto . . . . . . . . . . . . . . . . . . . . . . 20

2 Conceitos Fundamentais $\quad 22$

2.1 Realidade Aumentada . . . . . . . . . . . . . . . . . . . . . . 22

2.2 Telecomunicação Imersiva $\ldots \ldots \ldots$. . . . . . . . . . . . . . . . . . . . . . . . . . . . . . . . 24

2.3 Vídeo-Avatar . . . . . . . . . . . . . . . . . . . . . 25

2.4 Reconstrução Geométrica e Renderização . . . . . . . . . . . . . . . . . . . . 25

2.5 Considerações Finais . . . . . . . . . . . . . . . . . . . . . . . . . . . . . . . 26

3 Técnicas de Reconstrução Geométrica e Renderização, Captura de Dados e $\begin{array}{ll}\text { Processamento } & 28\end{array}$

3.1 Remoção de Fundo . . . . . . . . . . . . . . . . . . . . . . . . . . . . . . . 28

3.2 Representação Bidimensional e Estereoscópica . . . . . . . . . . . . . . . . . . . 30

3.3 Mapa de Profundidade . . . . . . . . . . . . . . . . . . . . . . . . . . . 32

3.4 Reconstrução por Mapa de Alturas e Deformação de Malhas Triangulares . . . 34

3.5 Renderização de Voxel Colorido e Renderização por Nuvem de Pontos . . . . . 36

3.6 Splats . . . . . . . . . . . . . . . . . . . . . . 36 
3.7 Visual Hull . . . . . . . . . . . . . . . . . . . . . . . . . . . . . . . . . . . . . . . . . . . . . . 37

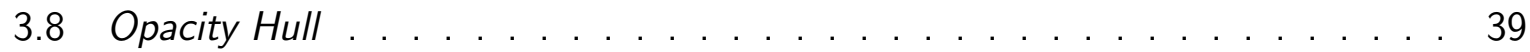

3.9 Microfacet Billboarding . . . . . . . . . . . . . . . . . . . . . . 41

3.10 Considerações Finais . . . . . . . . . . . . . . . . . . . . . . . . . . . . . . . 42

4 Modelo Teórico Proposto $\quad 45$

4.1 Módulos . . . . . . . . . . . . . . . . . . . . . . . . . . 46

4.1 .1 Aquisição de Dados . . . . . . . . . . . . . . . . . . . . . . . . 46

4.1 .2 Modelagem Geométrica . . . . . . . . . . . . . . . . . . . 46

4.1 .3 Renderização . . . . . . . . . . . . . . . . . . . . . . . . . . 47

4.2 Transições . . . . . . . . . . . . . . . . . . . . . . . . . . . . . . . . 47

4.3 Técnicas Existentes $\ldots \ldots \ldots$. . . . . . . . . . . . . . . . . . . . . . . . . . . . . . . . . . . 49

4.4 Considerações Finais . . . . . . . . . . . . . . . . . . . . . . . . . . . . . . . 51

5 Técnicas de Reconstrução e Renderização Propostas 53

5.1 VBMB: Video-Based Microfacet Billboarding . . . . . . . . . . . . . . . . 53

5.1 .1 Base Conceitual . . . . . . . . . . . . . . . . . . . 55

5.1.2 Controle de Nível de Detalhamento $(L o D) \ldots \ldots . . . . . . . .57$

5.1.3 Iluminação Utilizando Técnicas de Mapa de Normais . . . . . . . . . . . 58

5.1 .4 Splats . . . . . . . . . . . . . . . . . . 60

5.2 Non-photorealistic Vídeo-avatar . . . . . . . . . . . . . . . . . . . 63

5.2.1 Base Conceitual . . . . . . . . . . . . . . . . 63

5.2 .2 Base Técnica . . . . . . . . . . . . . . . . . . . . . . . . 64

5.2 .3 Caricatured Vídeo-Avatar . . . . . . . . . . . . . . . . . 68

5.3 Considerações Finais . . . . . . . . . . . . . . . . . . . . . . . . . . 70

6 Resultados $\quad 71$

6.1 Implementação . . . . . . . . . . . . . . . . . . . . . 71 
6.1 .1 java3D: Imagem Estática f . . . . . . . . . . . . . . . . 71

6.1 .2 Visualização: Vídeo-Based . . . . . . . . . . . . . . . . 72

6.1 .3 Coerência de Iluminação . . . . . . . . . . . . . . . . . . . . . . . . 73

6.1 .4 Non-photorealistic Vídeo-Avatar . . . . . . . . . . . . . . . . . . . 75

6.1 .5 Splats + VBMB . . . . . . . . . . . . . . . 76

6.1 .6 Big Head . . . . . . . . . . . . . . . . . . . . . . . . . . . . . . . . . . . 78

6.2 Testes e Análise . . . . . . . . . . . . . . . . . . . . . . . . . . . . . . . . . . . . 78

6.2 .1 Testes de Desempenho . . . . . . . . . . . . . . . . . . . . . . 79

6.2 .2 Testes com Usuários . . . . . . . . . . . . . . . . . . . . . . . . . . 81

6.3 Integração com o Sistema iLive . . . . . . . . . . . . . . . . . 87

6.4 Considerações Finais . . . . . . . . . . . . . . . . . . . . . . . . . . . . . . . 88

7 Conclusão $\quad 89$

7.1 Discussões Sobre o Trabalho . . . . . . . . . . . . . . . . . . . . . . . . . . 89

7.2 Vídeo-Avatar e Jogos Eletrônicos . . . . . . . . . . . . . . . . . . . . . 91

7.3 Trabalhos futuros . . . . . . . . . . . . . . . . . . . . . 95

$\begin{array}{ll}\text { Referências Bibliográficas } & 96\end{array}$

$\begin{array}{ll}\text { Apêndices } & 103\end{array}$

I Teste com Usuários $\quad 103$ 


\section{INTRODUÇÃO}

Prover novas experiências para os usuários sempre foi uma das preocupações em diversas áreas, incluindo as de educação, realidade aumentada e jogos computacionais. Atualmente, um tema de pesquisa desafiador para essas áreas é o de telecomunicação imersiva (LEE et al., 2005; OGI et al., 2003), que envolve sistemas que possibilitam o compartilhamento de um ambiente virtual imersivo por múltiplos participantes remotos e interação desses com o ambiente. A figura 1.1 mostra um exemplo conceitual do ideal desses ambientes.

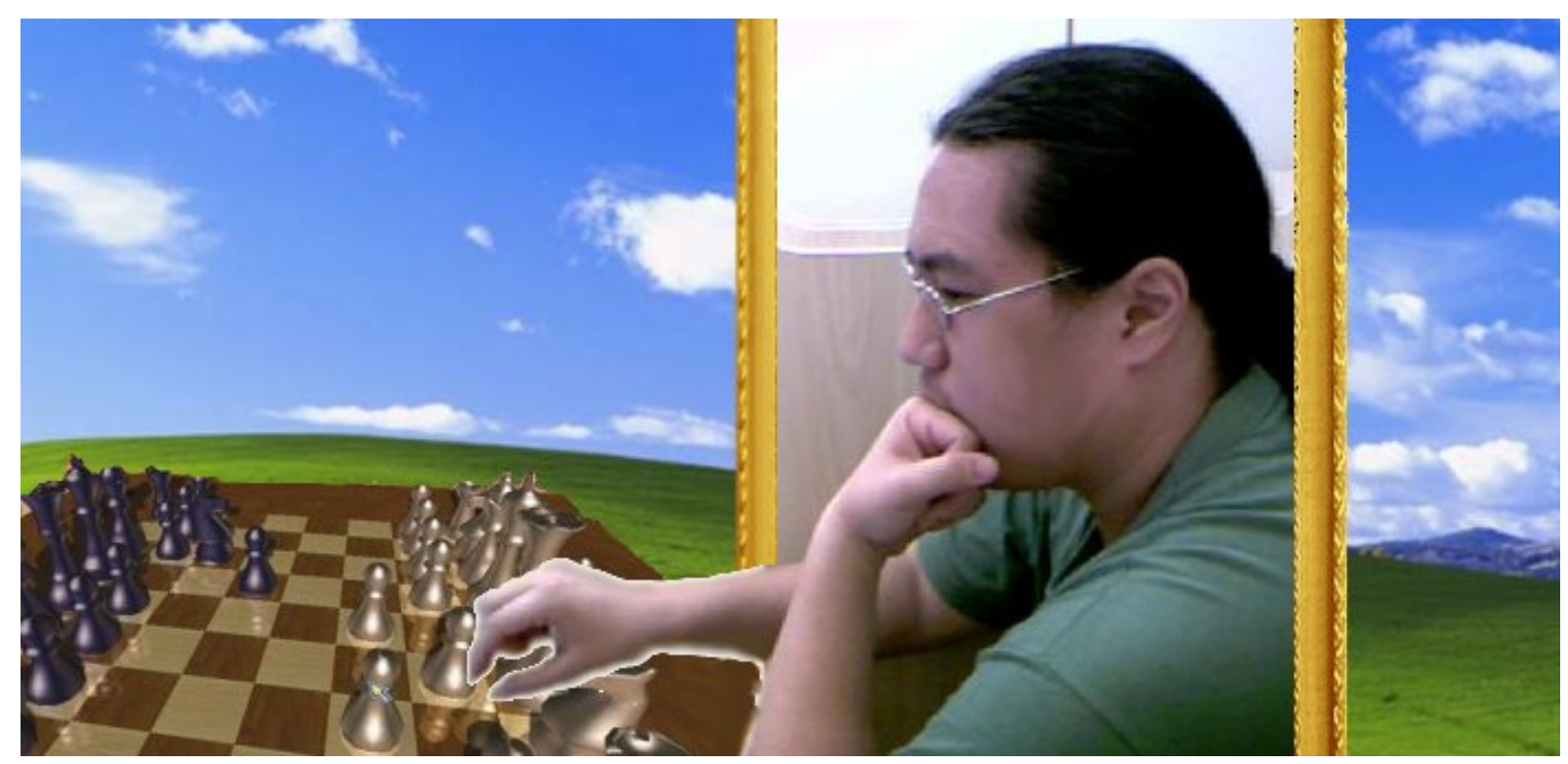

Figura 1.1: Conceito de um sistema de telecomunicação imersiva

O Interlab (Laboratório de Tecnologias Interativas da Escola Politécnica da Universidade de São Paulo) tem como uma de suas linhas de pesquisa essa telecomunicação imersiva voltada para o uso em jogos eletrônicos e educação. Uma iniciativa dessa linha é o projeto iLive (Imersive Ludic\&Learning Interactive Vídeo-avatar Environment) que faz parte do projeto de pesquisa Tidia, projeto financiado pela FAPESP que tem como objetivo o desenvolvimento de soluções inovadoras para aprendizagem eletrônica sobre a infraestrutura da Internet Avançada.

Um importante elemento desses sistemas imersivos é o vídeo-avatar (NAKAMURA, 2008), representação em tempo-real dos participantes dentro do ambiente virtual. Essa representação 
deve permitir que os visualizadores possam identificar e interpretar o participante dentro de um ambiente virtual, e mais, ela deve transmitir a ilusão que o participante se encontra realmente dentro do ambiente virtual. Desta forma, em uma aula virtual, os alunos possam entender os gestos e expressões faciais do professor que está dentro do ambiente virtual, tornando a experiência de educação mais rica e interessante (KELTON, 2007; TORI, 2010).

Com base nesses casos, pode-se dizer que a representação do participante deve possuir as seguintes características:

- Tempo-real;

- Representação detalhada do participante;

- Integração avatar dentro do ambiente virtual.

No exemplo da aula virtual, a característica de tempo-real é necessária para que o professor consiga ministrar a aula e interagir com o ambiente em tempo-real, não sendo uma aula prégravada e pós-processada. A representação detalhada é importante para que o aluno possa interpretar feições faciais do professor e seus gestos, como apontar para um objeto virtual, tornando a comunicação entre participantes mais natural (CANTONI; CELLARIO; PORTA, 2004). Por fim, a integração do avatar com o ambiente virtual torna a sensação de presença dos participantes maior, aumentando a sensação de imersão dos participantes (BERGH; LALIOTI, 1999).

Nota-se que, dentre as diferentes características do vídeo-avatar, essas características levantadas acima se relacionam com a representação visual do participante. Para se obter essa representação visual, diferentes técnicas de computação gráfica podem ser utilizadas, como as de reconstrução geométrica e renderização. Muitos estudos sobre essas técnicas podem ser encontrados dentro da literatura, tais como o visual hull (MATUSIK; BUEHLER; MCMILLAN, 2001), opacity hull (MATUSIK et al., 2002) e microfacet billboarding (YAMAZAKI et al., 2002). Porém muitas delas não satisfazem as três características simultaneamente, por exemplo, não sendo em tempo-real, ou não possibilitando a representação de detalhes do participante.

O presente trabalho tem como foco a pesquisa e implementação de técnicas para a renderização da representação visual do participante que possuam as três características levantadas acima. Dessa forma, possibilitando a representação do usuário dentro dos sistemas de telecomunicação imersiva voltados a educação e jogos eletrônicos. 


\subsection{Objetivos}

O objetivo deste trabalho é propor novas formas de reconstrução geométrica e renderização, focando-se no processo de renderização para a representação do participante dentro do ambiente virtual. Essa representação deve possuir as características de ser: em tempo-real, poder representar detalhes do participante e transpor a ilusão de estar integrado no ambiente virtual. Características que foram levantadas como necessárias para a criação de um sistema de telecomunicação imersiva voltada para aplicações de educação e jogos eletrônicos.

Para se criar uma técnica de reconstrução geométrica e renderização que satisfaça essas características, inicialmente é proposto uma forma de se modularizar o conceito de reconstrução geométrica e renderização, possibilitando uma análise das técnicas existentes. Para a implementação da representação visual do participante, a técnica de microfacet billboarding (YAMAZAKI et al., 2002) é estendida para ser utilizada em tempo-real, juntamente com a técnica de mapa de alturas (NAKAMURA; TORI, 2008). Ainda, no trabalho, é proposto o conceito de vídeo-avatar não fotorrealístico, forma de renderizar o vídeo-avatar não tendo como foco a fidelidade visual em relação à realidade, mas com o foco de integrar o visual do avatar em relação ao ambiente virtual no qual o avatar será situado. Aumentado a integração do vídeo-avatar em relação ao ambiente, e por sua vez provendo maior sensação de presença do usuário.

\subsection{Motivação e Justificativa}

Pode se inferir por diferentes trabalhos (OGI et al., 2003; PRINCE et al., 2002; HAUBER et al., 2005) que a imersão total do usuário dentro de um ambiente virtual é um dos pontos que se aspira alcançar em diversas áreas como as de realidade aumentada e realidade virtual. Os sistemas de telecomunicação imersiva (OGl et al., 2003; LEE et al., 2005) tornam, em certo nível, possível o compartilhamento de um ambiente virtual entre participantes remotos, permitindo essa imersão dentro de um ambiente virtual, troca de informações entre esses participantes e interação desses com o ambiente virtual.

Esse ambiente imersivo que permite o compartilhamento do ambiente virtual com diversos participantes pode ser utilizado em aplicações de educação ou jogos eletrônicos para prover novas experiencias aos usuários, tornando esse processo de educação ou entretenimento mais rico (KELTON, 2007; TORI, 2010). Assim, para se analisar essas experiencias de usuário utilizando-se esses ambientes de telecomunicação imersiva em educação e jogos eletrônicos, 
iniciou-se o projeto do sistema de telecomunicação imersiva, denominado iLive, no Interlab.

Verificou-se, através de pesquisas exercidas sobre os sistemas de telecomunicação imersiva existentes, que um dos mais importantes fatores nesses ambientes está na representação visual do participante, denominado vídeo-avatar (NAKAMURA, 2008). Diferentes técnicas de reconstrução geométrica e renderizaçãos podem ser utilizadas para se gerar esses vídeo-avatares. Porém, muitas dessas técnicas não possuem todas as características que se julgou ser necessárias para sistema iLive (tempo-real, representação de detalhes e integração com o ambiente tridimensional). Assim este trabalho teve como motivação esse desafio de criar um vídeo-avatar que tenha essas características, para se gerar a representação visual do participante dentro do sistema iLive, e desta forma, permitido a inserção dos participantes dentro do ambiente virtual.

\subsection{Requisitos do Trabalho}

Este trabalho, como apresentado previamente, segue os requisitos propostos pelo desenvolvimento do sistema iLive, que por sua vez, se baseia na especificação do sistema de teleconferência apresentado no trabalho de Siscoutto (2003). Desta forma, considera-se que o vídeo-avatar é inserido em um local do espaço virtual definido pelo próprio participante. Considera-se também que a câmera virtual é controlada diretamente pelo participante, assim os usuários observadores não tem controle total da visualização.

O sistema iLive também utiliza o conceito de "Janela3D", apresentado por Trias e Tori (2009). Aqui, os usuários podem modificar a posição da câmera virtual, em pequenos ângulos, de acordo com a posição de sua cabeça. Assim, o usuário pode ter a ilusão de estar visualizando o ambiente virtual através de uma "janela".

Desta forma, pode se afirmar que os requisitos considerados neste trabalho são os três derivados da aula virtual (tempo-real, representação de detalhes e integração do avatar com o ambiente virtual) apresentados no capítulo 1 , e os propostos pelo próprio sistema iLive, apresentados nesta seção (os requisitos baseados nos trabalhos de Siscoutto (2003) e Trias e Tori (2009)).

\subsection{Contribuições}

As contribuições deste trabalho podem ser separadas em três grandes grupos: modelo conceitual, técnica de renderização e integração com o sistema iLive. A primeira contribuição é o modelo teórico para a modularização das técnicas de reconstrução geométrica e renderização, 
possibilitando a análise das técnicas em nível de informação e facilitando a visualização das possíveis concatenações de diferentes técnicas.

A segunda contribuição é o conjunto de técnicas de renderização do visual do participante. Para tal representação, propõe-se a técnica de video-based microfacet billboarding (VBMB), que estende a técnica de Yamazaki et al. (2002) para ser utilizado em tempo-real e com a coerência de sombreamento com a iluminação virtual. Para aumentar a integração do avatar em relação ao ambiente, o conceito de non-photorealistic video-avatar também é proposto neste trabalho, e sua implementação foi integrada com o VBMB como parte da técnica de representação visual do participante.

Uma última contribuição deste trabalho é a integração da técnica de renderização com o sistema de telecomunicação imersiva iLive, desenvolvido pelo Interlab. Isso torna possível a renderização do avatar tridimensional dentro do ambiente virtual compartilhado remotamente entre os participantes.

\subsection{Metodologia}

Para proceder a este trabalho, inicialmente foi exercida uma pesquisa sobre os sistemas de telecomunicação imersiva, para o levantamento de aspectos importantes nesses sistemas. Após esse passo, foram efetuadas pesquisas de técnicas de reconstrução geométrica e renderização, para se analisar as técnicas utilizadas atualmente na literatura.

Depois das pesquisas sobre a área, foram criadas provas de conceito (POC) dos métodos a serem utilizadas na técnica de visualização do participante, possibilitando a análise e provar a viabilidade dessas técnicas. A técnica de representação do usuário, a ser proposta neste trabaIho, se deriva dessas provas de conceitos. Após essas etapas, testes com usuários especialistas e testes de desempenho da técnica foram exercidos.

\subsection{Organização do Texto}

Esta dissertação é constituída por um total de sete capítulos. Inicialmente os objetivos, motivações, metodologia e estrutura do texto são apresentados neste capítulo, de forma a apresentar uma visão geral do trabalho para o leitor. No capítulo 2, os conceitos fundamentais utilizados, necessários para a compreensão do texto, são apresentados. O capítulo 3 se dedica a apresentar e discutir as técnicas de reconstrução geométrica e renderizaçãos e técnicas relacionadas, utilizadas para gerar o vídeo-avatar, de uma forma mais detalhada. 
Os capítulos 2 e 3 fazem parte da pesquisa exercida, se dedicando a apresentar trabalhos já existentes na literatura. Já os capítulos 4, 5 e 6 descrevem as propostas e resultados deste trabalho. O capítulo 4 apresenta o modelo conceitual proposto para modularizar o conceito de reconstrução geométrica e renderização, dando base à técnica de renderização implementada. O capítulo 5 se dedica a apresentar as propostas de técnicas de renderização utilizadas para a representação do participante dentro do ambiente virtual. No capítulo 6, os resultados obtidos neste trabalho são apresentados e discutidos.

Por fim, o capítulo 7 apresenta as conclusões obtidas na dissertação bem como discussões sobre a área. Nesse capítulo também é discutida a utilização de vídeo-avatares em jogos, mostrando seus potenciais e problemas no seu uso nessas situações. Também, nesse capítulo, serão apresentados possíveis trabalhos futuros desta dissertação. 


\section{CONCEITOS FUNDAMENTAIS}

Este capítulo dedica-se a apresentar os conceitos fundamentais abordados, que serão utilizados como base para a explicação e desenvolvimento deste trabalho. São eles os conceitos de: realidade aumentada, vídeo-avatar, telecomunicação imersiva e reconstrução geométrica.

\subsection{Realidade Aumentada}

Uma das primeiras formalizações do conceito de realidade aumentada foi proposta por Milgram et al. (1994). Nesse trabalho, Milgram propõe a ideia do Virtual Reality continuum, uma taxonomia para classificar os sistemas computacionais que misturam informações virtuais com informações das cenas reais. A figura 2.1 ilustra essa proposta.

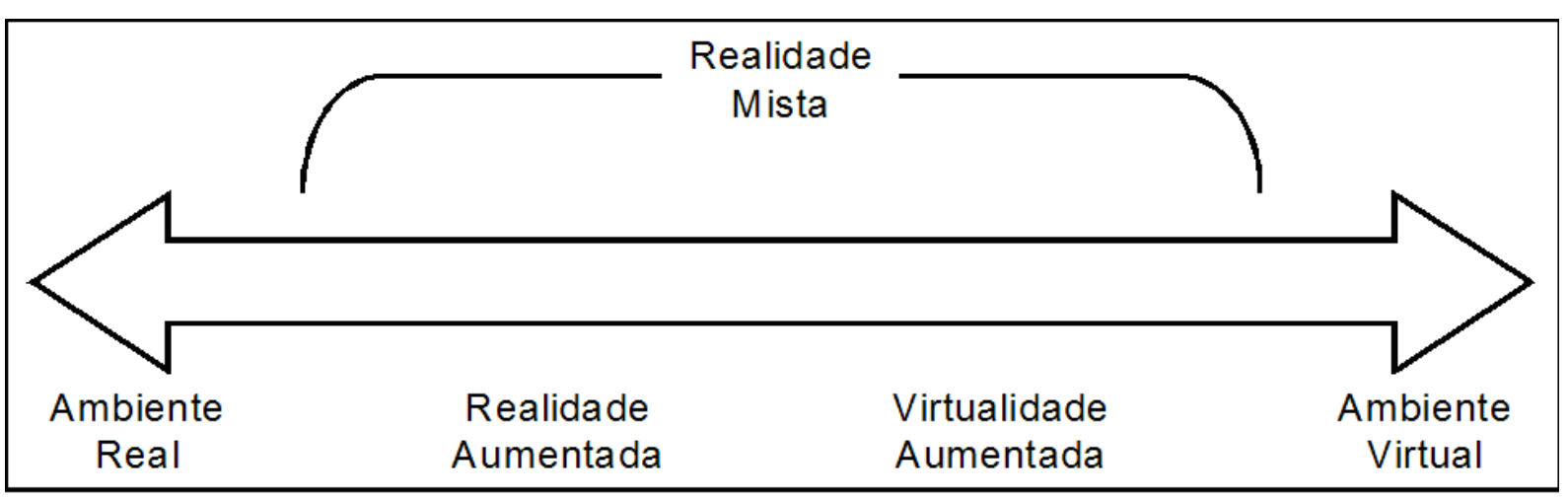

Figura 2.1: Virtual Reality continuum (MILGRAM et al., 1994)

Um dos extremos do continuum de Milgram é a realidade virtual, que compreende ambientes totalmente sintetizados. O outro extremo são os ambientes reais, nos quais incluem-se os sistemas de telepresença, em que o usuário observa remotamente ambientes reais. Todos os sistemas intermediários que fazem o uso composto de elementos reais e virtuais são definidos pelo autores como sistemas de Realidade Mista (Mixed Reality). Dentro desse grande grupo, Milgram define dois sub-grupos de sistemas, os sistemas de Realidade Aumentada (Augmented Reality) e Virtualidade Aumentada (Augmented Virtuality). A definição de realidade aumentada considera que, os objetos virtuais são inseridos no ambiente real, dessa forma 
"aumentando" o ambiente real com elementos sintetizados. Já na definição de virtualidade aumentada, esses conceitos são invertidos, de forma que o ambiente virtual é "aumentado" com a inserção de elementos reais.

Essa definição proposta por Milgram possui a vantagem de permitir se definir mais detaIhadamente o tipo do sistema, auxiliando a compreensão das técnicas e soluções existentes. Porém a distinção entre realidade aumentada e virtualidade aumentada é muito tênue nessa definição, podendo tornar complexa a classificação de alguns sistemas.

Outra formalização do conceito de realidade aumentada é a proposta por Azuma (AZUMA, 1995). Azuma, em seu trabalho, define a realidade aumentada como sendo todo o "intermediário" entre ambientes totalmente sintéticos (realidade virtual) e totalmente reais. Essa definição é similar a definição de realidade mista de Milgram. Porém, Azuma também define que os sistemas de realidade aumentada são aqueles que possuem as seguintes três características:

- Combinação de virtual e real;

- Interação em tempo-real;

- Registro em 3D.

A combinação de virtual e real caracteriza a combinação visual harmoniosa de elementos reais e virtuais. A interação em tempo-real define que os sistemas de realidade aumentada devem possibilitar alguma forma de interação do usuário em tempo-real, descartando sistemas de pós-processamento, por exemplo, os efeitos especiais em cinema. Por fim, o registro em 3D caracteriza que o sistema deve ter uma coerência espacial entre os objetos virtuais e reais. Descartam-se, portanto, simples inserções de imagens virtuais no ambiente, ainda que interativas e tridimensionais, que não possuam registro espacial com o restante do ambiente. Essa definição possui a vantagem de ser independente de tecnologias específicas e incertezas de classificação.

Para se obter uma combinação visual mais natural de elementos reais e virtuais, muitas propostas são apresentadas na literatura. Por exemplo, tentando-se renderizar os objetos virtuais de forma realista sem inconsistências visuais com o ambiente ( $\mathrm{GROSCH}, 2005)$, ou tentando-se sintetizar os elementos reais e virtuais de forma a aparentarem não possuir inconsistências visuais entre si (FISCHER; HALLER; THOMAS, 2008).

Já na área de interações em tempo-real, técnicas de interação 3D, como os apresentados no trabalho de Bowman (BOWMAN et al., 2004) podem ser aplicadas. Porém, prover interações mais intuitivas e diretas se mostra um dos grandes desafios dessa área. Uma forma 
de se superar esse desafio é utilizando-se técnicas de interações tangíveis (ISHII, 2008). Por fim, as informações de registro podem ser obtidos através de técnicas como marcadores fiduciais (KOLSCH; TURK; HOLLERER, 2004) ou métodos estatísticos de SLAM (Simutaneous Localization and Learning) (BLESER; WUEST; STRICKER, 2006).

\subsection{Telecomunicação Imersiva}

Avanços tecnológicos de diversas áreas tornam possível a criação de novos meios de telecomunicação que permitem interações e comunicações mais ricas e diversificadas. Uma nova linha de pesquisa dentro da área de realidade aumentada é a de telecomunicação imersiva, que tem como objetivo o compartilhamento de ambientes virtuais entre participantes utilizando-se informações da realidade. Nesses ambientes, os participantes podem compartilhar um ambiente virtual, interagir com os objetos virtuais e trocar informações por voz e por meios visuais, como gestos e expressões faciais. Dessa forma, provendo uma experiência de comunicação mais rica entre os participantes.

Ogi apresenta em seu trabalho o conceito do MVL (Multimedia Virtual Laboratory) (OGI et al., 2003), um laboratório virtual que possibilita trabalhos em grupos com alta sensação de presença dentro de ambientes virtuais. Ogi idealiza que, com esses ambientes imersivos, engenheiros, designers e cientistas podem discutir sobre projetos, compartilhando remotamente os mesmos modelos virtuais de design e resultados de experimentos.

Lee (LEE et al., 2005) apresenta a telecomunicação imersiva como sendo uma área de pesquisa desafiadora. $\mathrm{O}$ autor cita que o principal objetivo desses sistemas é prover modalidades de comunicação ricas, semelhante às comunicações feitas em reuniões do tipo face-a-face através de gestos, expressões faciais e coerência sonora espacial. Outra importante característica desses sistemas está na possibilidade de interação do participantes com o ambiente virtual, se diferenciando assim da vídeo-conferências ou conferências baseadas em realidade virtual.

Um importante aspecto nesses trabalhos é a representação do usuário dentro dos ambientes virtuais, para que ocorra a imersão do usuário e a troca de informações entre participantes. Para tal representação podem ser utilizados os vídeo-avatares, representações virtuais de pessoas utilizando-se informações da realidade. 


\subsection{Vídeo-Avatar}

A palavra avatar tem como origem a linguagem sânscrito, que tem o significado de "encarnação". Já na área de realidade virtual, essa palavra pode ser definida como uma representação do usuário, humanoide ou não, dentro do ambiente virtual (KIRNER et al., 2001).

Nakamura (2008) estende essa definição para o conceito de vídeo-avatar. O autor define o vídeo-avatar como sendo uma representação virtual baseada na imagem do usuário, obtida através de um dispositivo de aquisição de vídeo e atualizado em tempo-real. É importante notar que essa definição não limita o avatar como sendo uma representação completa do corpo do usuário, englobando representações de usuários que não tem uma reconstrução completa, como no trabalho de (OGI et al., 2003), ou representações planares (SISCOUTTO; TORI, 2004). Também é importante notar que a definição de Nakamura considera a aquisição e atualização da representação o visual do usuário em tempo-real. Dessa forma, essa definição não considera a atualização de modelos 3D previamente modelados por model fitting (BLANZ; VETTER, 1999).

\subsection{Reconstrução Geométrica e Renderização}

Renderização baseada em imagens ("image-based rendering") é a denominação para técnicas que tem o objetivo de renderizar novas visualizações de uma cena ou objeto através de imagens capturadas do ambiente real. Shum e Kang (1999) definem que as técnicas de renderização baseadas em imagens podem ser separadas em três categorias dependendo do nível de informação geométrica utilizada: a abordagem sem a utilização de geometrias, a abordagem com a utilização implícita de geometrias e a abordagem com a utilização explicita de geometrias.

Na literatura existem muitos trabalhos que fazem parte dessa última categoria, onde seu objetivo é obter e renderizar modelos tridimensionais de cenas ou objetos reais através de imagens capturadas da cena real. Essa obtenção permite a utilização desses modelos geométricos, não só para a renderização, mas também para a interação desses com outros objetos virtuais (PETIT et al., 2009). Essas técnicas são denominadas image-based modeling and rendering(SHUM; CHAN; KANG, 2006), porem, esses métodos possuem o problema de não conseguirem representar cenas dinâmicas.

Por outro lado, existem trabalhos na literatura que tem como objetivo capturar movimentos da cena real para se tentar obter informações dinâmicas da cena, como as técnicas de motion capture (RASKAR et al., 2007). Magnor (2005), define o conceito de renderização baseada em vídeos ("video-based rending") como uma união dessas duas ideias, de image-based rendering 
e motion capture. O autor afirma que o objetivo final da renderização baseada em vídeos é renderizar de forma realista uma cenas, ou objetos, reais e dinâmicos em 3D e em temporeal. O autor também afirma que em ambos os casos, image- e video-based rendering, são executados dois processos: o de análise de imagem e síntese de imagem.

Neste trabalho, são denominados como métodos de reconstrução geométrica e renderização as técnicas de renderização baseadas em imagem ou vídeo que fazem parte das abordagens com a utilização explicita de geometrias da categoria definida por Shum e Kang (1999) ("imageou video-based modeling and rendering").

\subsection{Considerações Finais}

Neste capítulo alguns conceitos importantes utilizados neste trabalho foram apresentados. Esta seção se dedica a discutir e definir quais definições dos conceitos serão utilizadas neste trabalho, auxiliando a compreensão dos demais capítulos.

Para a definição de realidade aumentada, a definição de Azuma (AZUMA, 1995) será utilizada, uma vez que os sistemas de vídeo-avatar e telecomunicação imersiva encontram-se exatamente na linha tênue entra as definições de realidade aumentada e virtualidade aumentada propostas por Milgram et al. (1994), podendo complicar a classificação de alguns sistemas. Já, para a definição de vídeo-avatar a definição de Nakamura (NAKAMURA, 2008) será adotada neste trabalho.

Na seção 2.2, a definição de dois sistemas de telecomunicação imersiva foram apresentadas, o sistema de Ogi (OGl et al., 2003) e Lee (LEE et al., 2005). Através dessas duas definições, podemos levantar algumas importantes características desse tipo de sistema:

- Compartilhamento de um ambiente virtual entre participantes remotos;

- Representação visual dos participantes;

- Interação dos participantes com o ambiente virtual em tempo-real.

Dessa forma, podemos definir que um sistema de telecomunicação imersiva é um sistema que possui essas três características listadas, provendo uma experiência imersiva entre usuários remotos, onde eles podem se comunicar de forma mais natural e interagir com o ambiente virtual.

Por fim, neste trabalho, o conceito de reconstrução geométrica e renderização é abordado como sendo a junção dos processos de image-based e video-based modeling and rendering, 
apresentados por Shum, Chan e Kang (2006). Dessa forma podemos definir que a reconstrução geométrica e renderização é a denominação para os processos de sintetização de modelos tridimensionais reconstruídos através de informações ou sequências de informações, como imagens, capturadas do ambiente real e a sua renderização tridimensional. 


\section{TÉCNICAS DE RECONSTRUÇÃO GEOMÉTRICA E RENDERIZAÇÃO, CAPTURA DE DADOS E PROCESSAMENTO}

Um dos principais módulos de sistemas de vídeo-avatar e telecomunicação imersiva é a representação do usuário dentro do ambiente virtual. Para se obter essa representação diferentes métodos de reconstrução geométrica e renderização e diferentes técnicas de processamento de imagens podem ser utilizadas. Neste capítulo veremos algumas técnicas de reconstrução geométrica e renderização, métodos para a aquisição de dados, processamento e renderização que podem ser utilizados para a representação do usuário no ambiente 3D.

\subsection{Remoção de Fundo}

A remoção de fundo é um processo que consiste na segmentação das regiões desejadas de uma imagem, como a imagem do usuário, em relação ao restante da cena. Esse procedimento é bastante utilizado em vários dos métodos de reconstrução e renderização, uma vez que muitos desses métodos necessitam da imagem do usuário isolado do restante da cena.

Para tal remoção, muitas técnicas podem ser utilizadas, tais como as baseados em cor e contraste (BERGH; LALIOTI, 1999; CRIMINISI et al., 2006), movimentação (BARRON; FLEET; BEAUCHEMIN, 1994; CRIMINISI et al., 2006), métodos estatísticos (CRIMINISI et al., 2006), informações temporais ou espaciais (BOYKOV; JOLLY, 2001; KUMAR; TORR; ZISSERMAN, 2005). Uma das técnicas mais simples e amplamente utilizada é a de chromakey (SANCHES, 2007), que se baseia na informação de cor dos pixeis da imagem. Nesse método, um ambiente com fundo monocromático é preparado previamente e todas as regiões que contem essa cor são subtraídas no processo de remoção, de forma que somente a imagem do usuário restaria como resultado. Esse método tem como vantagem a implementação simples e, devido a esse fato, seu custo computacional também é baixo. Porém, a detecção de uma determinada cor pode falhar em muitos casos devido as imprecisões da cor capturada, proveniente da câmera ou da iluminação local. Para se evitar tais erros, muitos trabalhos acrescentam uma faixa de 
tolerância em relação a cor que se deseja ser capturada.

Bergh e Lalioti (1999) propõem uma extensão da técnica de chromakey, introduzindo essa faixa de tolerância com o intuito de diminuir as falhas de detecção da cor. Os autores inicialmente restringem a cor que podem ser detectada ao azul ${ }^{1}$. Dado essa restrição, considera-se um plano $S$ que corta o cubo RGB, que representa o espaço de cores, e considerase também que esse plano é perpendicular ao vetor que une o centro do cubo à cor primária que se deseja detectar. Considera-se que todas as cores que se encontram "sobre" o plano é a cor a ser detectada. A figura 3.1 ilustra a proposta.

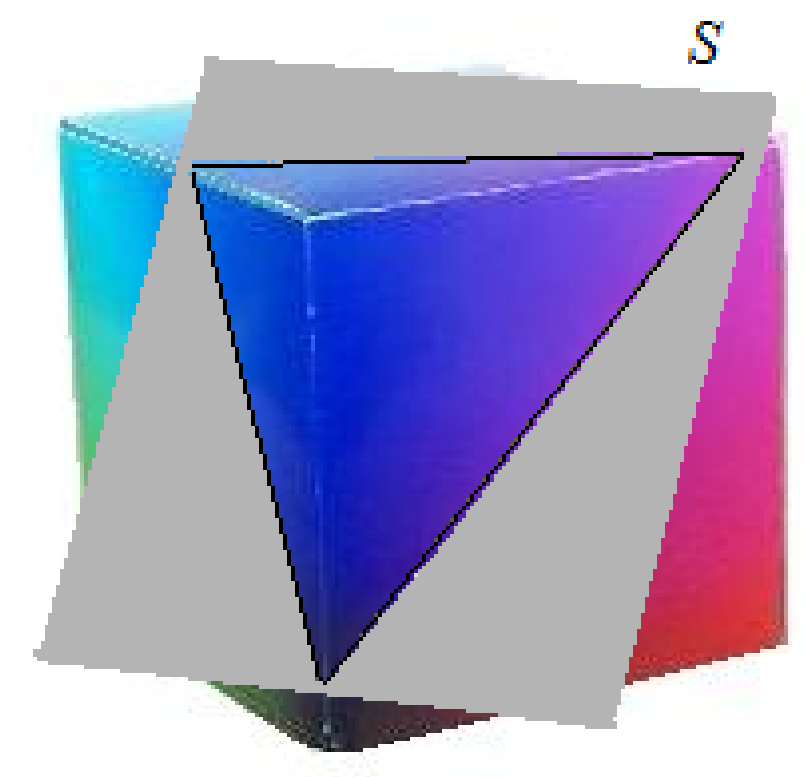

Figura 3.1: Proposta da detecção de fundo proposta por Bergh e Lalioti (1999)

Para se verificar se um pixel está "sobre" ou "sob" o plano $S$, a seguinte equação é utilizada:

$$
D=2 * B-R-G
$$

Caso $D$ seja maior que uma constante, considera-se que a cor está "sobre" o plano. Essa equação é uma simplificação do cálculo de distância do pixel relativo ao plano que corta o espaço de cores, mais detalhes sobre o algoritmo podem ser encontrado no trabalho original (BERGH; LALIOTI, 1999). Esse método possui a vantagem de ser simples, ter menos falhas e possuir desempenho computacional melhor em relação a outros métodos.

Outro método utilizado para a remoção de fundo é a proposta por Qian e Sezan (1999). Nesse método, a informação do fundo deve ser previamente conhecida. Para tal, inicialmente

\footnotetext{
${ }^{1}$ Porém esse método pode ser utilizado para qualquer uma das cores primárias, i.e. vermelho, verde ou azul
} 
uma imagem do fundo é capturada. O processo de remoção é executado verificando-se a diferença da imagem atual em relação à imagem capturada inicialmente. Caso um pixel seja igual ao pixel da imagem de capturada, esse é considerado como fundo. O método possui a vantagem de não necessitar de uma configuração física especial, porém é menos robusto que os métodos de chromakey apresentado mais falhas na remoção.

Sanches, Sementille e Tori (2009) apresentam em seu trabalho um método que mescla essas duas propostas além da estimativa de valores de transparência variável para pixeis com valores intermediários, com o intuito de melhorar a qualidade da remoção. Nesse método, cada pixel é analisado através da detecção por subtração de fundo. Caso o pixel seja classificado como fundo, outra verificação, utilizando-se o método de detecção por chromakey, é efetivada. Nesse momento, caso o pixel não obtenha um valor que o defina como sendo fundo, um valor de alpha proporcional ao seu valor é atribuído. Dessa forma, criando uma zona de transição entre os pixeis que representam o fundo e a imagem desejada. A figura 3.2 ilustra o algoritmo utilizado.

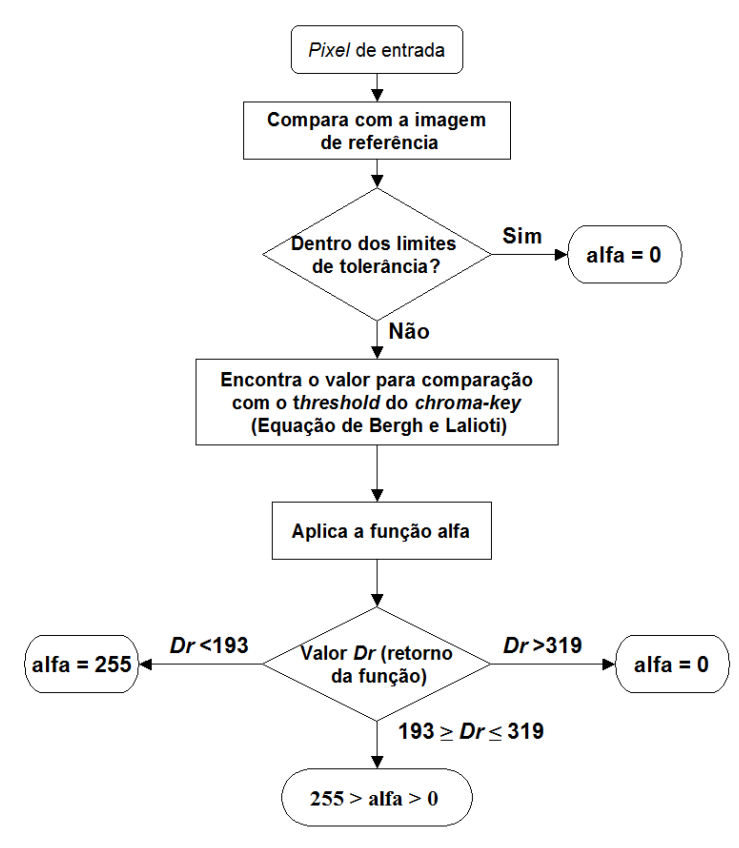

Figura 3.2: Fluxograma do processo de remoção de fundo porposto no trabalho Sanches, Sementille e Tori (2009)

\subsection{Representação Bidimensional e Estereoscópica}

Uma forma simples de representar o avatar é utilizando uma representação bidimensional no ambiente tridimensional. Para tal, sequencias de imagens capturadas do usuário são aplicadas em um plano no ambiente tridimensional, aparentando que o usuário esteja dentro do ambiente 
tridimensional. Esses planos podem ou não acompanhar a movimentação da câmera virtual, de forma que o plano sempre se apresente de forma perpendicular ao usuário visualizador. Nesse caso, em que o plano acompanha a visualização do usuário, técnicas de Billboarding (AKENINE-MöLLER; HAINES; HOFFMAN, 2008, p. 446) podem ser aplicadas, de forma que o usuário sempre visualiza o modelo plano ortogonalmente.

Para se obter um resultado melhor, múltiplas imagens capturadas em diferentes ângulos do usuário a ser representado podem ser utilizadas. Essa técnica é conhecida como switching planes (INSLEY; SANDIN; DEFANTI, 1997). Nessa técnica, a imagem do avatar virtual, a ser aplicada no plano, é selecionada de acordo com o ângulo que ele é visto, simulando o ambiente real. A figura 3.3 ilustra essa ideia.

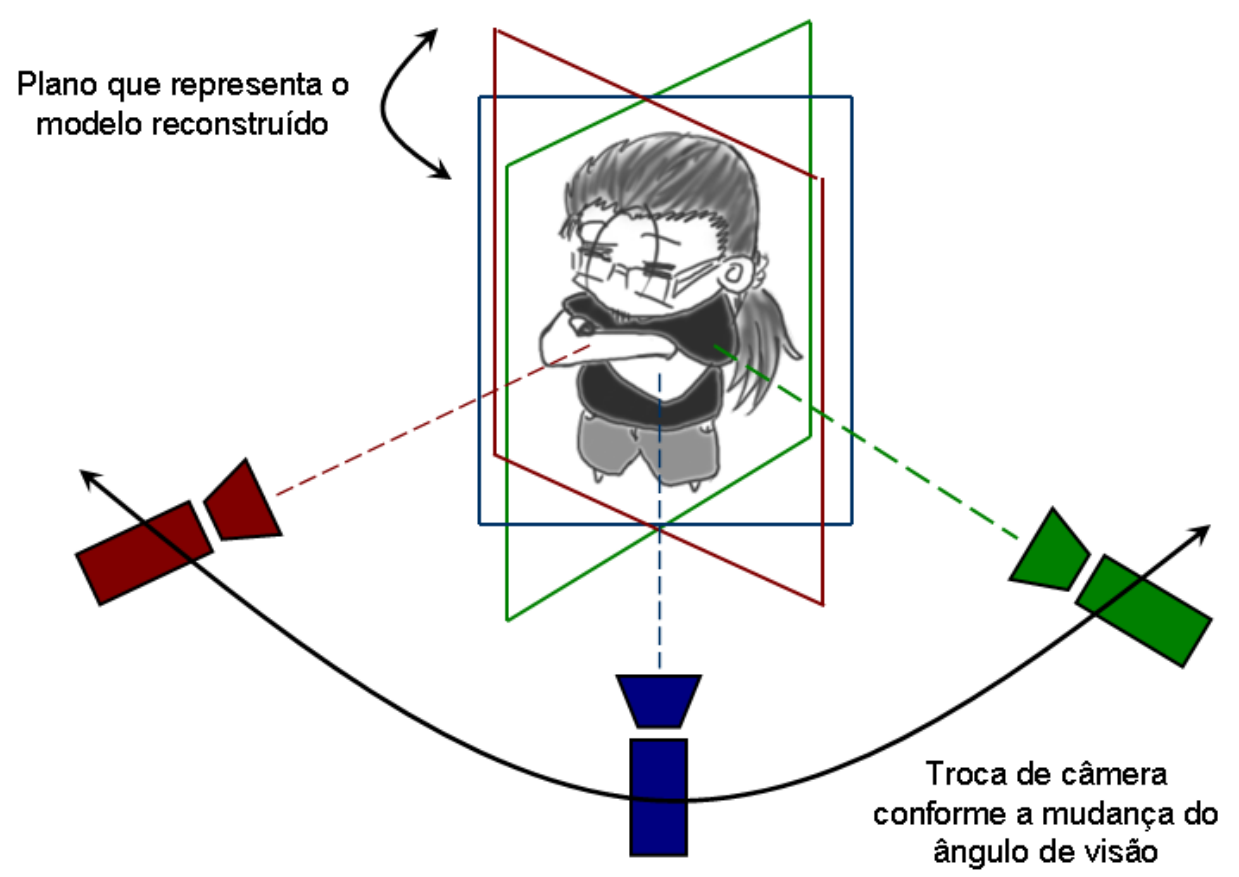

Figura 3.3: Técnica de switching planes.

Uma forma de acrescentar a sensação de profundidade nesse avatar plano é através do uso de técnicas de visualização estereoscópica (TOMOYOSE; SANCHES; TORI, 2009). Para o uso dessa técnica imagens capturadas por um par de câmeras são colocadas no mesmo plano virtual. A cada quadro a ser renderizado, são executadas duas passadas de renderização, uma correspondendo a cada olho. Nesse momento, a imagem do usuário correspondente a cada olho é devidamente selecionada. Dessa forma cada olho do usuário visualizador vê uma imagem correspondente a captura estéreo, dando assim a sensação de profundidade no próprio avatar.

Siscoutto (SISCOUTTO; TORI, 2004), em seu trabalho, utiliza essa técnica de representação 
bidimensional utilizando billboards e imagens estereoscópicas para representar o participante no ambiente virtual. A imagem 3.4, apresentada no trabalho de Siscoutto, ilustra esse efeito com a estereoscopia utilizando-se equipamentos de shutter glasses.

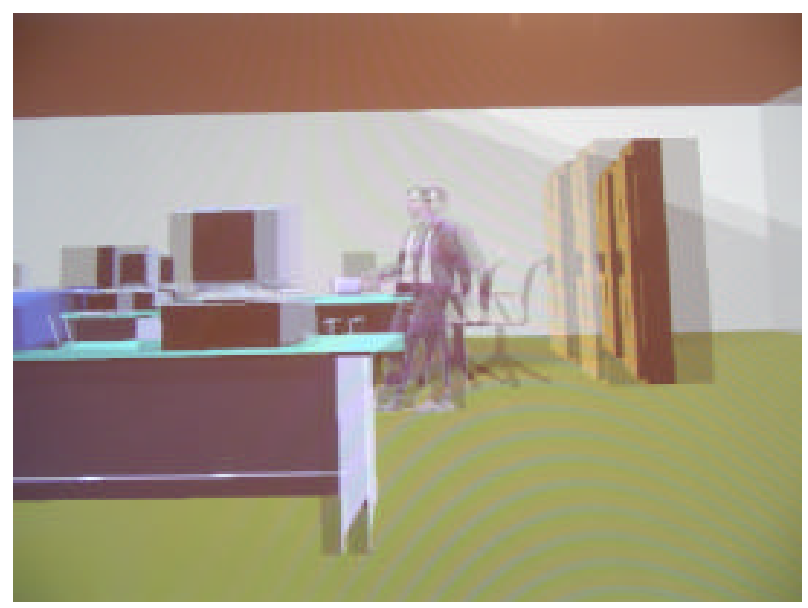

Figura 3.4: Avatar planar com o uso de estereoscopia (SISCOUTTO; TORI, 2004).

\subsection{Mapa de Profundidade}

O mapa de profundidade é um dos meios de se obter informações 3D sobre o ambiente real que está sendo capturado. Esse mapa de profundidade é constituído pelas distancias dos objetos da cena em relação a câmera. Considerando que o ponto $I$, como mostrado na figura 3.5, é a projeção do ponto $P$, do ambiente real, no plano da imagem, pode se considerar a distancia $D$ como sendo a profundidade do ponto $I$. Dessa forma, o mapa de profundidade de uma imagem plana é uma matriz com a mesma dimensão com as profundidades de cada pixel dessa imagem. Muitos autores denominam esses dados como mapa de alturas, considerando que a distancia $D$ calculada é a altura do ponto $I$ até a câmera.

Diferentes técnicas podem ser utilizadas para se obter esse mapa de profundidade. Muitas dessas técnicas utilizam como base a diferença entre imagens que capturam a mesma cena, por exemplo utilizando a diferença focal de imagens capturadas por uma mesma câmera na mesma posição (HIRSCH et al., 2009) ou utilizando-se a variação de iluminação. Porém muito dessas técnicas não possibilitam a captura das informações em tempo-real ou que possam capturar uma distancia longa o suficiente em relação a câmera de captura, para capturar a imagem do corpo inteiro da pessoa.

Uma técnica relativamente simples para se obter esses mapas de profundidades em temporeal é o uso de técnicas baseadas no imageamento estéreo, como o utilizado no sistema AVMix (NAKAMURA; TORI, 2008). Para tal, utiliza-se um par de imagens onde a posição das 


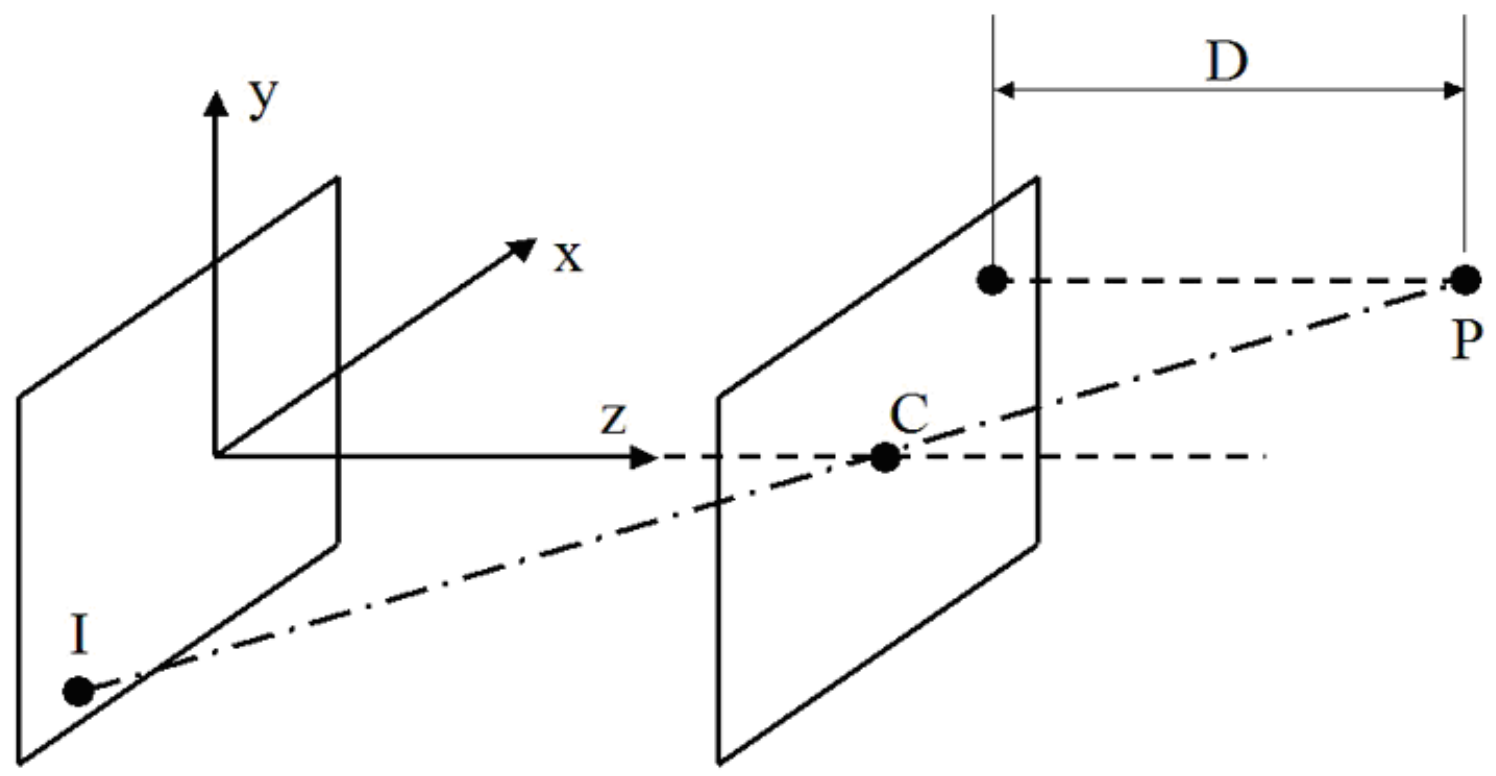

Figura 3.5: A profundidade D correspondente a um ponto I da imagem

câmeras que capturam a cena são conhecidas. Essa técnica simula a forma que nossos olhos "capturam" a informações de profundidade, utilizando a informação da disparidade entre as imagens capturadas. A figura 3.6 ilustra essa ideia. Nakamura (NAKAMURA; TORI, 2008), em seu trabalho, discute em detalhes essa técnica da geração de mapas de profundidades.

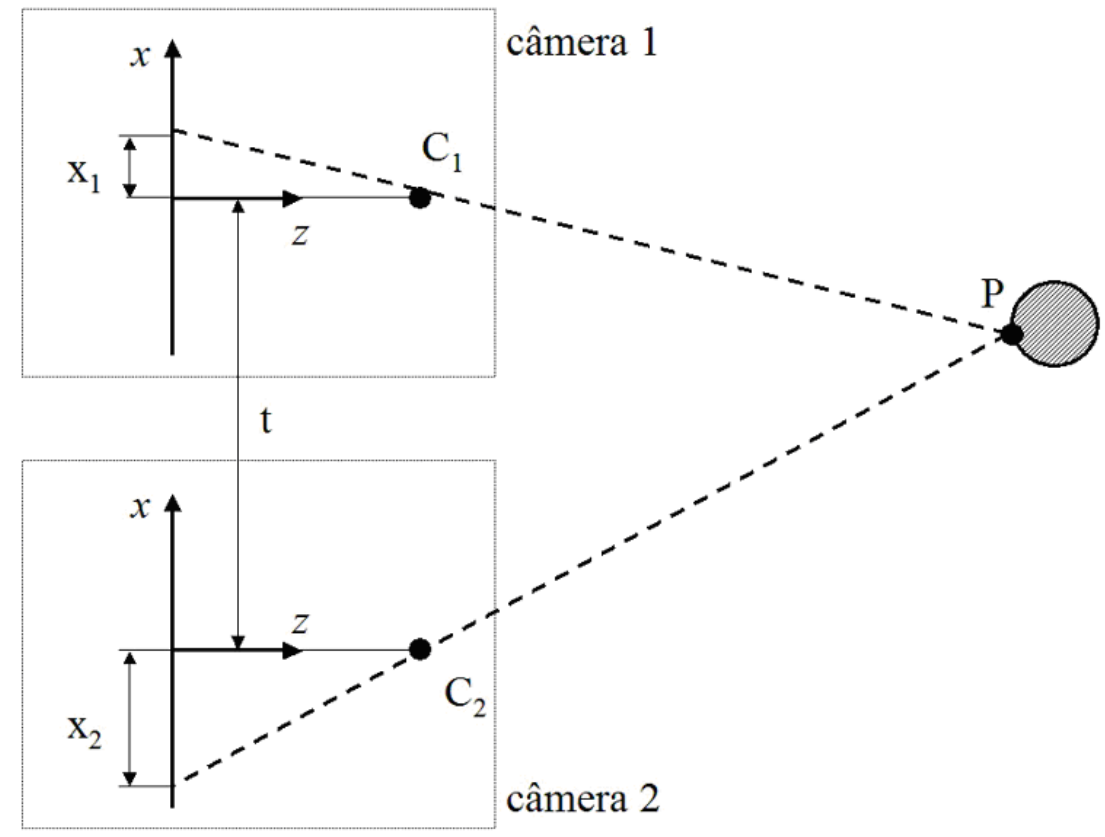

Figura 3.6: Arranjo para imageamento estéreo (NAKAMURA, 2008).

Outra forma de se obter esses mapas de profundidades é através da utilização de equipa- 
mentos específicos. Atualmente, alguns equipamentos comerciais já possuem essa capacidade de capturar informações de mapa de profundidades. Por exemplo, a câmera estéreo Bumbble Bee da Point Grey ${ }^{2}$. Essa câmera utiliza um método similar com a técnica baseada no imageamento estéreo para a captura dos dados espaciais. Outro hardware que possibilita a captura dessas informações é a Zcam da 3DV system (GVILI et al., 2003). Nesse caso, as informações de profundidade são capturadas através de pulsos de luz infra-vermelho. Dado a diferença de tempo de retorno desses pulsos, o mapa de profundidade é calculado.

\subsection{Reconstrução por Mapa de Alturas e Deformação de Malhas Triangulares}

As informações obtidas através do mapa de profundidade podem ser utilizadas para a reconstrução geométrica e renderização, parcial ou completa, de um objeto real. Uma dessas técnicas é a de reconstrução por mapa de alturas e deformação de malhas triangulares. Essa técnica também é nomeada por muitos autores como reconstruçãoe renderização 2,5D. Pois utiliza informações bidimensionais com a informação de profundidade, não reconstruindo o objeto completamente devido as oclusões que ocorrem na captura.

Ogi et al. (2003), em seu trabalho, propõe a representação do avatar através da criação de uma malha de triângulos interconectados, onde cada vértice da malha é posicionada no ambiente 3D conforme a informação de profundidade do mapa. Considerando que a informação de profundidade $z_{i j}$ é conhecida, a posição $x_{i j}$ e $y_{i j}$ do vértice podem ser obtidas através das equações 3.2 e 3.3 .

$$
\begin{aligned}
& x_{i j}=z_{i j} \frac{(i-W / 2)}{(W / 2) \tan \alpha} \\
& y_{i j}=z_{i j} \frac{(H / 2-j)}{(H / 2) \tan \beta}
\end{aligned}
$$

Onde $\alpha$ e $\beta$ são respectivamente os ângulos de abertura focal da câmera na horizontal e na vertical. $W$ e $H$ são respectivamente a largura e altura da imagem capturada, a figura 3.7 ilustra essa ideia. Após da criação e deformação da malha de triângulos, a imagem capturada do usuário é mapeada sobre essa malha, gerando a representação do participante.

Este método possui a limitação de não conseguir reconstruir e renderizar por completo

\footnotetext{
${ }^{2}$ site pointgrey
} 


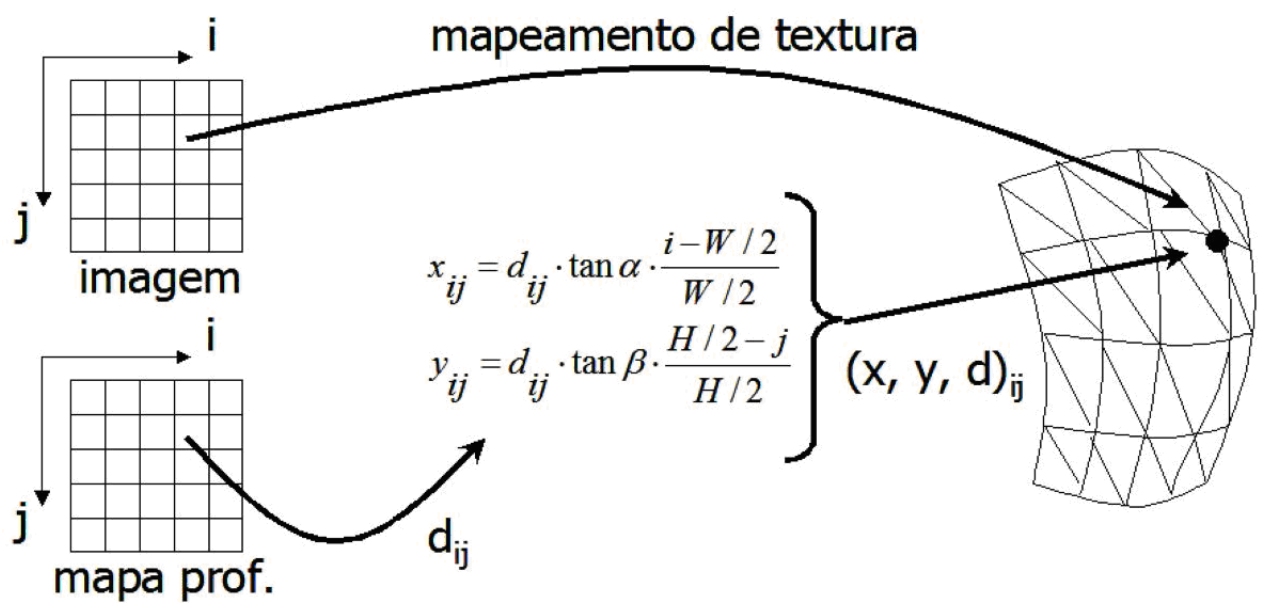

Figura 3.7: Deformação de malhas triangulares por mapa de alturas (NAKAMURA, 2008).

a cena ou objeto desejado. Assim, seu ângulo máximo de visualização sem distorções é aproximadamente de 15 graus, como apresentado por Tamagawa et al. (2001). Porem, nesse método a ideia de switching planes também pode ser utilizada. Ogi et al. (2001) utiliza múltiplos pares de câmeras, posicionadas ao redor do objeto. Durante a execução, a imagem e mapa de altura que mais se adéqua ao ponto de visão do usuário visualizador é selecionada, possibilitando a visualização completa do participante. Os autores denominam essa técnica de Switching Depth Model. A figura 3.8 ilustra esse caso.

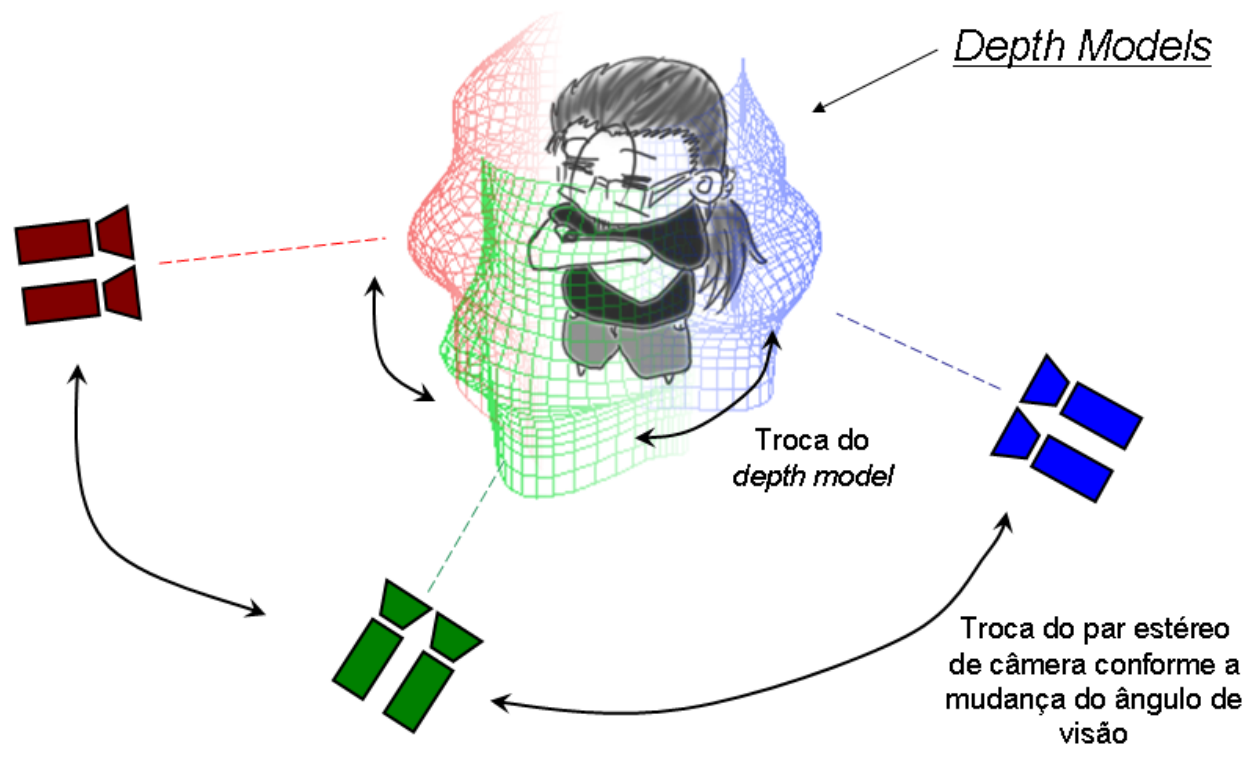

Figura 3.8: Switching Depth Model(OGl et al., 2001). 


\subsection{Renderização de Voxel Colorido e Renderização por Nuvem de Pontos}

Uma outra forma para renderizar o usuário é utilizando a técnica de renderização de modelos em voxel coloridos. A representação de modelos 3D por voxel se assemelha com a representação de imagens 2D por pixel. Em ambas as situações, a informação visual é representada por microestruturas, pelo conjunto de pixeis (picture element) no caso da imagem 2D e pelo conjunto de voxeis (volume element) nas geometrias 3D. A técnica de modelo de voxel colorido é uma forma de renderizar esses voxeis e, nessa técnica, cada voxel é representado por um cubo com a cor do modelo.

Outra forma de representar os dados tridimensionais é pelo modelo de nuvem de pontos. Nesse caso, a estrutura 3D é mantida por um conjunto de amostra de pontos do objeto tridimensional. Muitos equipamentos de captura de informações 3D atuais, como os scanners à laser e ópticos, tem como retorno essa amostragem de pontos da superfície do objeto. Para a representação visual desse modelo de dados pode-se utilizar pequenos pontos 2Ds renderizados sobre cada ponto amostrado. Mais detalhes sobre o modelo de voxel e suas representações visuais podem ser encontrados no trabalho de Watt (2000, p. 51, p.140).

\subsection{Splats}

Uma outra forma de renderizar diretamente o modelo de nuvem de pontos é através do uso da técnica chamada surface splatting (ZWICKER et al., 2001; REN; PFISTER; ZWICKER, 2002). Essa técnica de renderização e texturização, que possibilita a renderização direta dos pontos opacos ou transparente não conexos, utiliza como base a formalização espacial do Elliptical Weighted Average filter (GREENE; HECKBERT, 1986).

Para possibilitar a visualização do objeto, através dos pontos capturados e suas cores, considera-se que a coloração de um local qualquer é dada pela média ponderada das cores dos pontos mais próximos com certo decaimento, a figura 3.9 ilustra essa ideia. Dessa forma o cálculo da cor de um certo local $Q$ é dada por uma função $F(Q)$ que é calculada através da soma das cores $C_{i}$ dos $N$ pontos capturados, mais próximos à $Q$, multiplicados por uma função de decaimento $D$, proporcional à distancia entre $\mathrm{Q}$ ao ponto $\mathrm{P}$. Esse cálculo da cor é representado pela equação 3.4 .

$$
F(Q)=\sum_{k \in N} C_{i} * D(Q-P)
$$




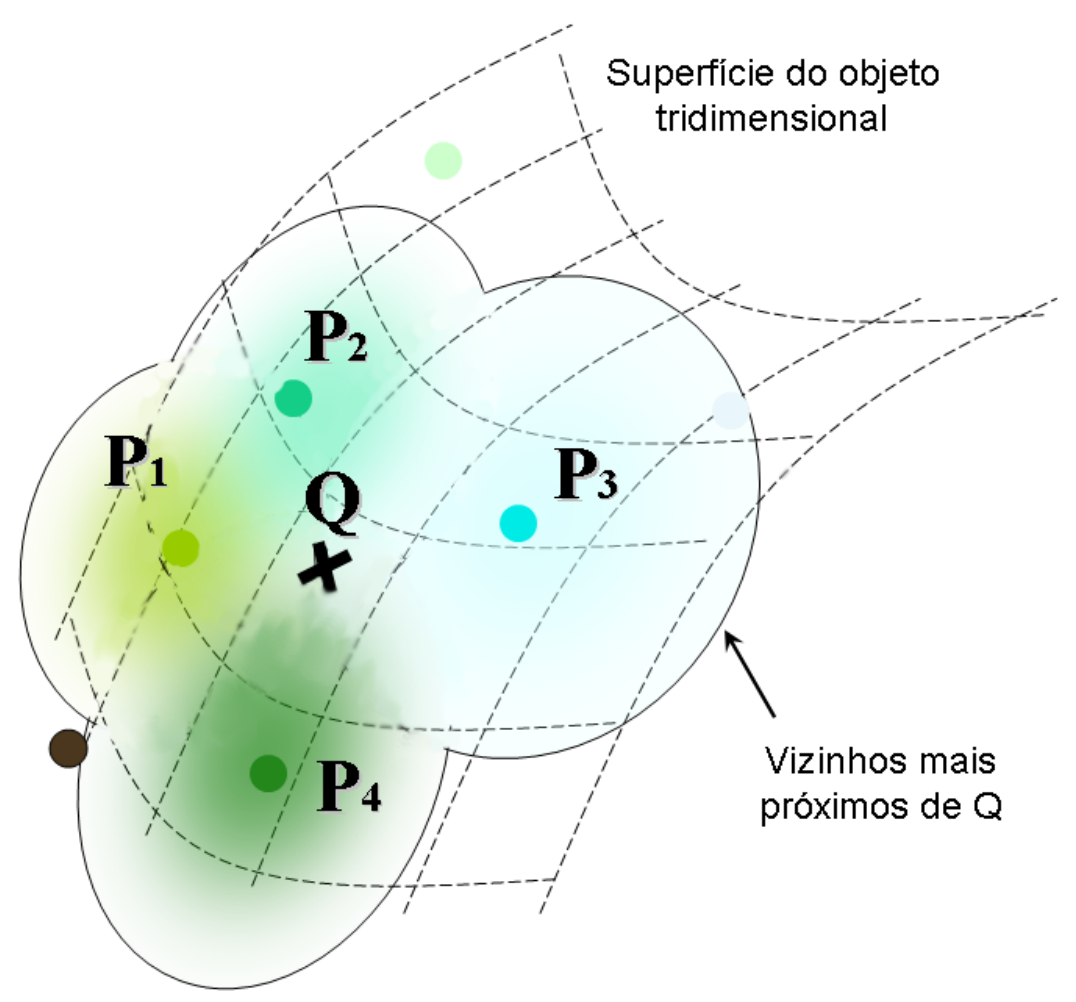

Figura 3.9: Cálculo de coloração na técnica de splats

Naef, Staadt e Gross (2004) propõem uma simplificação dessa técnica. Nesse trabalho os pontos são representados por discos devidamente posicionados no ambiente 3D com um certo raio. A cor de cada disco é dada pela cor do ponto que ele representa, com um decaimento gaussiano de sua transparência em relação ao centro do disco. A figura 3.10 ilustra essa simplificação. Uma vez que os discos possuem um decaimento da transparência, os locais entre os pontos são apresentados para o visualizador como sendo a média das cores dos pontos mais próximos. Assim essa simplificação continua seguindo a ideia proposta por Zwicker (ZWICKER et al., 2001). Essa ideia é implementada no projeto Blue-C (NAEF; STAADT; GROSS, 2004; GROSS et al., 2003; NAEF; STAADT; GROSS, 2002), nesse sistema o modelo volumétrico é obtido utilizando-se a técnica de visual hull (LAURENTINI, 1994) e depois renderizado utilizando-se a técnica de splats.

\subsection{Visual Hull}

A técnica de visual hull é baseada na reconstrução do modelo do objeto real utilizando as silhuetas do objeto obtidas através de múltiplas imagens capturadas em diferentes ângulos. Inicialmente proposta por Laurentinni (LAURENTINI, 1994), a reconstrução é dada pela intersecção das projeções das silhuetas nas diferentes imagens capturadas. A figura 3.11 ilustra a 


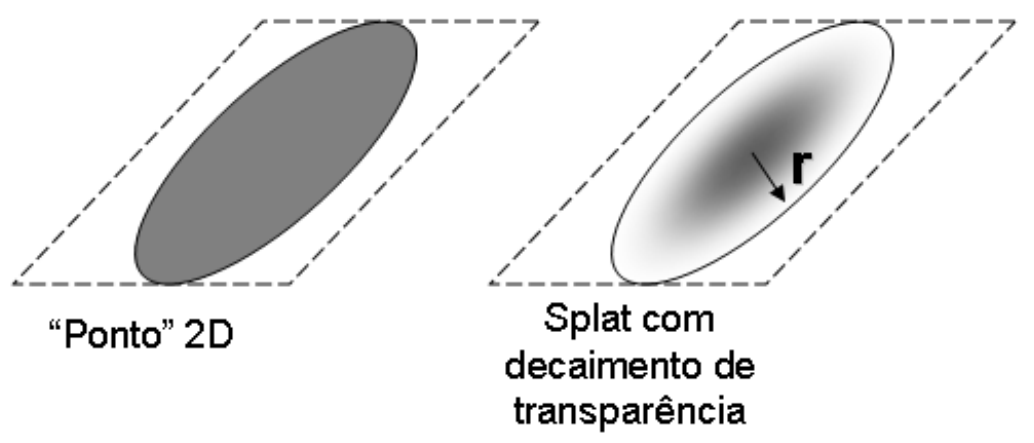

Figura 3.10: Simplificação de splats proposta por Naef (NAEF; STAADT; GROSS, 2004)

ideia geral do procedimento de reconstrução.

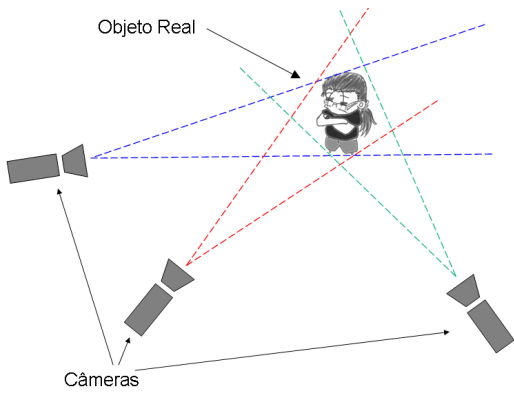

(a) Captura de dados

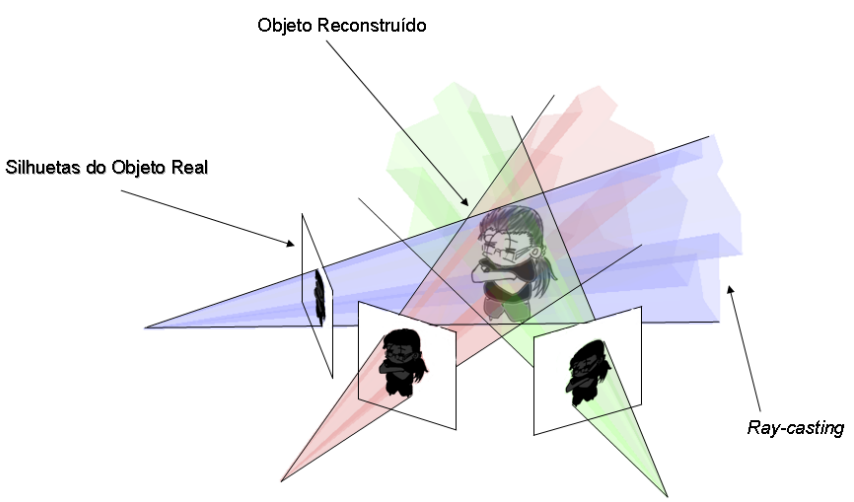

(b) Processo de reconstrução utilizando técnicas de ray-casting

Figura 3.11: Reconstrução geométrica por visual hull

A reconstrução do visual hull pode ser feita de duas formas, a reconstrução baseada em voxel ou reconstrução por poliedros (MAGNOR, 2005). No caso da reconstrução por voxeis um cubo sólido de voxeis é "esculpido" através das áreas que estão oclusas pela silhueta do objeto em cada imagem. Assim, os voxeis finais que compõe o modelo reconstruído são aqueles que se encontram internos à silhueta do objeto real em todas as imagens utilizadas. Matusik, em seu trabalho (MATUSIK et al., 2000; MATUSIK; BUEHLER; MCMILLAN, 2001), propõe a utilização da técnica em tempo real utilizando a reconstrução por poliedros e técnicas de ray-casting para a texturização do modelo final.

O método de Visual Hull, em geral, possui a vantagem de ser rápido em relações a outras formas de reconstrução e o resultado obtido é relativamente bom. Dessa forma muitos trabalhos de telecomunicação imersiva e vídeo-avatar utilizam esse método para a representação visual dos participantes, como os trabalhos de Lee et al. (2005), Prince et al. (2002), Kanade e Narayanan (2007) e Petit et al. (2009). 
Porém essa técnica possui o problema de não conseguir reconstruir partes côncavas do objeto original. Isto se deve ao fato de ele utilizar as intersecções das silhuetas, dessa forma áreas que não são representadas nas silhuetas não podem ser reconstruídas. Alguns trabalhos utilizam, juntamente ao visual hull, o mapa de profundidade para melhorar a acurácia do modelo gerado. Assim, por meio do uso de mapas de profundidades é possível de se obter as informações das áreas côncavas, esses dados são utilizados sobre o modelo gerado pelo Visual Hull, para se refinar esse modelo. Em seu trabalho, Li et al. (2002) colocam um par de câmeras, ao invés de câmeras individuais, ao redor do objeto a ser reconstruído, dessa forma, obtendo-se o mapa de profundidade de cada imagem capturada do objeto.

Outro problema que a técnica de visual hull possui é o fato de necessitar múltiplas câmeras. Esse fato faz com que o requisito inicial de equipamentos seja mais alto, podendo atrapalhar a sua configuração inicial. Outro problema que o grande numero de câmeras traz é a necessidade de calibração dessas câmeras, pois cada câmera possui a sua característica própria. Para serem utilizadas juntas no método é necessário uma calibração individual, por exemplo de distorção da imagem, de forma que todas elas fiquem semelhantes. Também é necessário um processo de calibração em relação a disposição física entre elas. Dessa forma, a utilização de múltiplas câmeras pode dificultar o preparo inicial do sistema.

\subsection{Opacity Hull}

Uma melhora da técnica visual hull, apresentada por Matusik, é o opacity hull (MATUSIK et al., 2002). Nessa proposta, Matusik captura, além das informações espaciais, as informações de transparência, reflexão, entre outras informações do objeto a ser reconstruído. A utilização dessas informações em conjunto com o modelo capturado pela técnica de visual hull possibilita a representação visual de objetos com alto nível de reflexão especular, transparência e muitos detalhes. Por exemplo, objetos como porcelanas e penas, objetos que eram impossíveis de serem representados com alta fidelidade visual utilizando-se scanners tradicionais e outros métodos de reconstrução.

Para captura das informações, uma instalação especial é utilizada. Essa instalação é constituída por seis câmeras CCD QImaging QICAM com resolução de 1360×1036 pixeis, duas TVs de plasma com resolução de 1024×768 pixeis, uma colocada como base rotatória para o objeto e outra posicionada atrás do objeto para ser utilizado como fundo das imagens capturadas. Também são posicionadas uma série de luzes para iluminar o objeto durante a aquisição de dados. A figura 3.12 ilustra a instalação de captura utilizada por Matusik em seu 
trabalho.

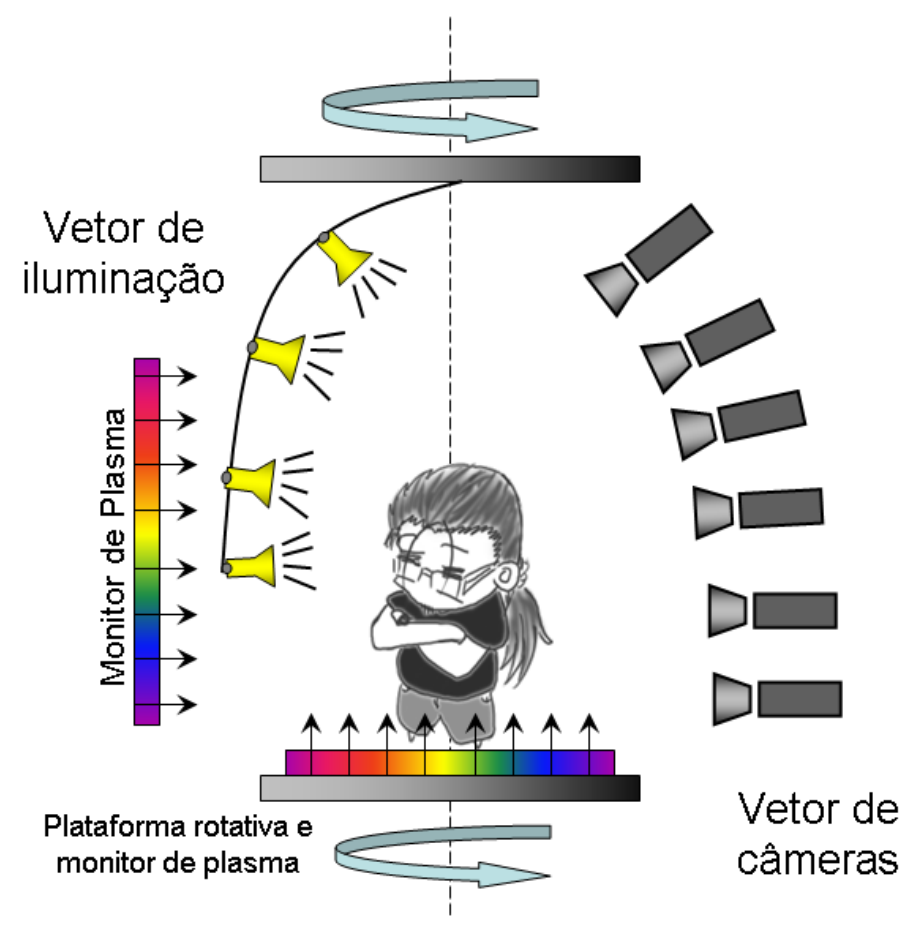

Figura 3.12: Ambiente de captura utilizado por Matusik (MATUSIK et al., 2002)

Para a aquisição dos dados de transparência, uma variante da técnica proposta por Smith e Blinn (1996) é utilizada. Nessa variante, múltiplas imagens do objeto são capturadas utilizando diferentes fundos projetados pela TV de plasma situada atrás do objeto. Dado a diferença entre as imagens capturadas, é possível de se obter um mapa de transparência que depende do ponto de vista. Por fim, a geometria do objeto é modelado utilizando-se o método de visual hull e o objeto é renderizado utilizado-se essas informações de geometria e transparências.

Apesar do método de opacity hull possibilitar a reconstrução visual com alto nível de fidelidade, o método ainda não possibilita a reconstrução geométrica perfeita do objeto. Pois, igualmente ao método visual hull, ele não consegue reconstruir as partes côncavas do objeto. Dessa forma, o método falha quando uma geometria mais fiel ao objeto original é necessitada, por exemplo quando se deseja ter interação ou colisão com o objeto reconstruído.

Outro problema desse método é o fato desse método ter um requisito de hardware alto, necessitando de muitos equipamentos e uma instalação inicial mais complexa. Por fim, o principal problema desse método, para a criação de avatares, é o fato do método não poder ser utilizado para reconstrução em tempo-real, devido à sua complexa fase de aquisição. 


\subsection{Microfacet Billboarding}

Uma outra forma para se representar visualmente objetos com muitos detalhes é utilizando a proposta de Microfacet Billboarding de Yamazaki et al. (2002). Em seu trabalho, Yamazaki propõe o conceito de microfacet billboarding, uma forma de renderização dos objetos 3D utilizando pequenos billboards (AKENINE-MöLLER; HAINES; HOFFMAN, 2008, p. 446) espalhados sobre a superfície do objeto a ser reconstruído.

Esse método possui a vantagem de poder representar pequenos detalhes dos objetos, principalmente nas laterais do modelo observado pelo visualizador. Isso se deve ao fato que, diferentemente dos modelos de malhas triangulares texturizados, na renderização por microfacet billboarding as laterais do objeto serão representadas por planos paralelos ao plano de visualização, assim os detalhes do objeto são renderizados ao visualizador da mesma forma que foram capturados. No caso da renderização por modelos de malhas triangulares, as laterais são representados por planos perpendiculares ao plano de visualização, assim, os detalhes capturados do objetos não são mostrados ao visualizador, caso esses detalhes não forem reconstruídos na própria malha triangular. A figura 3.13 ilustra essa ideia.

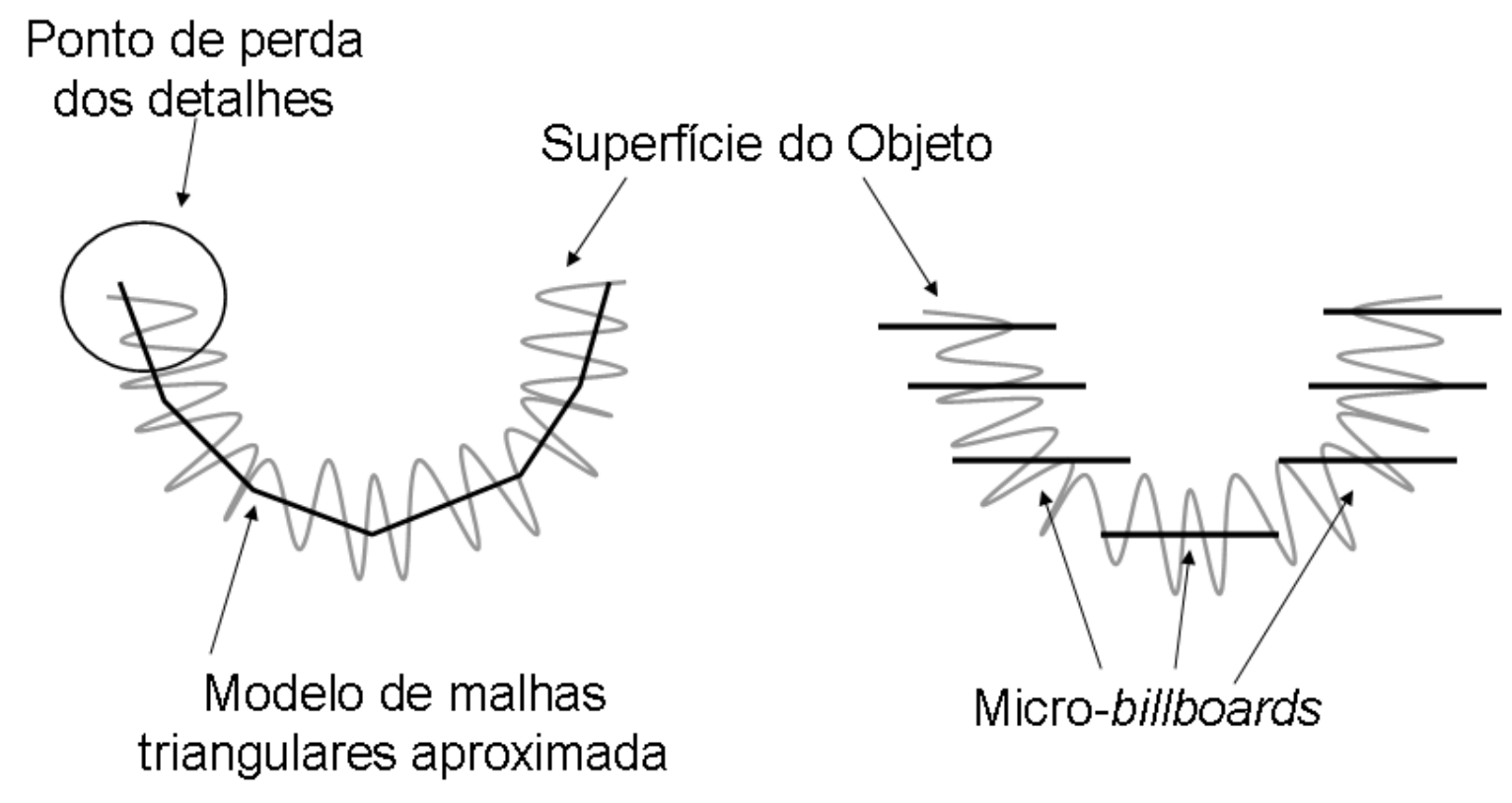

Figura 3.13: Microfacet Billboarding (YAMAZAKI et al., 2002)

Para possibilitar essa representação, Yamazaki faz a captura estática do modelo de superfície do objeto através de um scanner 3D, e após essa etapa esse modelo de núverns de pontos é convertido em um modelo de voxel. Outro dado capturado são as imagens do objeto em diferentes ângulos, para possibilitar a texturização do modelo. Por fim o objeto é renderizado utilizando-se a técnica de microfacet billboarding. 


\subsection{Considerações Finais}

Neste capítulo, foram apresentadas diversas técnicas de reconstrução geométrica e renderização e técnicas relacionadas, que podem ser utilizadas para a representação visual do vídeo-avatar. Ogi, em seu trabalho (OGl et al., 2003), faz uma comparação de diferentes técnicas de reconstrução para a geração de um vídeo-avatar. Com base nessa comparação efetuada por Ogi e na pesquisa das técnicas de reconstrução efetuada neste capítulo, uma comparação entre as diferentes técnicas foi realizada.

A tabela 3.1 apresenta essa comparação em relação as características que se considerou necessárias para a criação do sistema iLive. As características abordadas nessa comparação são: se a técnica pode ser executada em tempo-real, se detalhes podem ser representados, se o objeto reconstruído é tridimensional, se o usuário pode visualizar o objeto tridimensionalmente em movimento (paralaxe em movimento), o quão completo a técnica consegue reconstruir da geometria do objeto/cena capturado e a complexidade da configuração física.

Dentre as características listadas, a "tempo-real" e "representação de detalhes" são as duas características necessárias no projeto iLive, desta forma, considerou-se que essas características possuem maior prioridade em relação à outras. As características "reconstrução 3D", "paralaxe de movimento" e "completude da reconstrução" são características que se considera importante para que o avatar seja integrado com o ambiente virtual. Por fim, a "complexidade da configuração física" é uma característica desejada para o projeto como um todo, uma vez que seu uso é destinado a educação e entretenimento, não podendo-se considerar que todos os participantes possuam uma configuração física complexa para utilizarem o sistema. Nessa tabela o simbolo " $O$ " representa que a técnica apresenta a característica, " $X$ " representa que não apresenta e " $\Delta$ ", a técnica apresenta parcialmente ou com restrições a característica.

Dado essa comparação efetuada na tabela 3.1 e a análise das técnicas efetuadas neste capítulo, pode-se afirmar que nem uma das técnicas de reconstrução satisfazem, simultaneamente, todas as características que o sistema iLive necessita (tempo-real, representação de detalhes e integração com o ambiente virtual). Assim, nem uma dessas técnicas são adequadas para a criação da representação visual no sistema.

A reconstrução bidimensional não provê a sensação de integração do avatar dentro do ambiente virtual devido a falta de informação tridimensional. Métodos de estereoscopia poderiam ser utilizados em conjunto com o avatar bidimensional para se obter a paralaxe estereoscópica, porém o usuário necessitaria de algum tipo de equipamento estereoscópico para a visualização, não sendo apropriado em alguns casos. 
Tabela 3.1: Técnicas de reconstrução $X$ características

\begin{tabular}{|c|c|c|c|c|c|c|c|}
\hline & \multicolumn{6}{|c|}{ Características } \\
\hline & & 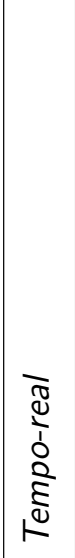 & 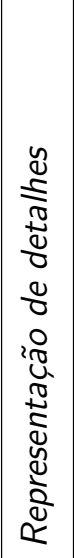 & 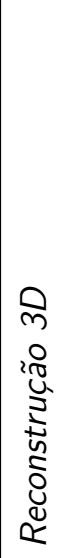 & 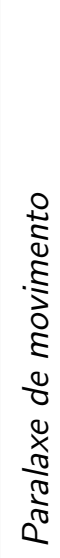 & 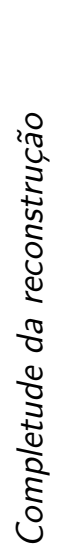 & 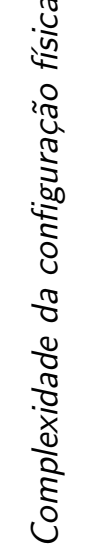 \\
\hline \multirow{10}{*}{ 蒈 } & Bidimensional & $O$ & $O$ & $X$ & $X$ & $X$ & baixo \\
\hline & Switching Planes & $O$ & $O$ & $X$ & $X$ & $\Delta$ & alto \\
\hline & Bidimensional Estereoscópica & $O$ & $O$ & $X$ & $\Delta$ & $X$ & baixo \\
\hline & Switching Planes Estereoscópicos & $O$ & $O$ & $X$ & $\Delta$ & $\Delta$ & alto \\
\hline & Mapa de alturas e deformação de malhas & $O$ & $X$ & $O$ & $O$ & $\Delta$ & baixo \\
\hline & Switching Depth Model & $O$ & $X$ & $O$ & $O$ & $O$ & alto \\
\hline & Blue-C System(Splats) & $O$ & $X$ & $\mathrm{O}$ & $\mathrm{O}$ & $\mathrm{O}$ & alto \\
\hline & Visual Hull & $O$ & $X$ & $\mathrm{O}$ & $\mathrm{O}$ & $\mathrm{O}$ & alto \\
\hline & Opacity Hull & $X$ & $O$ & $O$ & $\mathrm{O}$ & $\mathrm{O}$ & alto \\
\hline & Microfacet Billboarding & $X$ & $O$ & $O$ & $O$ & $\mathrm{O}$ & alto \\
\hline
\end{tabular}

Já a reconstrução por mapa de altura e deformação de malha triangular pode ser executada em tempo-real e ela prôve, em certo nível, a integração com o ambiente tridimensional. Porém, alguns detalhes visuais do usuário reconstruído, como os detalhes do cabelo, podem ser perdidos devido a sua renderização por malhas triangulares. Esse fato é levantado por Ogi em sua comparação e o autor também afirma que, quando um vídeo-avatar com melhor qualidade de imagem é requerido, essa reconstrução não é apropriada. Mais detalhes sobre a deformação visual que a malha triangular prove é descrita na seção 3.9.

A técnica de visual hull aparenta satisfazer as características necessárias para o sistema. Porém, sua configuração física necessita de muitos equipamentos, fato que pode complicar a sua instalação em uso educacional ou em jogos. Outro fato que torna o uso do visuall hull inapropriado para o iLive é a sua dependência da quantidade e qualidade das imagens capturadas para que alguns detalhes possam ser reconstruídos, como o dedo que professor utiliza para apontar um objeto virtual. Esse nível de reconstrução não é obtida em muitos dos casos, uma vez que alguns detalhes do participante podem ser desconsiderados durante o processo de reconstrução. Por exemplo, quando esses detalhes diferem visualmente de uma imagem para outra, ou pela falta de imagens que capturam esses detalhes ou por que as imagens não possuem resolução o suficiente para capturar esses detalhes. 
Para possibilitar essa renderização de detalhes do participante, a técnica de microfacet billbording se mostra adequada, pois a maioria dos detalhes capturados na imagem original são preservados quando a reconstrução tridimensional é efetuada. Porém essa técnica não prevê o uso em tempo-real, uma vez que essa técnica originalmente depende da captura de informações tridimensionais através de um scanner 3D. O mesmo fato ocorre na reconstrução por opacity hull, que possibilita a representação visual quase que perfeita das cenas capturadas, porém o processo de captura não permite o seu uso em tempo-real.

Assim, pode se notar que as técnicas citadas neste trabalho não são suficientes por si só para a implementação da representação visual do participante no sistema de telecomunicação imersiva voltada para educação e jogos eletrônicos, uma vez que essas técnicas não satisfazem todas as três características levantadas para o sistema. Este trabalho apresenta novas técnicas para a reconstrução geométrica e renderização, que visa satisfazer essas características e tem como base as técnicas apresentadas neste capítulo.

Os capítulos 2 e 3 apresentaram a etapa de pequisa deste trabalho, dando uma visão de técnicas e trabalhos existentes na literatura. Os capítulos 4, 5 e 6, que seguem, apresentarão as propostas deste trabalho, contribuições e os resultados obtidos. 


\section{MODELO TEÓRICO PROPOSTO}

Procedendo a pesquisa sobre técnicas de reconstruções geométricas, pôde se observar que em muitos trabalhos os autores separam implicitamente algumas etapas em comuns. Isso se deve à natureza da reconstrução geométrica que, como definido por Magnor (2005) e visto na seção 2.4, necessita executar a análise e síntese de imagem. Nesses dois casos, três importantes etapas são executadas, são elas:

- Aquisição de dados

- Modelagem Geométrica

- Renderização do Modelo

Onde a aquisição de dados e modelagem geométrica fazem parte da análise, e a renderização, parte da síntese de imagem.

Neste trabalho, propõe-se um modelo teórico para se modularizar as técnicas de reconstrução geométrica ${ }^{1}$, possibilitando a visualização das informações tratadas em cada etapa. Esse modelo também facilita a visualização das possíveis concatenações de diferentes técnicas, ampliando as possibilidades na criação de novas formas de reconstrução.

A figura 4.1 representa visualmente o modelo proposto. Os retângulos verticais são os módulos apresentados, os retângulos dentro de cada módulo representam as informações em cada momento da reconstrução geométrica, e as setas que interligam as informações são os processos de transições entre as informações. Por fim, o retângulo tracejado, que engloba as informações nos módulos, representa uma técnica de reconstrução geométrica ou parte dela.

\footnotetext{
${ }^{1}$ Considera-se "modelo", neste trabalho, uma um padrão de estrutura para algo, no caso, as técnicas de reconstrução geométrica e renderização.
} 


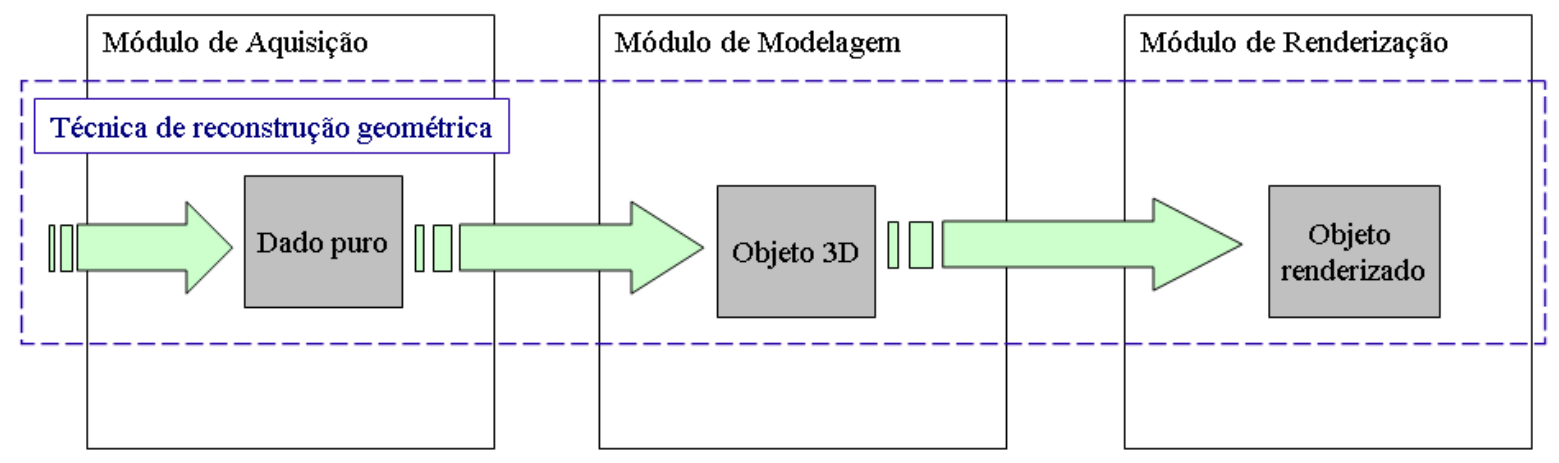

Figura 4.1: Representação visual do modelo teórico proposto

\subsection{Módulos}

No modelo proposto, cada módulo representa cada uma das três etapas das técnicas de reconstrução geométrica, já discutidas anteriormente. Esses módulos são constituídos de diferentes níveis de informações: dados puros, objeto tridimensional e imagem renderizada. Considera-se que uma reconstrução necessariamente passa por essas três etapas nessa sequência. Nesta seção, os módulos serão apresentados em mais detalhes.

\subsubsection{Aquisição de Dados}

Toda reconstrução geométrica se inicia com a aquisição dos dados necessários para a reconstrução do objeto/cena. Esses, são dados puros nesse momento, não constituindo uma informação espacial, i.e., não possuindo semântica espacial. Um dos dados mais comuns nos trabalhos de reconstrução geométrica é a informação de imagem da cena, porém diferentes dados podem ser capturados nesse momento, tais como posições e propriedades das câmeras, pontos retornados por scanner 3D, entre outros. Esse módulo auxilia a identificação dos equipamentos e configurações necessárias para se implementar diferentes métodos.

\subsubsection{Modelagem Geométrica}

O módulo de modelagem geométrica contem as informações com semântica espacial, ou seja, informações que constituem um objeto ou cena tridimensional e suas características, tais como malhas de polígonos, mapa de alturas, modelo de voxeis, etc. Informações, como transparências, mapa de normais e texturas, que fazem parte das informações visuais do objeto a ser reconstruído também se encontram nesse módulo. 
É importante notar que as informações do módulo de aquisição, que são dados puros, passam a possuir um significado espacial nesse momento. Dessa forma, considera-se que equipamentos especiais como scanners 3D e câmeras especias como a Zcam (GVILI et al., 2003), que possibilitam a captura direta de informações tridimensionais, executam internamente as duas etapas de aquisição e modelagem. Nesse caso a informação no módulo de aquisição são simples coordenadas e essas informações podem passar inalteradas ao módulo de modelagem quando o programa utiliza esses dados como um modelo tridimensional.

\subsubsection{Renderização}

O último módulo do modelo proposto é o de renderização. Esse, por sua vez, contem as informações das imagens renderizadas e apresentadas para o usuário. Para se obter a informação desse módulo, diferentes técnicas de renderização podem ser utilizadas, tais como mesh render, microfacet billboarding (YAMAZAKI et al., 2002), modelo de voxel colorido (WATT, 2000, p. 51), splats (NAEF; STAADT; GROSS, 2004), entre outros.

\subsection{Transições}

Nesse modelo, as transições representam os processos de modificações das informações. As transições mais comuns são as transições entre módulos, que representam a modificação do nível de informação. Porém, com o modelo proposto, mais transições podem ser visualizadas de forma simples, por exemplo transições internas, entre módulos ou utilizando-se múltiplos dados. A figura 4.2 apresenta visualmente algumas possíveis transições de informações.

As possíveis transições levantas neste trabalho são:

- Transição entre módulos;

- Uso de diferentes dados;

- Refinamento da informação;

- Alteração do formato;

- Diferentes tipos de renderização;

- Modificação do estilo. 


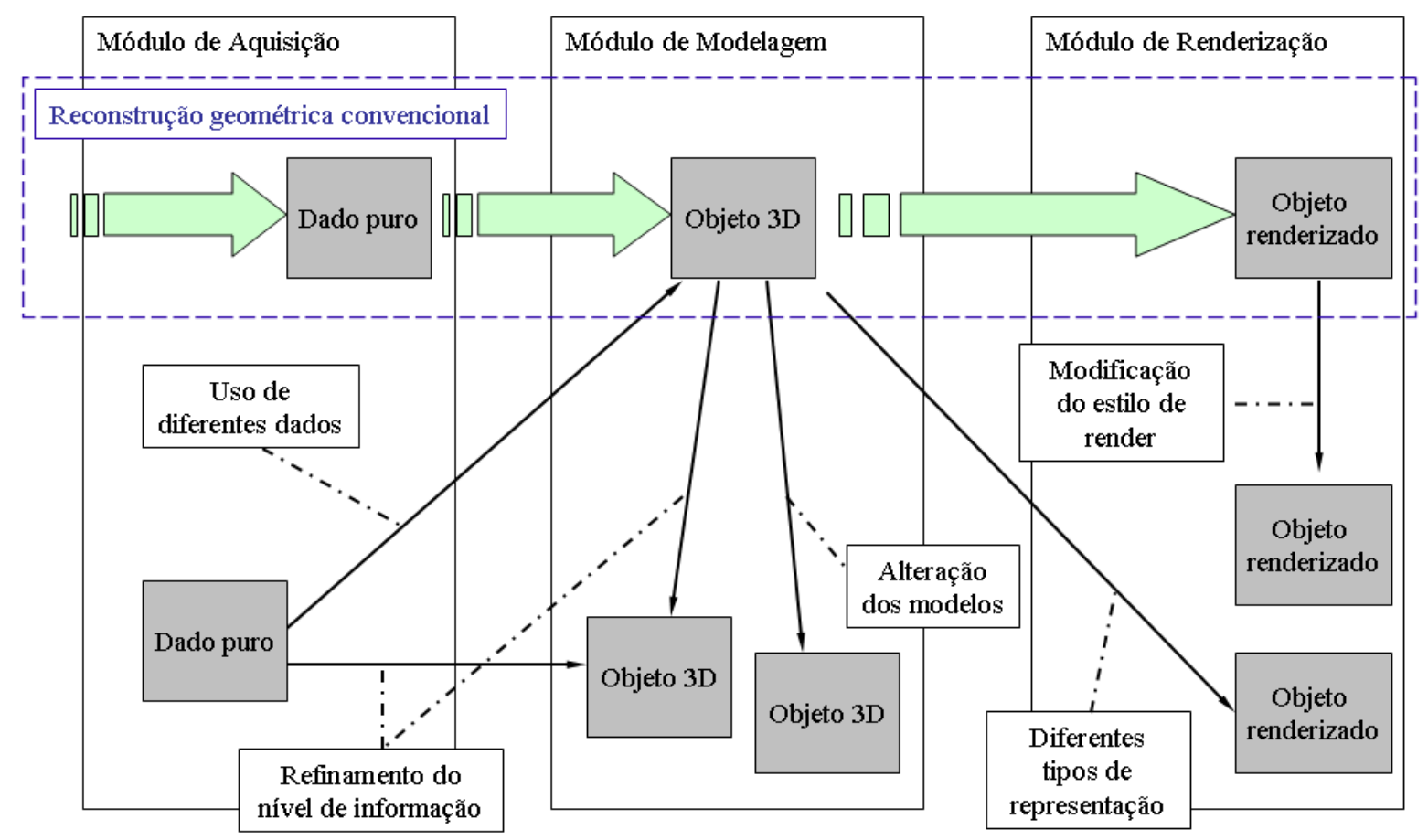

Figura 4.2: Possíveis transições de informações propostas

Onde a transição entre módulos representa a transição convencional, essas transições são representadas na imagem 4.2 com uma seta maior.

Uma possível transição, além da transições entre módulos, é o uso de dois ou mais diferentes dados para se obter um único modelo. Outra possibilidade levantada é a de refinar um modelo existente com outras informações. Esse tipo de transição pode ser visto na técnica de opacity hull (MATUSIK et al., 2002), onde o modelo tridimensional, obtido com a técnica de visual hull (LAURENTINI, 1994), é refinado com o modelo de opacidade, utilizando-se imagens com diferentes condições de iluminações.

A alteração de formatos é uma transição onde as informações de um modelo 3D, em um certo formato, são convertidas para um outro formato. Por exemplo, um modelo de nuvens de pontos, obtido utilizando-se um scanner 3D, pode ser convertido para uma malha de triângulos para ser renderizado com algoritmos de renderização convencionais. Já, a transição "uso de diferentes tipos de renderização" mostra que um mesmo modelo pode ser renderizado utilizando-se diferentes algoritmos. Juntas, essas duas transições mostram que um objeto reconstruído pode ser representado de diferentes formas, uma vez que um modelo pode ser convertido para um outro formato e renderizado com uma técnica não convencional. Dessa forma, em alguns casos é possível de se adequar a representação do objeto aos requisitos do projeto, independentemente da técnica utilizada para a modelagem geométrica. 
Por fim, a última transição proposta neste trabalho é a modificação de estilo. Nessa transição, considera-se processos que alteram os resultados da imagem final, tais como os processos utilizados para gerar o non-photorealistic video-avatar. Uma diferença dessa transição em relação ao uso de diferentes tipos de técnicas de renderização está no fato de que essa transição utiliza alguma técnica de renderização como base para se aplicar o estilo. Assim, diferentes técnicas de renderização podem ser utilizadas como base para se aplicar o mesmo estilo. Por exemplo, utilizar o microfacet billboarding ou mesh rendering como base para se aplicar um estilo não fotorrealístico.

\subsection{Técnicas Existentes}

Esta seção apresenta as diferentes técnicas estudadas no capítulo 3 descritas segundo o modelo teórico proposto neste trabalho, apresentando o fluxo dos dados dessas técnicas dentro de cada módulo. Um primeiro exemplo a ser apresentado é o caso do visual hull (LAURENTINI, 1994; MATUSIK; BUEHLER; MCMILLAN, 2001), a figura 4.3 apresenta graficamente a técnica descrita segundo o modelo proposto.

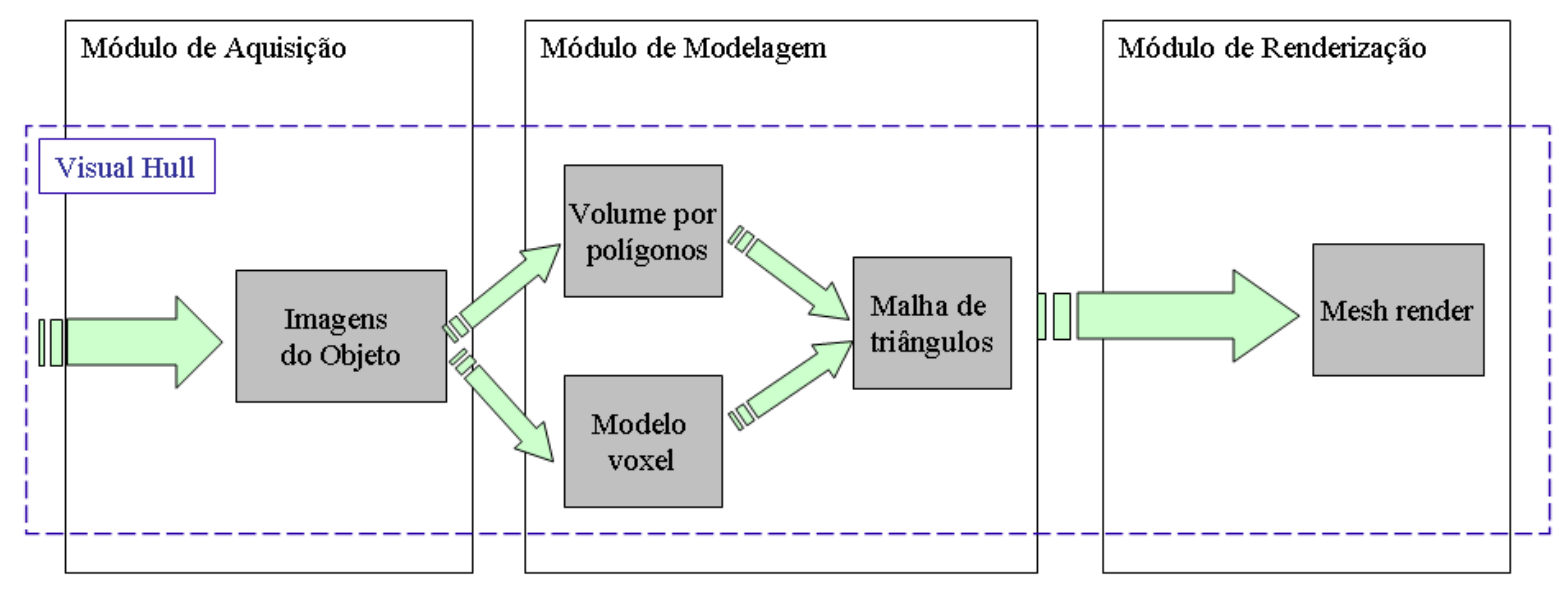

Figura 4.3: Técnica de Visual Hull (LAURENTINI, 1994; MATUSIK; BUEHLER; MCMILLAN, 2001) descrita segundo o modelo proposto.

Nesse caso, as informações obtidas no módulo de aquisição são imagens em diferentes ângulos do objeto a ser reconstruído e as informações de posição e propriedades das câmeras. Essas informações são processadas para se obter um modelo de voxel colorido ou um volume por polígonos texturizado, como apresentados no capítulo 3. Ainda no módulo de modelagem geométrica, o modelo de polígono ou de voxel obtido é convertido no modelo de malha triangular texturizado, note que essa transformação é uma "alteração de formato" apresentado na seção 4.2 . 
Por fim, esse modelo de malha triangular é renderizado utilizando-se a mesh rendering, técnica convencional do OpenGL ${ }^{2}$. Pode-se notar que o modelo de polígonos ou voxel, obtido durante a etapa de modelagem, pode ser renderizado utilizando-se outras técnicas, por exemplo, a técnica de splats ou de microfacet billboarding, processo que não é proposto originalmente e que pode ser visualizado com o modelo teórico.

O opacity hull (MATUSIK et al., 2002), por sua vez, pode ser representado como uma técnica que é composta por parte da técnica de visual hull. Nessa técnica, capturam-se, na etapa de aquisição de dados, imagens do objeto a ser reconstruído em diferentes ângulos, como na reconstrução por visual hull, e também imagens do objeto com diferentes fundos e diferentes condições de iluminação. No módulo de modelagem, um modelo tridimensional por polígonos é obtido utilizando-se na técnica de visual hull. Porém, depois desse processo, esse modelo é refinado utilizando-se as imagens com diferentes iluminações e fundos. O resultado desse refinamento é um modelo de "light field", que contem as informações de transparência e refletância. Por fim, esses modelos são renderizados utilizando-se métodos que possibilitam a representação desses dados. A figura 4.4 apresenta graficamente o fluxo de dados. Note que neste caso, parte da técnica de visual hull é representada com um outro retângulo tracejado, representando que a técnica de opacity hull é constituída por parte do visual hull.

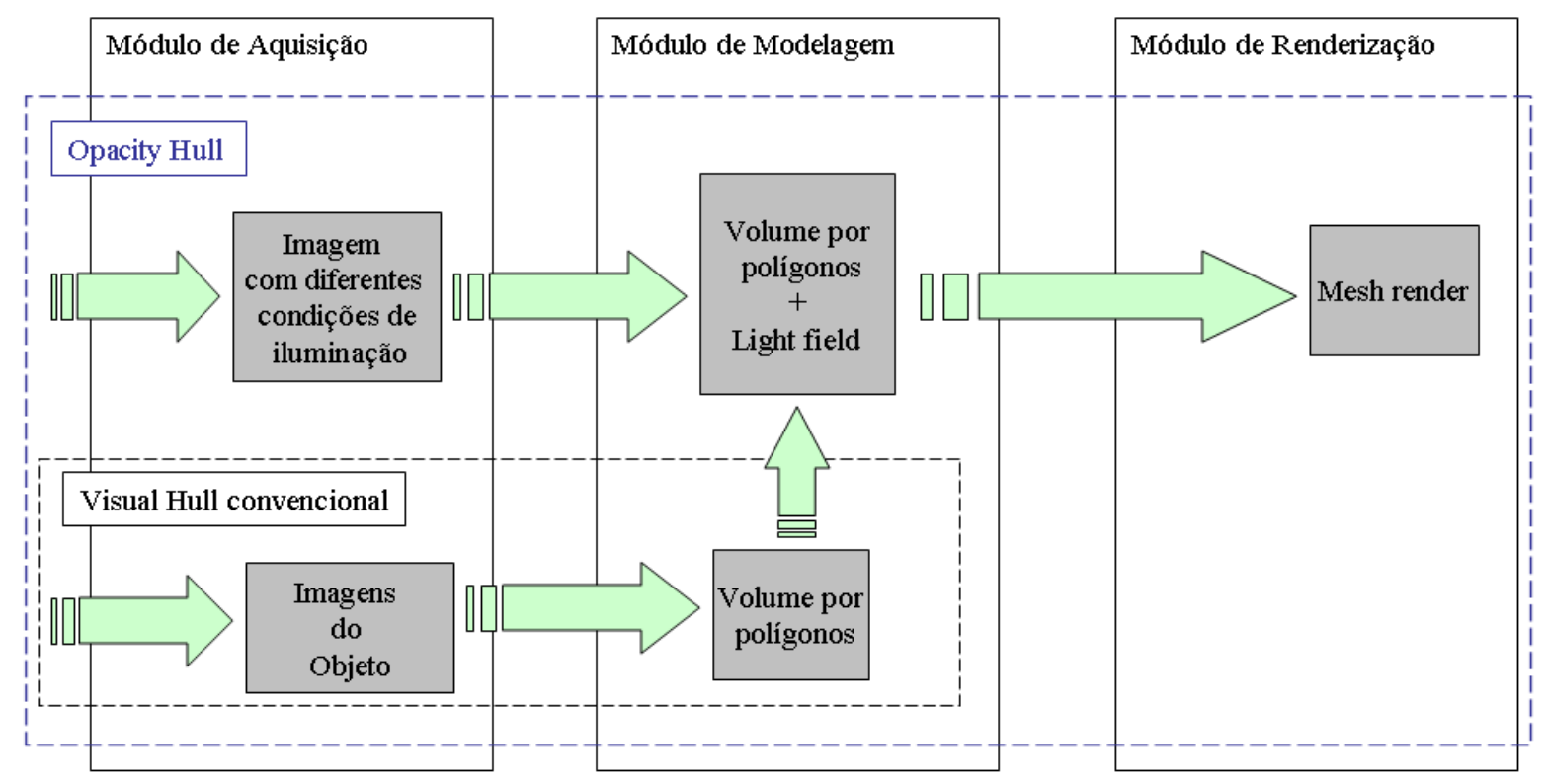

Figura 4.4: Técnica de Opacity Hull (MATUSIK et al., 2002) descrita segundo o modelo proposto.

A tabela 4.1 apresenta as informações obtidas em cada módulo das técnica de reconstrução apresentadas ao longo deste trabalho. Através desta tabela é possível se visualizar o fluxo de

\footnotetext{
${ }^{2}$ http://www.opengl.org/
} 
informações de cada técnica, auxiliando as suas visualizações gerais.

\subsection{Considerações Finais}

Através da aderência do modelo proposto às técnicas analisadas, dado que todos os casos estudados adequam-se ao modelo, e à definição de reconstrução geométrica que Magnor (2005) propõe, pode-se afirmar que o modelo proposto é válido. Desta forma, mostrando que as técnicas de reconstrução podem ser separadas nas três etapas de aquisição de dados, modelagem geométrica e renderização, facilitando a visualização dos fluxos de informações de cada técnica. Este modelo é utilizado como base neste trabalho, auxiliando a análise e implementação das novas técnicas de renderização propostas no capítulo 5. 
Tabela 4.1: Fluxo de dados de técnicas de reconstrução geométrica descritas segundo o modelo proposto

\begin{tabular}{|c|c|c|c|c|}
\hline & \multicolumn{3}{|c|}{ Módulos } \\
\hline & & Aquisição & Modelagem & Renderização \\
\hline \multirow{9}{*}{ : } & Bidimensional & $\begin{array}{l}\text { Sequência de uma ou } \\
\text { mais imagens }\end{array}$ & Modelo planar & Mesh rendering \\
\hline & $\begin{array}{l}\text { Bidimensional } \\
\text { Estereoscó- } \\
\text { pica }\end{array}$ & $\begin{array}{l}\text { Sequência de um ou } \\
\text { mais pares de Ima- } \\
\text { gens Estereoscópicas }\end{array}$ & Modelo planar & Mesh rendering \\
\hline & $\begin{array}{l}\text { Switching } \\
\text { Planes }\end{array}$ & $\begin{array}{l}\text { Imagens ao longo do } \\
\text { tempo e em diferen- } \\
\text { tes ângulos }\end{array}$ & Modelo planar & Mesh rendering \\
\hline & $\begin{array}{l}\text { Mapa de al- } \\
\text { turas e de- } \\
\text { formação de } \\
\text { malhas }\end{array}$ & $\begin{array}{l}\text { Par de imagens este- } \\
\text { reoscópicas ao longo } \\
\text { do tempo }\end{array}$ & $\begin{array}{l}\text { Mapa de alturas con- } \\
\text { vertidas em malha de } \\
\text { triângulos }\end{array}$ & Mesh rendering \\
\hline & $\begin{array}{l}\text { Switching } \\
\text { Depth Model }\end{array}$ & $\begin{array}{l}\text { Múltiplos pares de } \\
\text { imagens ao longo do } \\
\text { tempo e em diferen- } \\
\text { tes ângulos }\end{array}$ & $\begin{array}{l}\text { Múltiplos mapas de } \\
\text { alturas convertidos a } \\
\text { malhas de triângulos }\end{array}$ & Mesh rendering \\
\hline & $\begin{array}{l}\text { Sistema } \\
\text { Blue-C } \\
\text { (Splats) }\end{array}$ & $\begin{array}{l}\text { Imagens ao longo do } \\
\text { tempo e em diferen- } \\
\text { tes ângulos }\end{array}$ & Modelo por polígonos & Splat rendering \\
\hline & Visual Hull & $\begin{array}{l}\text { Imagens ao longo do } \\
\text { tempo e em diferen- } \\
\text { tes ângulos }\end{array}$ & $\begin{array}{l}\text { Modelo de voxel ou } \\
\text { polígonos convertido } \\
\text { em malha de triângu- } \\
\text { los }\end{array}$ & Mesh rendering \\
\hline & Opacity Hull & $\begin{array}{l}\text { Imagens em diferen- } \\
\text { tes ângulos, fundos e } \\
\text { iluminações }\end{array}$ & $\begin{array}{l}\text { Modelo de polígonos } \\
\text { refinado com o mo- } \\
\text { delo de light field e } \\
\text { convertido à malha de } \\
\text { triângulos }\end{array}$ & Mesh rendering \\
\hline & $\begin{array}{l}\text { Microfacet } \\
\text { Billboarding }\end{array}$ & $\begin{array}{l}\text { pontos capturados } \\
\text { por um scanner } \\
\text { 3D e imagens em } \\
\text { diferentes ângulos }\end{array}$ & modelo de voxel & $\begin{array}{l}\text { microfacet billboar- } \\
\text { ding }\end{array}$ \\
\hline
\end{tabular}




\section{TÉCNICAS DE RECONSTRUÇÃO E RENDERIZAÇÃO PROPOSTAS}

Para a criação da representação visual do participante que possua as três características necessárias para o projeto iLive (tempo-real, representação de detalhes e integração com o ambiente tridimensional), novas técnicas foram propostas neste trabalho. Essas propostas podem ser separadas em dois grandes grupos, o video-based microfacet billboarding (VBMB) e o nonphotorealistic video-avatar. O VBMB é uma técnica de reconstrução geométrica que tem como foco o módulo de renderização do modelo teórico proposto neste trabalho. Já o nonphotorealistic video-avatar é um novo conceito de vídeo-avatar que visa melhorar a integração do avatar no ambiente virtual.

\subsection{VBMB: Video-Based Microfacet Billboarding}

O Video-Based Microfacet Billboarding (VBMB ${ }^{1}$ ) é uma técnica que estende a reconstrução por microfacet billboarding proposta por Yamazaki et al. (2002). Essa técnica visa possibilitar o uso de microfacet billboarding em tempo-real, permitindo uma reconstrução que represente os detalhes do objeto real não estático. O VBMB também utiliza os conceito de mapeamento de normais (KRISHNAMURTHY; LEVOY, 1996), para aumentar a integração do objeto real na cena virtual através da coerência com a iluminação do ambiente virtual, e o conceito de splats (NAEF; STAADT; GROSS, 2004), para se melhorar a qualidade visual do avatar.

A técnica VBMB é constituída de duas técnicas de reconstrução geométrica, a técnica de mapa de alturas e deformação de malhas triangulares (OGI et al., 2003) e da técnica de microfacet billboarding. Essa concatenação de técnicas se torna mais simples de ser visualizada utilizando-se modelo teórico proposto neste trabalho. A figura 5.1 apresenta visualmente a técnica de VBMB descrita segundo o modelo.

Nesse caso, as informações capturadas no módulo de aquisição podem ser pares de imagens

\footnotetext{
1 Neste trabalho, o conjunto de técnicas apresentadas nesta seção são denominadas como VBMB, apesar do nome video-based microfacet billboarding remeter somente a base técnica da reconstrução geométrica.
} 


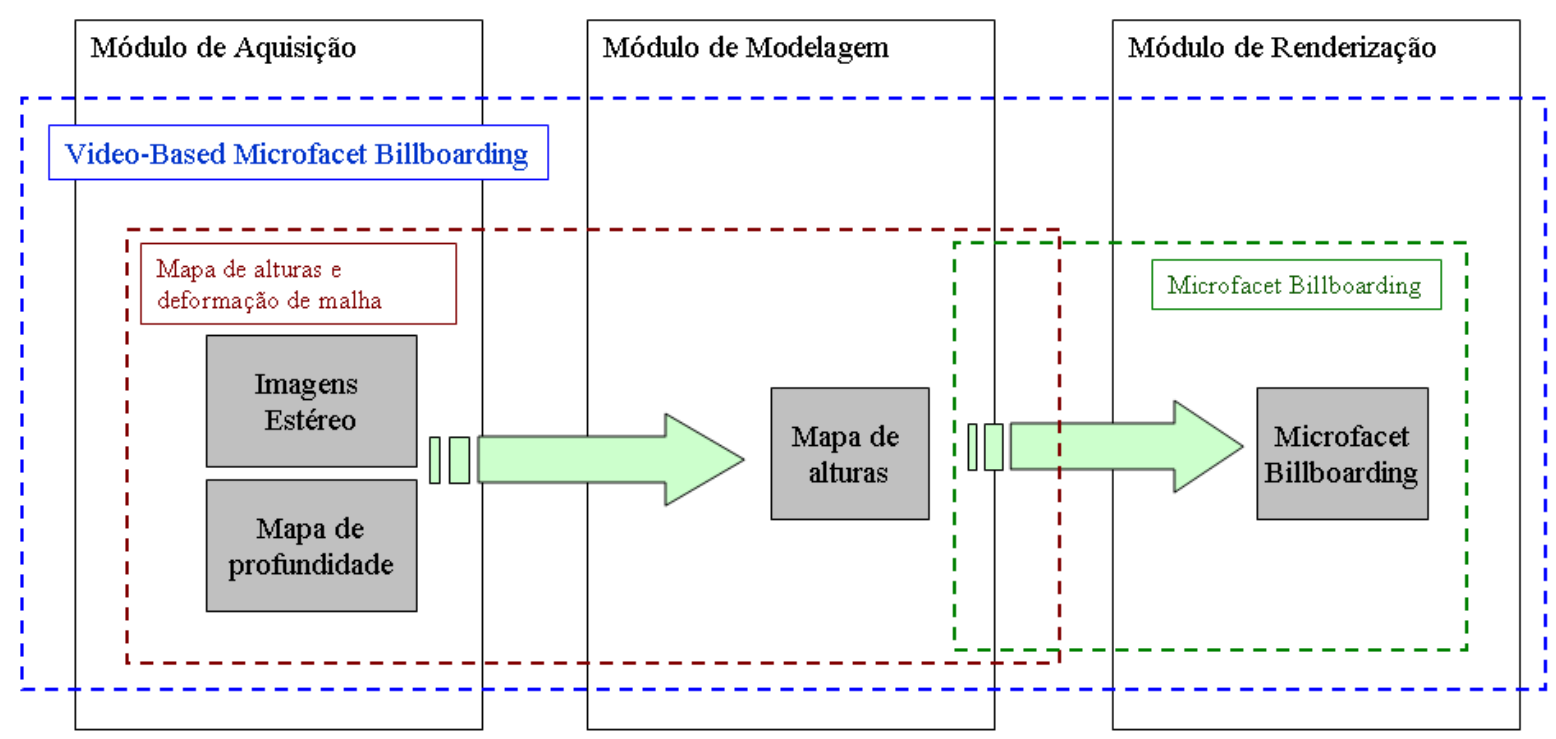

Figura 5.1: Técnica de Video-Based Microfacet Billboarding (VBMB) descrita segundo o modelo teórico proposto.

estereoscópicas, capturadas por câmeras convencionais, ou mapas de profundidades, capturadas por câmeras especiais. Esses dados capturados são processados devidamente de forma a se obter o mapa de alturas como resultado final do módulo de modelagem. Assim, pode se verificar que as duas etapas, de captura e modelagem, são as mesmas da técnica de mapa de alturas e deformação de malha triangular. Porém, para a reconstrução do VBMB, utiliza-se a renderização por microfacet billboarding como última etapa, visando melhorar a representação dos detalhes, característica que não é atingida pela renderização por malha de triângulos, como visto no capítulo 3.

Analisando-se as características que o VBMB possui, pode se verificar que a técnica tem grande possibilidade de possuir as três características necessárias para a criação da representação do participante no ambiente virtual. A tabela 5.1 apresenta a análise das características, listadas na seção 3.10, da técnica VBMB e de outras técnicas concatenadas com a renderização por microfacet billboarding.

Nota-se que, dentre as técnicas listadas na tabela, a técnica de VBMB é a única que apresenta todas as características, mesmo parcialmente, com uma baixa complexidade de configuração física. Se diferindo das outras técnicas (Visual Hull com a renderização por microfacet billboarding e Switching depth model com a renderização por microfacet billboarding), que possuem todas as características, mas possuem configurações físicas complexas. Uma vez que o sistema iLive será utilizado em aplicações de educação e jogos eletrônicos, é desejável que a configuração para os participantes seja de baixa complexidade. 
Tabela 5.1: VBMB e outas técnicas de reconstrução $X$ características

\begin{tabular}{|c|c|c|c|c|c|c|c|}
\hline & \multicolumn{6}{|c|}{ Características } \\
\hline & & $\begin{array}{l}\bar{\pi} \\
\frac{\pi}{0} \\
\vdots \\
\frac{0}{2} \\
\frac{1}{0}\end{array}$ & 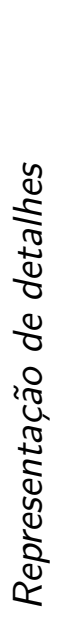 & 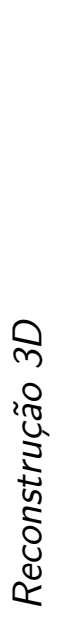 & 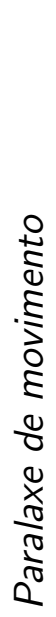 & 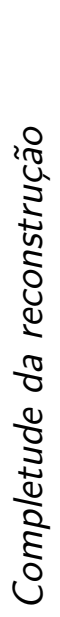 & 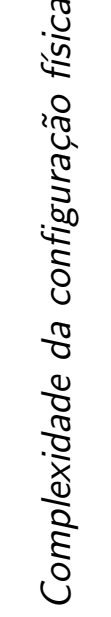 \\
\hline \multirow{3}{*}{ 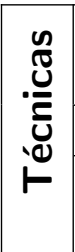 } & $\begin{array}{l}\text { Video-Based Microfacet Billboarding } \\
\text { (VBMB) }\end{array}$ & $O$ & $O$ & $O$ & $O$ & $\Delta$ & baixo \\
\hline & Visual Hull + microfacet billboarding & $O$ & $O$ & $O$ & $O$ & $O$ & alto \\
\hline & $\begin{array}{l}\text { Switching Depth Model + microfacet billboar- } \\
\text { ding }\end{array}$ & $O$ & $O$ & $O$ & $O$ & $O$ & alto \\
\hline
\end{tabular}

Sua única limitação, frente as outras técnicas, seria a reconstrução incompleta do avatar (apresentado na tabela pela completude da reconstrução parcial). Porem, uma vez que o avatar não seria visualizado livremente pelos usuários observadores, somente em pequenos ângulos devido ao requisito deste trabalho apresentado na seção 1.3, esta limitação é aceitável. Dessa forma, o VBMB se mostra a técnica mais adequada para a representação visual dos participantes dentro do ambiente virtual do iLive.

\subsubsection{Base Conceitual}

Para a geração do VBMB, inicialmente as informações de mapa de alturas devem ser geradas. Para tal, diferentes propostas podem ser utilizados, como o sistema AVMix (NAKAMURA; TORI, 2008) ou câmeras especiais de captura como a Pointgrey ou a Zcam(GVILI et al., 2003). Outra importante informação a ser capturada é a imagem RGB correspondente ao mapa de altura. Essas duas informações são as duas informações utilizadas para a reconstrução.

Para gerar o modelo tridimensional, um método similar ao de Ogi et al. (2003) é utilizado. Inicialmente a imagem colorida é subdividida em uma matriz de $N \times M$, onde $N$ e $M$ representam respectivamente o número de divisões na horizontal e na vertical. Para cada célula dessa matriz, um micro-billboard é criado e cada um deles é posicionado no espaço de acordo com a altura obtida pelo mapa de alturas. O conjunto de todos esses micro-billboards geram 
a representação da superfície do objeto. A figura 5.2 ilustra essa ideia.

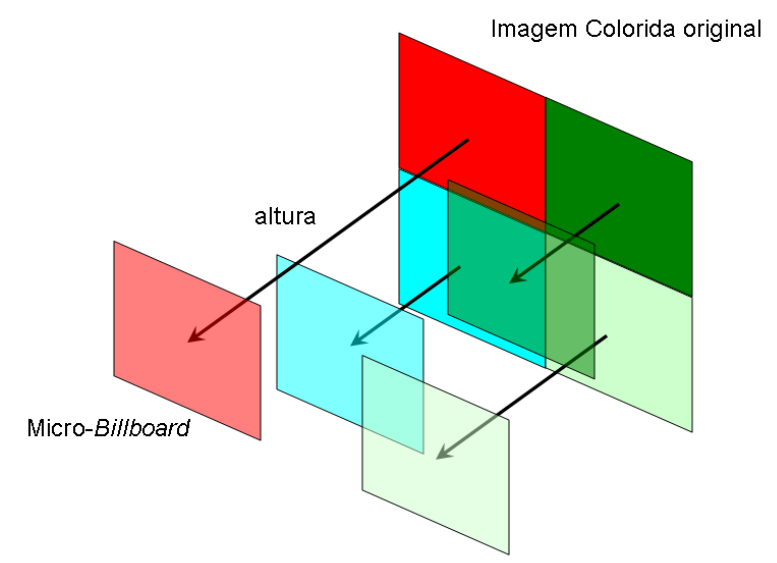

Figura 5.2: Conceito base da técnica VBMB

O tamanho de cada micro-billboard deve ser configurado de forma que o usuário visualizador não perceba falhas na superfície. Para tal, deve se garantir que os micro-billboards sempre tenham uma sobreposição entre eles do ponto de vista do usuário visualizador, independente do ângulo que são visualizados. Para uma imagem com largura $L$, a largura $l$ de cada micro-billboard é determinado como sendo:

$$
l=\sqrt{3}\left(\frac{L}{N}\right)
$$

Essa largura $l$ é a igual à diagonal de um cubo de tamanho $L \times L \times L$. Dado que, cada micro-billboard tem uma largura igual a essa diagonal, pode se garantir que sempre haverá sobreposição dos micro-billboards. Esse cálculo é análogo ao cálculo que se encontra no trabalho de Yamazaki et al. (2002). De mesma forma, define-se a altura do micro-billboard. A figura 5.3 ilustra essa ideia.

Um problema dessa proposta, são as falhas que o usuário pode visualizar quando dois micro-billboards são posicionados lado-a-lado com valores de alturas diferentes. Essas falhas decorrem da falta de informação de cor e superfície nas laterais do modelo tridimensional, limitação das reconstruções por mapa de altura. A figura 5.4(a) apresenta visualmente esse problema.

Para se evitar esse problema, os micro-billboards são replicados ao longo da altura, de forma a cobrir essas falhas e fazendo com que o modelo fique mais parecido com um modelo de voxeis. Essa ideia é análoga à criar uma "pilha de cartas" ao longo da altura, e o número de "cartas" dessa "pilha" depende do tamanho dos micro-billboards, problema similar ao problema do tamanho do micro-billboard. Porém, é importante notar que, devido à essa replicação, o 


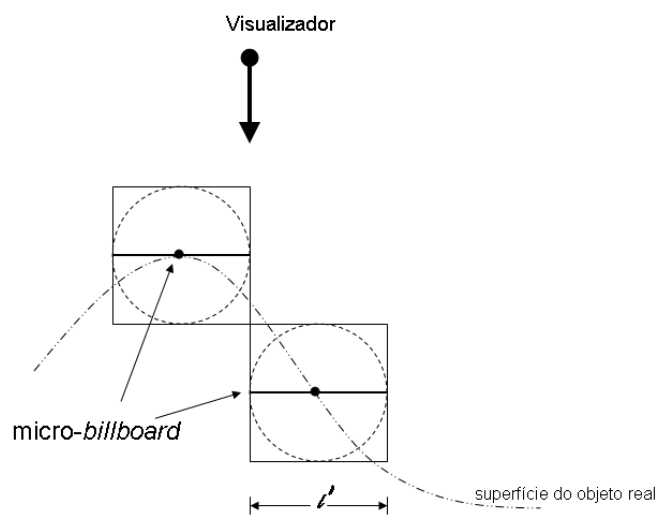

(a) Sem falha da superfície devido a posição do usuário

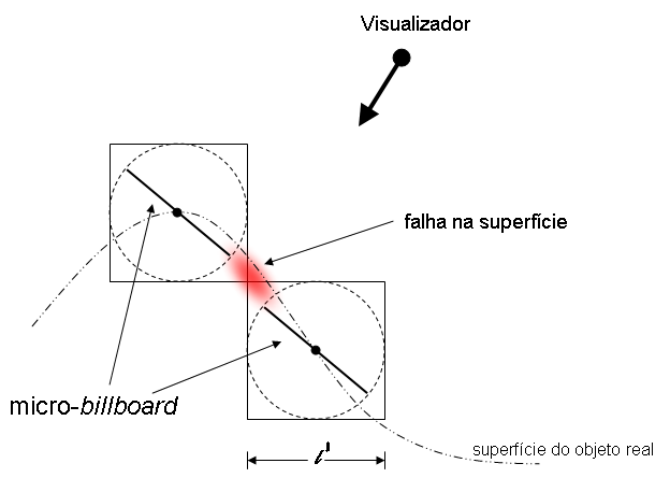

(b) Falha da superfície devido a posição do usuário

Figura 5.3: Falha da reconstrução devido ao tamanho do micro-billboard

desempenho dessa técnica depende diretamente das alturas utilizadas.

Também, devido a falta de informação de cor das laterais do objeto, utiliza-se as mesmas informações de cor em todos os micro-billboards replicados ao longo da altura. As figuras 5.4(b) e 5.4(c) ilustram essa ideia. Essa imagem é uma simples ilustração da proposta e no processo de renderização real, somente os micro-billboards que se encontram na superfície do objeto reconstruído são renderizados. Não havendo a renderização de micro-billboards que não são visíveis, como na ilustração. Dessa forma, diminuindo o custo computacional da renderização. O algoritmo utilizado para a renderização é apresentado na figura 5.5.

\subsubsection{Controle de Nível de Detalhamento (LoD)}

O uso dessa subdivisão da imagem como base conceitual para a geração do modelo tridimensional traz uma vantagem direta: o fácil controle de níveis de detalhamento da renderização do objeto (Level of Detail ou LoD). Esse controle é utilizado para diminuição do custo computacional da renderização de uma cena, diminuindo-se em tempo-real o nível de detalhes de objetos que se encontram longe, não prejudicando a qualidade da cena como um todo.

No caso do VBMB, esse efeito pode ser obtido simplesmente alterando-se o número de divisões " $N \times M$ " da matriz de acordo com a distância do avatar em relação à câmera. A figura 5.6 ilustra essa ideia. 


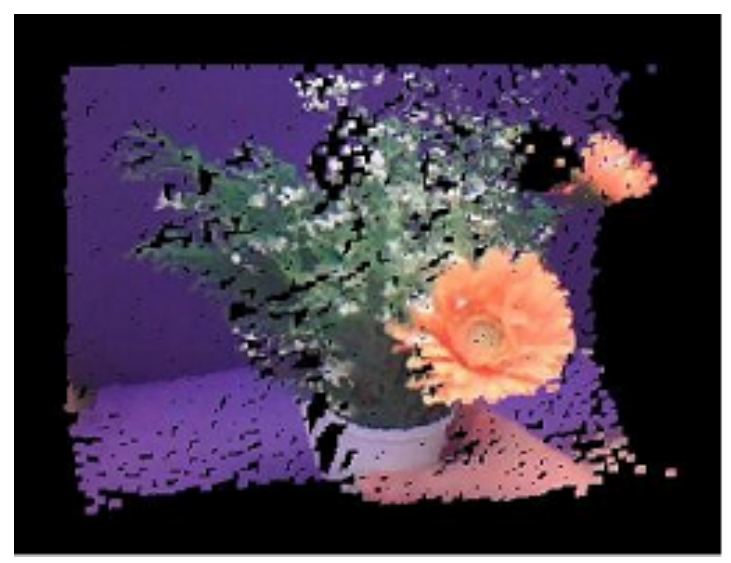

(a) Falhas decorrentes da falta de informação

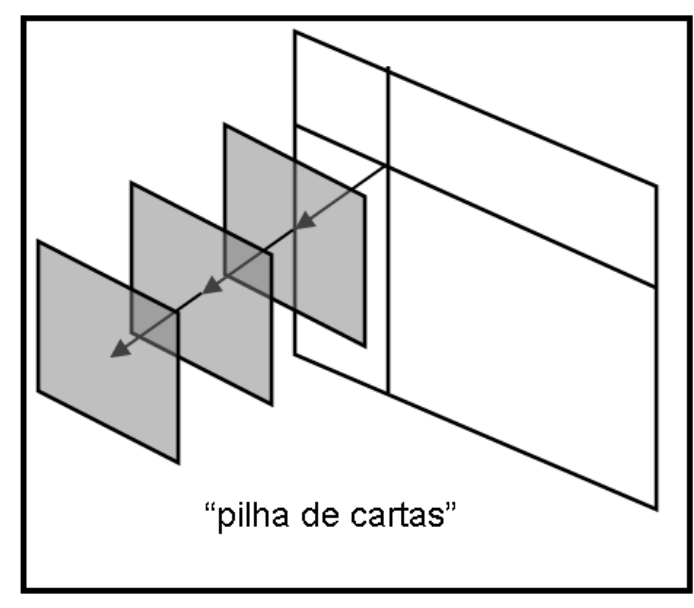

(b) Imagem conceito da redundância

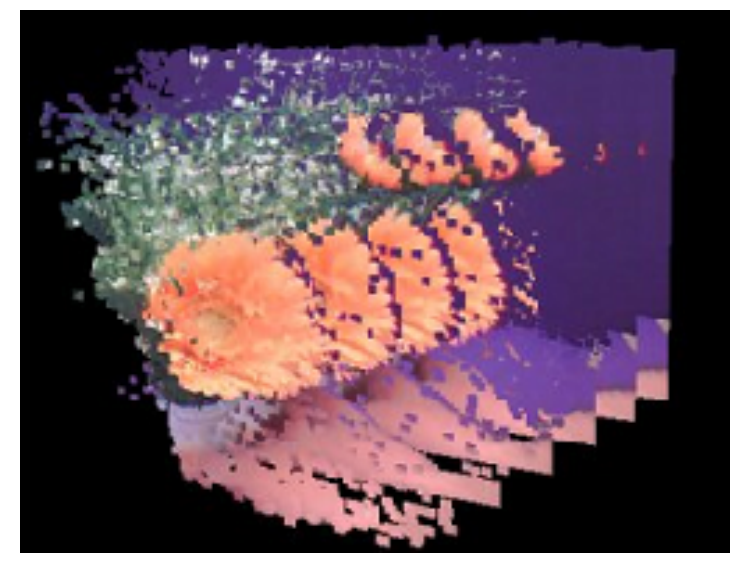

(c) Resultado ilustrando a redundância

Figura 5.4: Limitação da técnica de mapa de alturas

\subsubsection{Iluminação Utilizando Técnicas de Mapa de Normais}

Um importante fator para aumentar a integração do participante com o ambiente virtual é a coerência com a iluminação virtual, funcionalidade não presente em muitos trabalhos de reconstrução. Para se adicionar esse efeito ao VBMB, utilizou-se as informações do mapa de alturas para se gerar um mapa de normais. Através desse mapa de normais técnicas como mapeamento de normais (KRISHNAMURTHY; LEVOY, 1996), parallaxe mapping (KANEKO et al., 2001) ou relief mapping (OLIVEIRA; BISHOP; MCALLISTER, 2000; PAMPLONA; OLIVEIRA; NEDEL., 2008) podem ser utilizadas. Neste trabalho a técnica de mapeamento de normais foi utilizada para implementação da coerência do sombreamento do objeto em relação à iluminação virtual devido a sua simplicidade de implementação.

A normal de cada pixel é obtida através da média das normais dos triângulos que esse pixel forma com os pixeis vizinhos e suas respectivas alturas. Para cada pixel $\operatorname{pixel}(i, j) \mathrm{da}$ 


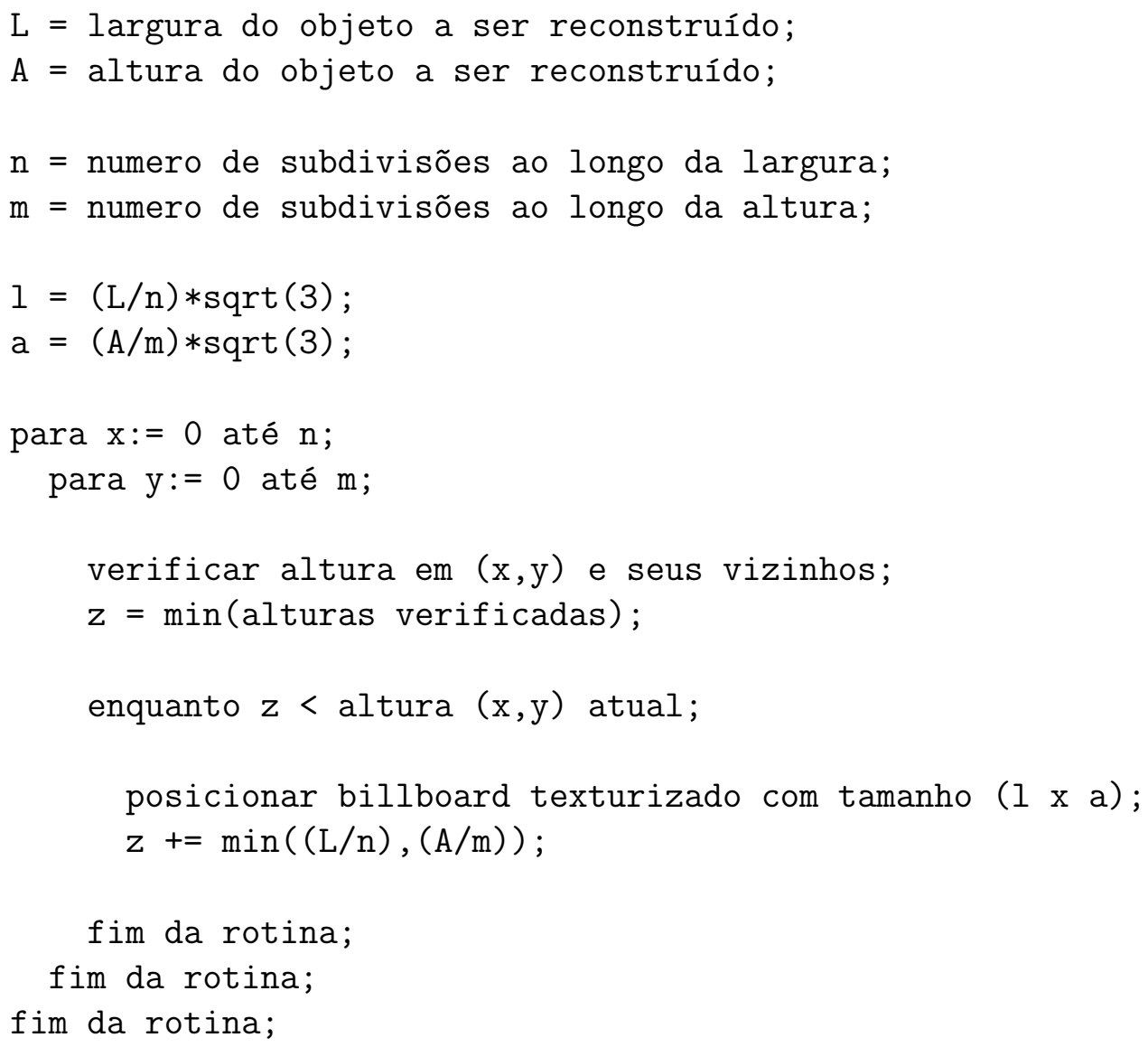

Figura 5.5: Algoritmo para renderização do vídeo-avatar.

imagem calcula-se o vetor tridimensional $V_{\text {pixel }(m, n)-\operatorname{pixel}(i, j)}$ que o pixel forma com os seus vizinhos, utilizando-se as coordenadas $X Y$ da imagem e a altura $Z$. A normal $N_{\text {face }(a)}$ do triângulo $i$, que o pixel forma com dois dos seus vizinhos, é obtido através do produto vetorial desses vetores $V_{\text {pixel }(m, n)-p i x e l(i, j)}$, e esse cálculo é repetido para todos os quatro triângulos que o pixel forma com seus pixeis vizinhos. Por fim, a normal do pixel $N_{\text {pixel }(i, j)}$ é estimada como sendo a soma de todas essas normais desses triângulos. O cálculo de $N_{\text {pixel }(i, j)}$ é descrito pelas equações 5.2 e 5.3, e a figura 5.7 ilustra essa ideia. As figuras 5.8 e 5.9 apresentam os algoritmos utilizados neste processo, 5.8 apresenta o processo de geração de mapa de normais e 5.9 apresenta o algoritmo utilizado na placa gráfica no processo de geração de pixeis para gerar o efeito de sombreamento.

$$
N_{\text {pixel }(i, j)}=\sum_{a=1}^{4} N_{f a c e(a)}
$$

onde 


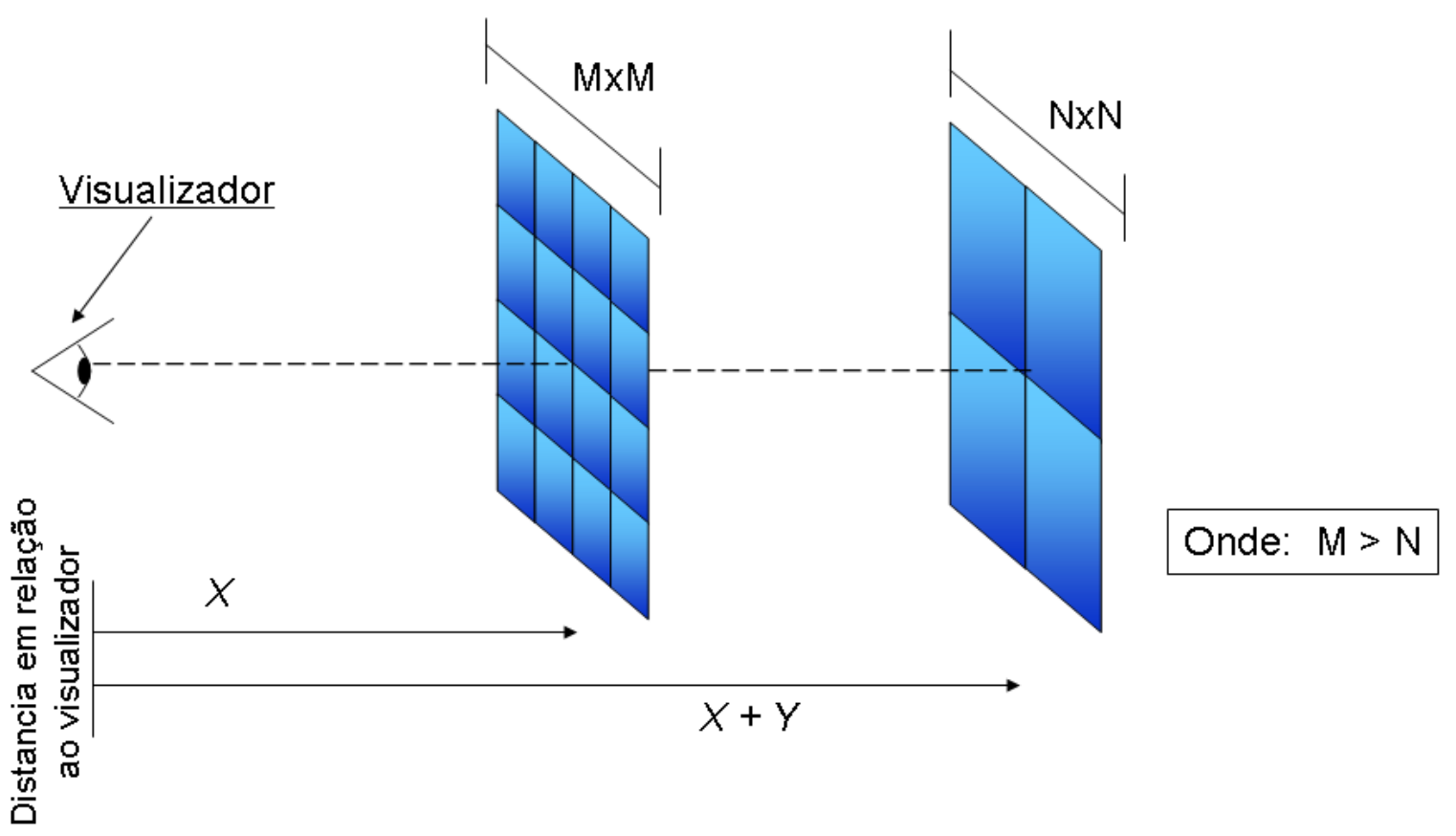

Figura 5.6: Controle de nível de detalhe na técnica VBMB

$$
N_{\text {face }(a)}= \begin{cases}V_{\text {pixel }(i-1, j)-\operatorname{pixel}(i, j)} \times V_{\text {pixel }(i, j-1)-\operatorname{pixel}(i, j)} & \text { caso } a=1 \\ V_{\text {pixel }(i-1, j)-\operatorname{pixel}(i, j)} \times V_{\text {pixel }(i, j+1)-\operatorname{pixel}(i, j)} & \text { caso } a=2 \\ V_{\operatorname{pixel}(i, j-1)-\operatorname{pixel}(i, j)} \times V_{\text {pixel }(i+1, j)-\operatorname{pixel}(i, j)} & \text { caso } a=3 \\ V_{\text {pixel }(i, j+1)-\operatorname{pixel}(i, j)} \times V_{\text {pixel }(i, j+1)-\operatorname{pixel}(i, j)} & \text { caso } a=4\end{cases}
$$

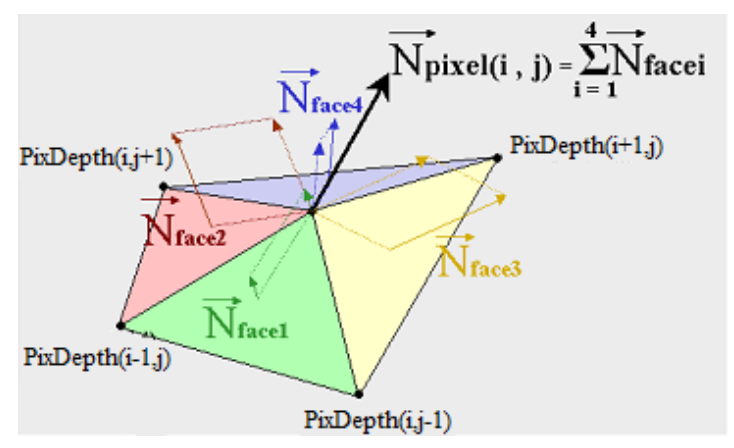

(a)

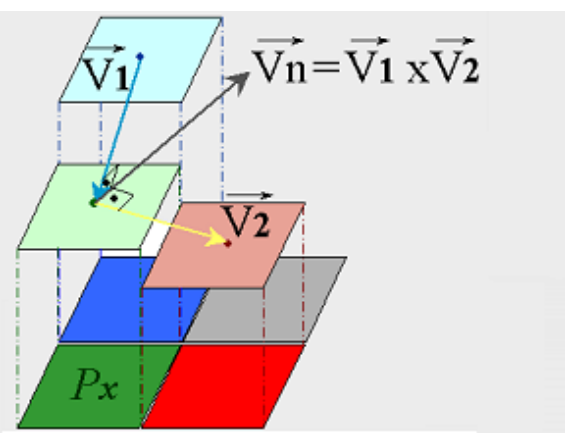

(b)

Figura 5.7: Cálculo da: 5.7(a) normal de cada pixel e 5.7(b) normal de cada face

\subsubsection{Splats}

Por fim, a abordagem de splats (NAEF; STAADT; GROSS, 2004; ZWICKER et al., 2001) pode ser aplicada à técnica de VBMB para se melhorar a qualidade visual final da reconstrução. Nesse caso, não se considera um espalhamento das cores sobre a superfície do objeto para o 


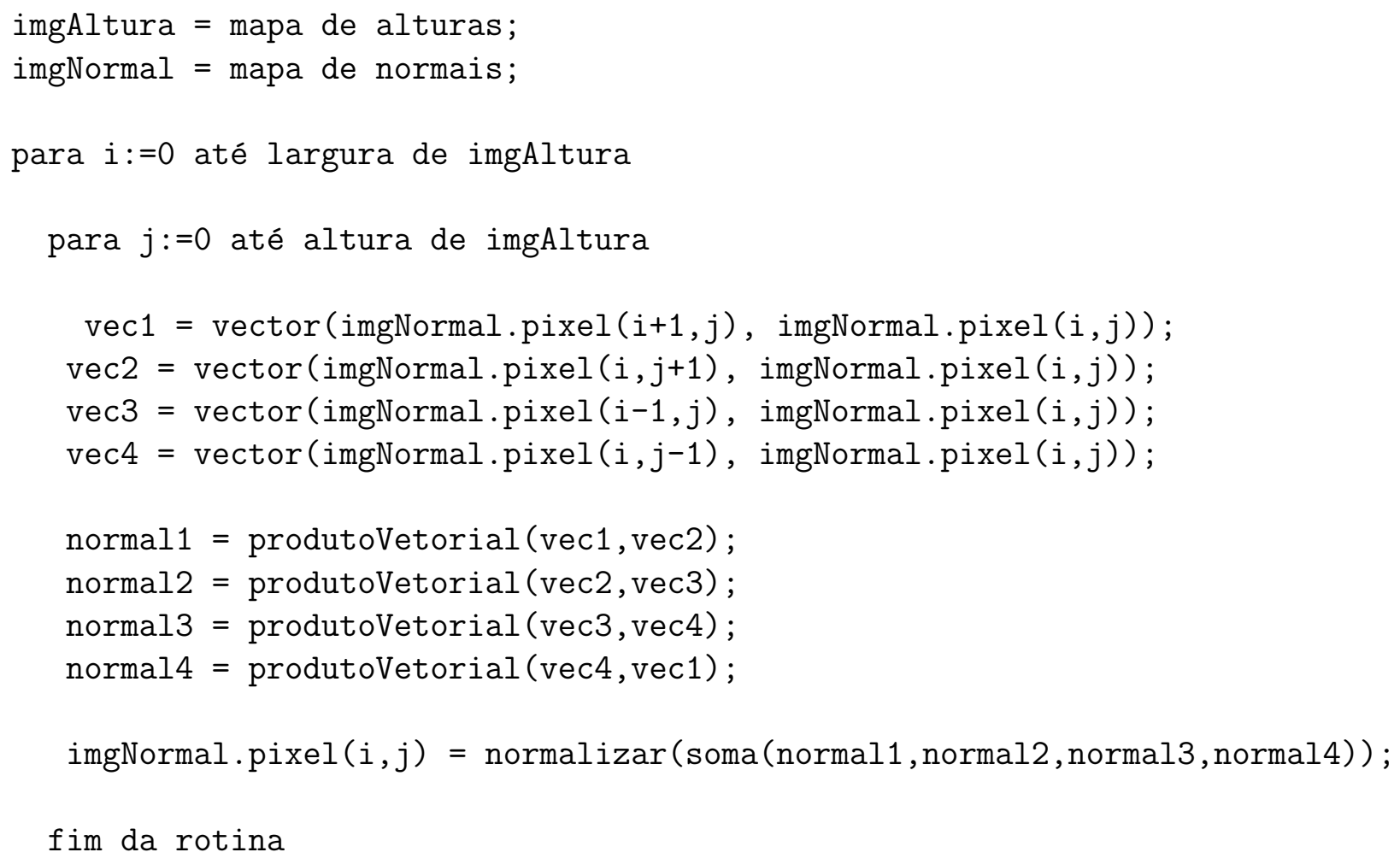

Figura 5.8: Algoritmo para geração do mapa de normais através do mapa de alturas.

cálculo da cor de um determinado local, como na abordagem original de splats, mas sim, o espalhamento das texturas sobre a superfície.

Uma vez que, nessa proposta de VBMB, a superfície do objeto reconstruído é representado por micro-billboards e não há a captura de informações de cores nas laterais do objeto real, incoerências nas bordas de cada micro-billboard podem ocorrer. Isto se deve ao fato de que essas informações de cores podem se encontrar em alturas diferentes da superfície original. Visualmente esses erros são apresentados ao usuário como quinas ao longo da superfície, pois cada micro-billboard é um polígono retangular. A figura 5.10 apresenta esses erros presentes no objeto reconstruído.

A abordagem de splats pode diminuir significantemente esses erros visuais. Nessa abordagem a cor/textura de um determinado local da superfície do objeto reconstruído é determinado pela média das texturas aplicadas nos micro-billboards ao redor, dessa forma, diminuindo os erros de posicionamento das cores. Para a aplicação dessa abordagem de splats na técnica 


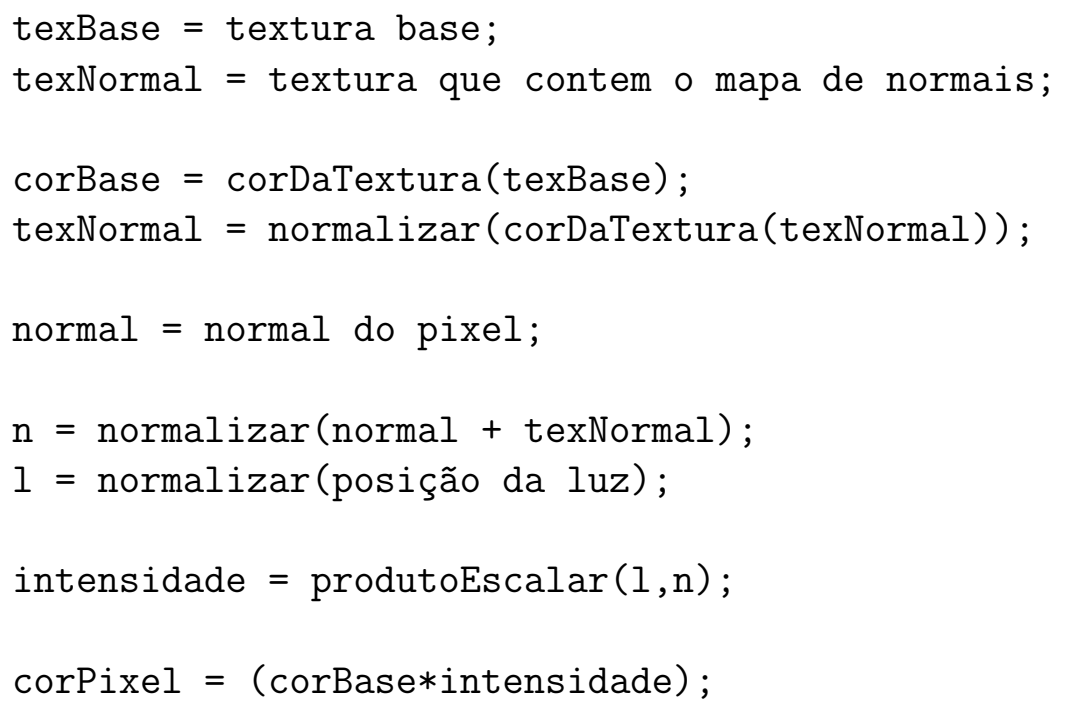

Figura 5.9: Algoritmo para renderização do avatar com a coerência com a iluminação virtual, utilizado no pixel shading da placa gráfica.
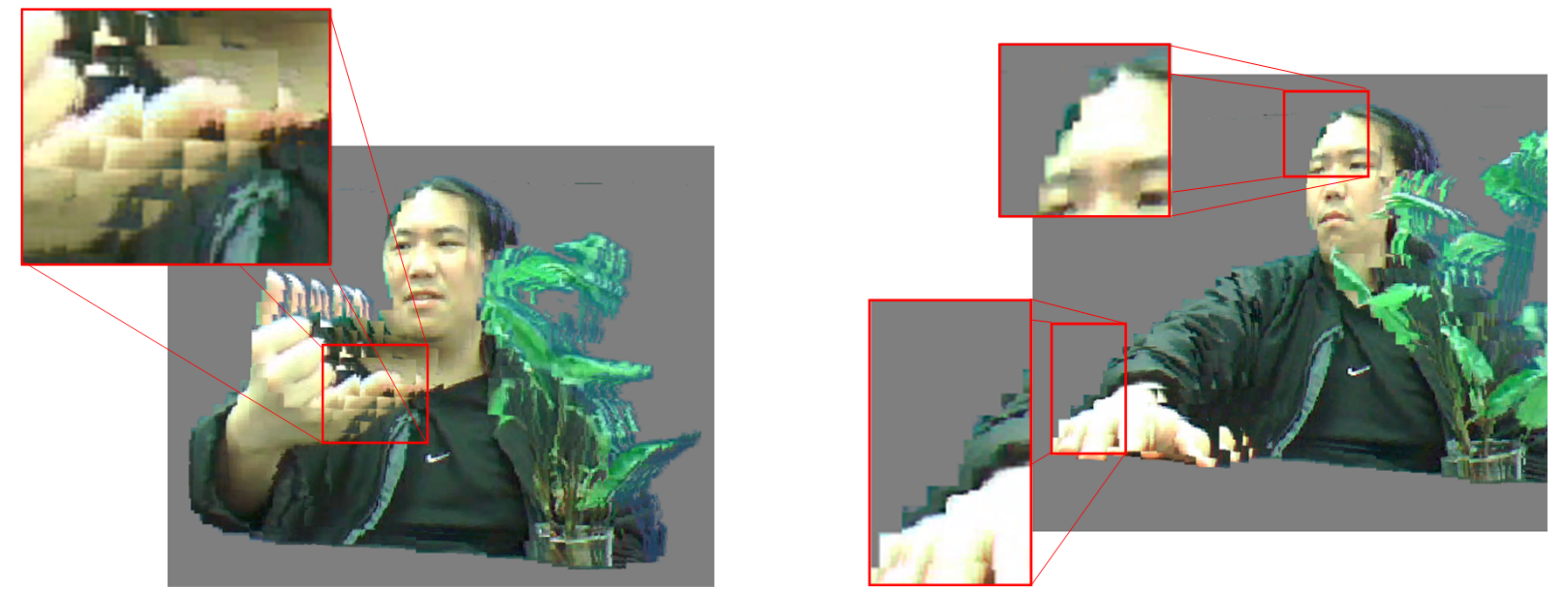

Figura 5.10: Quinas da imagem ao longo da imagem geradas pelo erro de posicionamento de cores.

VBMB, uma proposta similar à de Naef, Staadt e Gross (2004) foi utilizada. Aqui, um decaimento gaussiano de transparência é aplicado a cada micro-billboard. A figura 5.11 apresenta essa proposta. 


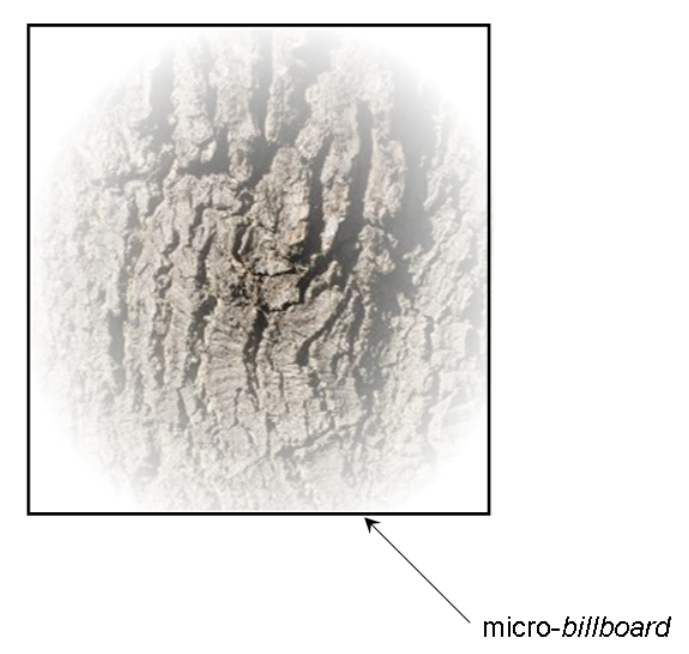

(a) Abordagem de splats aplicada a microbillboards

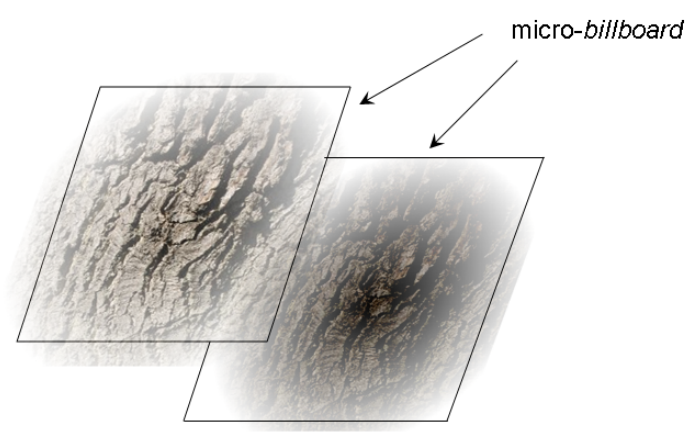

(b) Múltiplos micro-billboards com a técnica de splats espalhados sobre a superfície tridimensional

Figura 5.11: Técnica de splats aplicada ao VBMB

\subsection{Non-photorealistic Vídeo-avatar}

Neste trabalho também se propõe o conceito de non-photrealistc video-avatar como forma de aumentar a integração do vídeo-avatar com o ambiente tridimensional. Essa proposta utiliza como base o conceito de stylized augmented reality proposta originalmente por Fischer, Haller e Thomas (2008). O non-photorelaitic video-avatar propõe a utilização de estilos não fotorrealístico, tais como cel shading (DECAUDIN, 1996), no avatar e nos objetos virtuais para se obter um estilo único sobre toda a cena virtual, aumentando a integração do avatar na cena. Essa proposta também pode ser utilizada em aplicações que necessitem de renderizações com esse gênero de estilo por motivos de design, aumentando-se a integração do avatar com o ambiente e por sua vez, aumentando-se a imersão do usuário visualizador.

\subsubsection{Base Conceitual}

Um problema que muitos dos sistemas de realidade aumentada possuem é a incoerência visual dos objetos virtuais e dos objetos reais. Fischer, Haller e Thomas (2008) aponta que essas incoerências são decorrentes da diferença entre o nível de realismo visual dos objetos reais e virtuais. Trabalhos como os de Klein e Murray (2008) e Grosch (2005) tentam diminuir essa diferença de realismo renderizando os objetos virtuais de forma mais realista. Porém, obter objetos virtuais realistas o suficiente é um trabalho complexo sem a utilização de técnicas de renderização com alto custo computacional como os algoritmos de ray-tracing (DORNBACH, 1998), photon map (JENSEN, 1995) e radiosity (GORAL et al., 1984), como visto no trabalho 
de Drettakis, Robert e Bougnoux (1997).

Fischer, Haller e Thomas (2008) apresentam uma forma totalmente diferente para se diminuir essa diferença de nível de realismo. Em seu trabalho, os autores propõem o conceito de stylized augmented reality. Nessa proposta, a diferença entre os níveis de realismo é balanceado diminuindo-se o realismo dos objetos/cena real. Para tal, estilos não fotorrealísticos são aplicadas em todos os objetos virtuais e reais, assim toda a cena é unificada com um único estilo.

Essa proposta pode ser utilizada diretamente à vídeo-avatares. Como na proposta de Fischer, consideramos que o vídeo-avatar não precisa representar fielmente a realidade em alguns casos. Nesses casos, a perda da fidelidade, causado pela representação não fotorrealística, traz o aumento da integração do vídeo-avatar com a cena através do balanço do nível de realismo entre os objetos. Ao mesmo tempo, esse vídeo-avatar também permite que características do usuário, suas movimentações, expressões faciais e gestos sejam apresentados ao usuário visualizador. Denominamos esse tipo de vídeo-avatar como non-photorealistic video-avatar.

O non-photorealistic video-avatar também pode ser largamente utilizado em aplicações de jogos eletrônicos. Em muitos jogos, o ambiente virtual possui um estilo definido por motivos de design do jogo. Nesses casos, a representação do participante vídeo-avatares convencionais pode ser muito realista. Porém, a proposta de non-photorealistic video-avatar tenta adequar o estilo do vídeo-avatar no estilo do jogo, aumentando a integração do avatar com a cena e aumentando, por sua vez, a imersão do jogador.

\subsubsection{Base Técnica}

Para aplicar esse estilo não fotorrealístico sobre a cena e sobre o avatar, diferentes técnicas de renderização não fotorrealísticos, tais como o cel shading (DECAUDIN, 1996), real-time hatching (PRAUN et al., 2001), Comprehensible rendering (SAITO; TAKAHASHI, 1990) e outras técnicas encontradas no site de Reynolds ${ }^{2}$, podem ser utilizadas. Técnicas de estilização de imagens reais, como os propostos por Winnemöller, Olsen e Gooch (2006), também podem ser utilizadas para a geração do avatar não fotorrealístico.

Neste trabalho, uma modificação do cel shading (DECAUDIN, 1996) foi utilizada para se gerar uma prova de conceito dessa proposta. Nesse estilo, os tons mais escuros dos objetos renderizados são truncados para a cor preta, criando um estilo "sombrio" em toda a cena. Também foram incluídos ruídos nas cores dos objetos, simulando a renderização sobre superfícies

\footnotetext{
${ }^{2}$ http://www.red3d.com/cwr/npr/
} 
irregulares que variam ao longo do tempo.

\section{Renderização do Ambiente Virtual}

Inicialmente, para se renderizar os objetos virtuais do ambiente com o estilo "sombrio" desejado, as bordas dos objetos virtuais são renderizadas com uma abordagem similar à Fischer e Bartz (2005). Nessa abordagem os objetos virtuais são renderizados em wireframe e as faces frontais são cortadas de forma que somente as linhas laterais e das partes de trás são renderizadas. Após essa etapa, uma segunda passada de renderização é efetuada, através disso os cores dos objetos são renderizadas por cima das linhas de trás, apagando-as da imagem final. Assim, somente as linhas laterais que formam as bordas do objeto se mantem visíveis.

Nessa segunda passada, algumas modificações em relação ao algoritmo convencional foram aplicadas para se obter o estilo desejado. Primeiro, utilizando-se múltiplas texturas, uma sequencia de padrões de ruídos são aplicadas ao objeto em cada quadro renderizado. Para cada quadro, um padrão diferente da sequencia é utilizado, criando um efeito de ruído ao longo do tempo. Para adicional esse ruído do padrão, a cor $C_{i}^{\text {final }}$ de um ponto da superfície do objeto é calculado segundo a equação 5.4 .

$$
C_{i}^{\text {final }}=C_{i}^{\text {patt }}+\left(1-C_{i}^{\text {patt }}\right) * C_{i}^{\mathrm{obj}}, i \in R G B
$$

Onde $C_{i}^{\text {patt }}$ é a cor do padrão utilizado nesse quadro e $C_{i}^{\text {obj }}$ é a cor do objeto virtual. Nesse cálculo, quanto maior o brilho da cor do padrão, mais a cor do padrão é enfatizada criando um efeito de alpha blending entre as cores do padrão e do objeto.

Por fim, a proposta original de cel shading é alterada de forma à se obter o estilo "sombrio". Depois do cálculo de cores, a intensidade da reflexão difusa do objeto é calculado. Na proposta original de cel shading, essas intensidades de reflexões são truncadas em alguns valores e através dessas intensidades a cor final do objeto é obtido. Neste trabalho, alteramos a proposta original, truncando as intensidades mais baixas para zero, forçando as cores das superfícies com essas intensidades à cor preta, obtendo-se o estilo "sombrio". A figura 5.12 mostra os resultados intermediários dessa renderização e a figura 5.13 apresenta o algoritmo utilizado para gerar este estilo. Toda essa segunda passada é acelerado por hardware utilizando-se a linguagem GLSL Shaders ${ }^{3}$.

\footnotetext{
${ }^{3}$ http://www.opengl.org/documentation/glsl/
} 


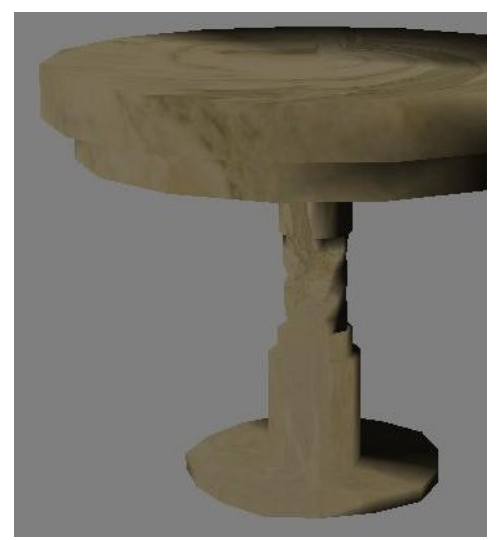

(a) Renderização convencional com OpenGL

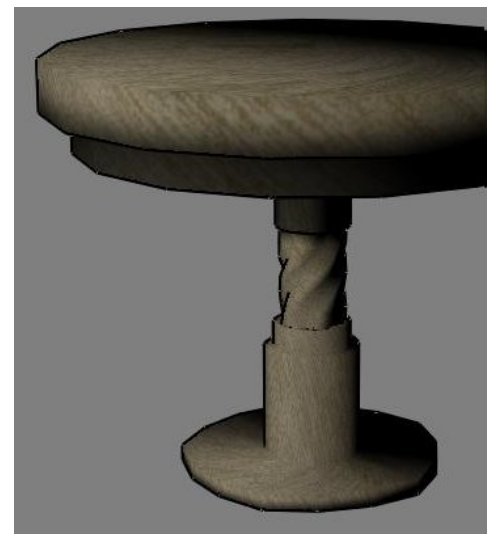

(d) Adição de ruídos

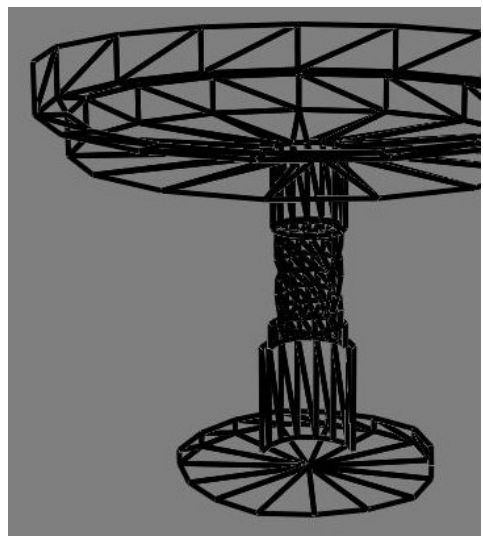

(b) Renderização de wireframe

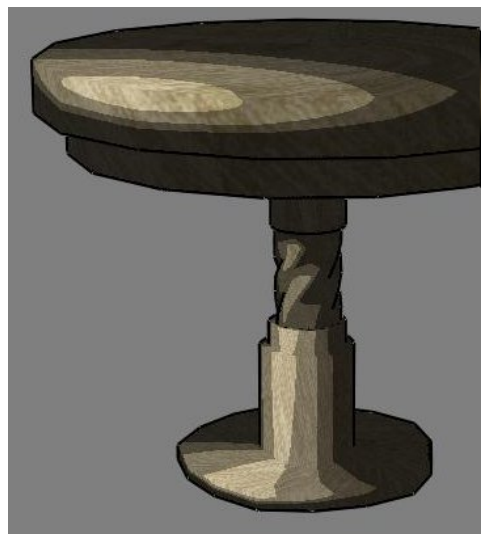

(e) Cel shading convecional

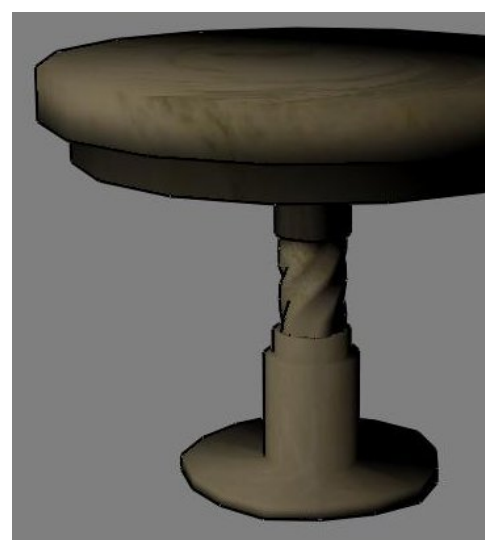

(c) Combinação de wireframe e renderização convencional

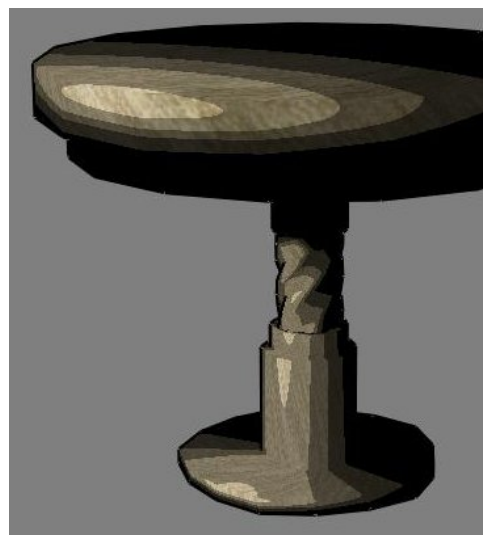

(f) Resultado final

Figura 5.12: Procedimento de renderização dos objetos virtuais utilizado para a geração do estilo "sombrio".

\section{Renderização do Avatar}

Para se aplicar um estilo similar ao ambiente, diversas técnicas podem ser utilizadas, como as técnicas de renderização não fotorrealística ou filtros e processamento de imagens. Neste trabalho, para se obter o mesmo estilo "sombrio", inicialmente um filtro de desfoque é aplicado à imagem de cor utilizada para gerar o avatar. Depois, as cores dos pixeis da imagem são convertidos ao modelo HLS, e o valor de light (L) são truncados em alguns níveis. Isto cria um efeito de gradiente das cores, simulando o efeito de cel shading.

Após essa etapa, o mesmo padrão de ruído utilizado para se renderizar os objetos virtuais é aplicado à imagem. Note que, diferentemente do processo de renderização dos objetos virtuais, esse padrão é aplicado diretamente ao avatar utilizando-se técnicas de processamento de imagem. Essa abordagem é possível, pois a técnica de VBMB utiliza uma única imagem como base para a reconstrução. O mesmo pode ser feito para se obter as bordas do avatar, 


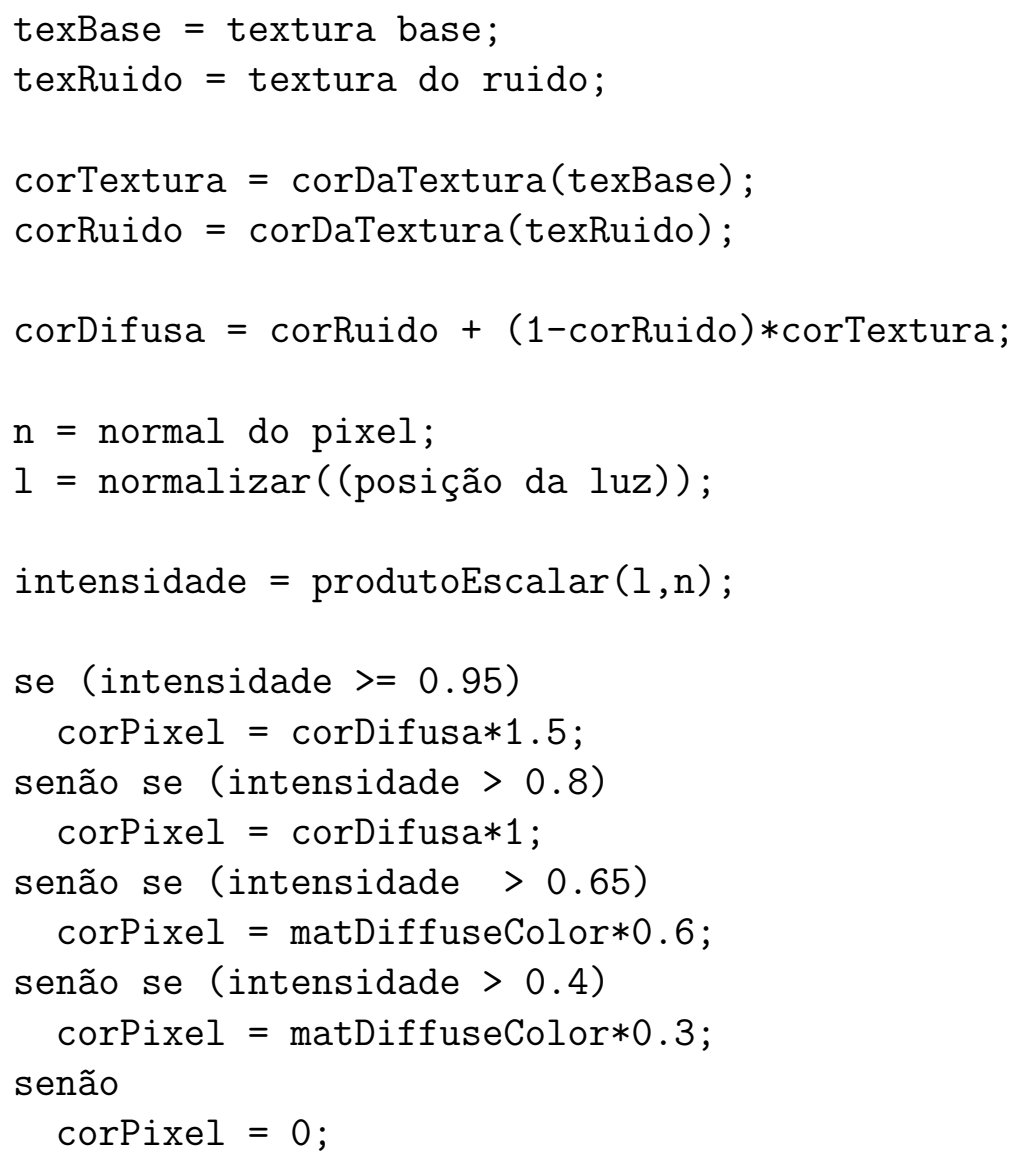

Figura 5.13: Algoritmo de cel shading modificado para a renderização dos objetos virtuais, utilizado no pixel shading da placa gráfica.

utilizando-se técnica de processamento de imagem, como o algoritmo de canny (CANNY, 1986), para se obter essas bordas. Neste trabalho, como prova de conceito, um algoritmo simples de detecção de bordas externas foi utilizado.

Por fim, as informações do mapa de normais obtidas na técnica de VBMB foi utilizada para se adicionar o efeito "sombrio" no avatar. Inicialmente as intensidade da reflexão difusa avatar, obtidas utilizado-se a técnica de mapeamento de normais, é truncado em alguns valores. Depois as intensidades mais baixas são truncadas à cor preta, como no processo de renderização dos objetos virtuais. A imagem 5.15 apresenta o algoritmo da renderização do avatar com este estilo e a imagem 5.14 mostra os resultados intermediários dessa renderização. 


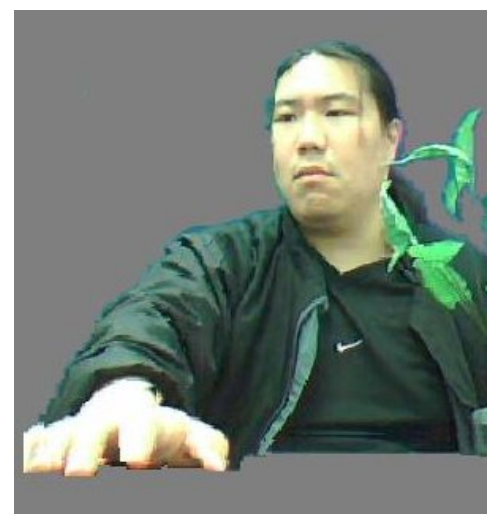

(a) Avatar realista

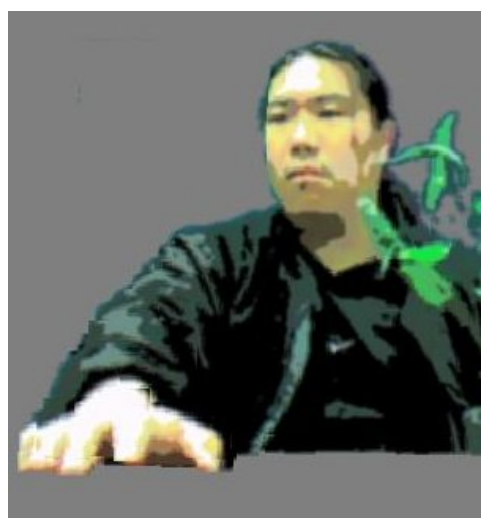

(b) Avatar com as cores truncadas para simular o cel shanding convencional

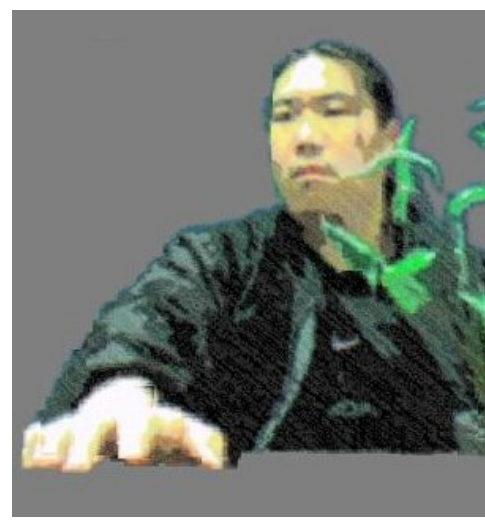

(c) Adição dos padrões de ruídos

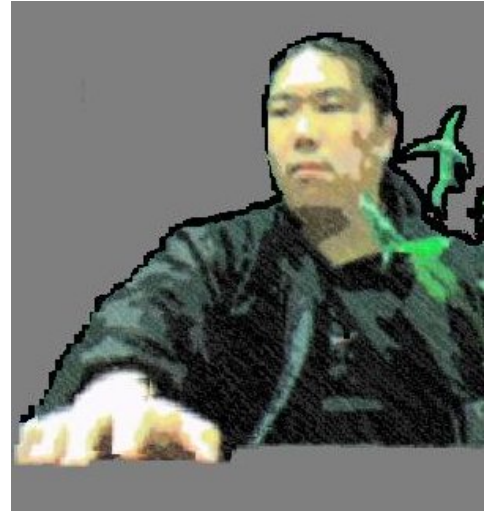

(d) Adição das bordas

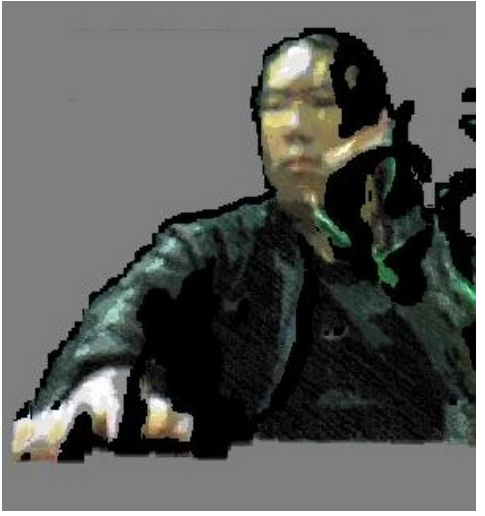

(e) Resultado final

Figura 5.14: Procedimento de renderização do avatar utilizado para a geração do estilo "sombrio".

\subsubsection{Caricatured Vídeo-Avatar}

O caricatured video-avatar estende do conceito de non-photorealistic video-avatar, visando aumentar a integração do usuário em determinados ambientes virtuais. Alguns ambientes virtuais, principalmente em jogos eletrônicos, possuem um design forte e podem não condizerem com o vídeo-avatar, mesmo estilizado de forma não fotorrealístico, uma vez que esse vídeoavatar ainda é muito realista para o design do ambiente. Uma forma de diminuir essa diferença de nível de realismo é o caricatured video-avatar que propõe a representação do participante de forma caricaturada.

Para se obter essa representação caricaturada diversas técnicas podem ser utilizadas como os propostos por Xie et al. (2009) ou Lim Fedorov (2007). Algoritmos de extração de características do rosto do participante, Blanz e Vetter (1999), também podem ser utilizados para se obter informação do rosto e realça-las. 


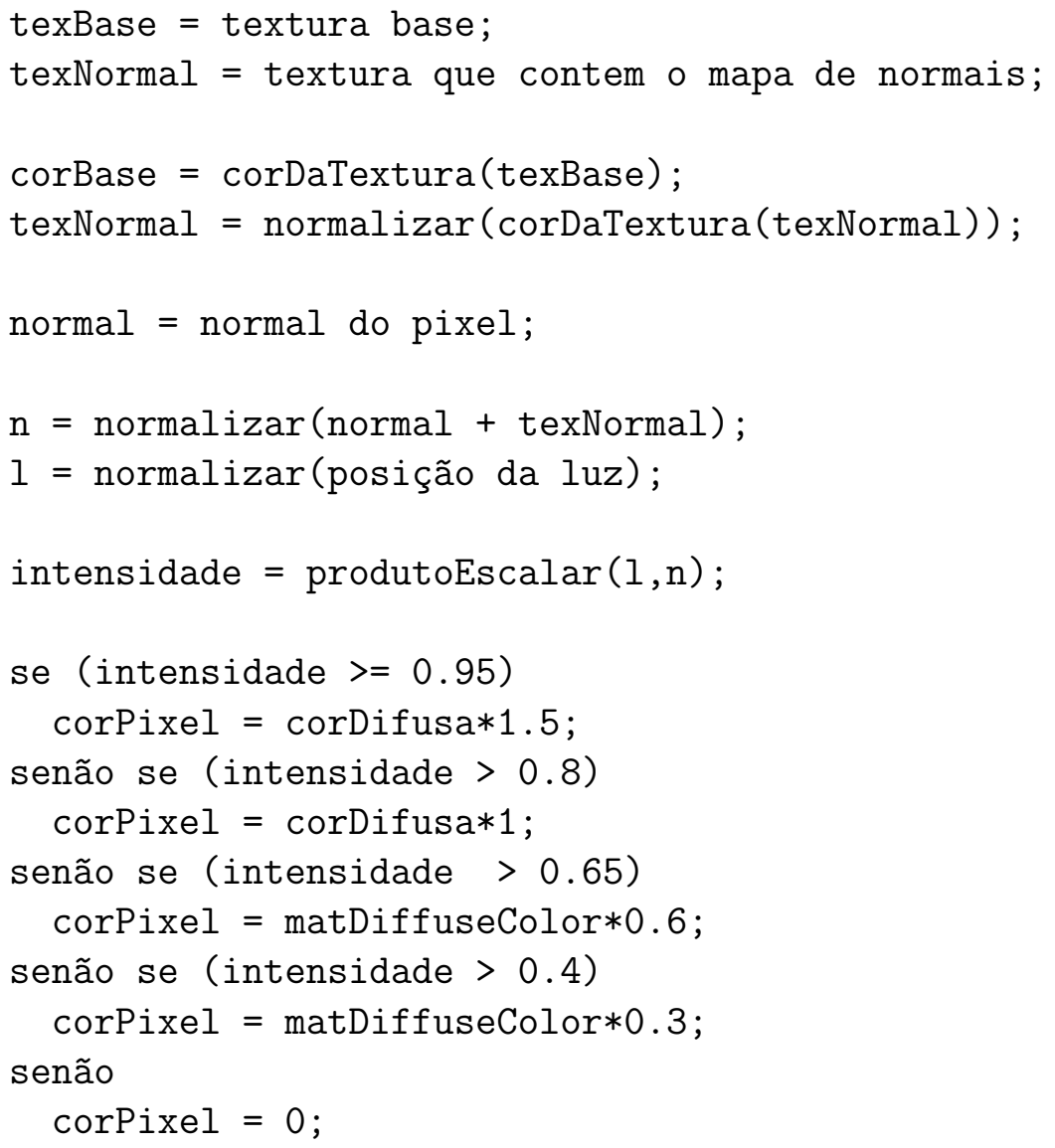

Figura 5.15: Algoritmo de cel shading modificado para a renderização do vídeo-avatar, utilizado no pixel shading da placa gráfica.

Para se gerar essa caricaturas sobre a técnica $\mathrm{VBMB}$, diversas propostas de geração de caricaturas bidimensionais como as propostas por Choi, Lee e Koo (2009) ou Chen WenHung Liao (2006) podem ser utilizadas, uma vez que a VBMB utiliza como base uma única imagem de cor como base. Neste trabalho, como protótipo inicial, um algoritmo que aumenta a imagem da cabeça do participante foi implementado para ser aplicada ao VBMB como trabalho futuro.

Por fim, propostas como os de Collomosse e Hall (2006) também podem ser utilizadas para se gerar exageros de movimentações, gerando não só uma estilização visual, mas também uma estilização no movimento do participante. A proposta de Collomosse e Hall (2006) particularmente pode ser utilizada diretamente no VBMB, mais uma vez, pois o VBMB utiliza uma única imagem como base. 


\subsection{Considerações Finais}

Este capítulo apresentou algumas propostas para a criação de uma representação visual do participante, dentro do ambiente virtual, que possua as três características necessárias para a implementação no sistema iLive (tempo-real, representação de detalhes e integração com o ambiente virtual). Utilizando-se o modelo teórico proposto no capítulo 4, propôs-se a técnica de video-based microfacet billboarding (VBMB), que utiliza as técnicas de mapa de alturas e microfacet billboarding. Essa técnica possui as características de ser em tempo-real, poder representar os detalhes do participante e possuir uma baixa complexidade de configuração física, requisito desejável para a implementação em aplicações de educação e jogos eletrônicos.

Outra proposta abordada neste capítulo é o non-photorealistic video-avatar. Essa proposta tem como objetivo aumentar a integração da representação visual do participante com o ambiente virtual, através da aplicação de um estilo único sobre a cena e o participante. Com a união dessas duas propostas, pôde-se criar uma técnica de reconstrução com grande potencial de possuir as três características necessárias. Assim, podendo ser integrada ao sistema iLive, possibilitando a criação de vídeo-avatares dentro do ambiente virtual.

No próximo capítulo, são apresentados os resultados obtidos neste trabalho. Tanto os resultados visuais, quanto testes de desempenho e testes com usuários, exercidos para testas as hipóteses levantadas neste capítulo. Por fim, como um último resultado, é apresentada a integração dessas técnicas dentro do sistema iLive, sistema de telecomunicação imersiva aplicada a educação e jogos em desenvolvimento pelo Interlab. 


\section{RESULTADOS}

Neste capítulo são apresentados e discutidos os resultados obtidos ao longo do trabalho. Esses, podem ser separados em três grandes grupos: os resultados da implementação das técnicas apresentadas no capítulo 5, onde grande parte dos resultados são visuais; os resultados de testes de desempenho das técnicas e testes preliminares com especialistas; e o resultado da integração das técnicas propostas neste trabalho no sistema de telecomunicação imersiva iLive.

\subsection{Implementação}

A implementação das técnicas propostas foram separadas inicialmente em implementações de diferentes provas de conceito e aplicações para visualizar se as propostas eram válidas. A seguir são apresentados os resultados obtidos em cada prova de conceito.

\subsection{1 java3D: Imagem Estática}

Inicialmente, para se provar o potencial da renderização utilizando-se a técnica de microfacet billboarding, uma prova de conceito utilizando-se a biblioteca Java3D ${ }^{1}$ foi criada. Nessa prova de conceito, imagens de objetos com uma superfície conhecida foram utilizadas para se poder gerar previamente as informações de mapa de alturas artificialmente por programação, para em seguida aplicar a técnica de microfacet billboarding.

Essa prova de conceito oferece indícios de que a técnica de microfacet billboarding possui alto potencial para se representar os detalhes de uma superfície tridimensional. Também foi possível se constatar que a paralaxe de movimento foi muito maior com o uso da técnica de microfacet billboarding que na representação bidimensional, dessa forma aumentando a integração dos objetos reconstruídos dentro do ambiente virtual. A figura 6.1 apresenta os resultados obtidos.

\footnotetext{
${ }^{1}$ https://java3d.dev.java.net/
} 


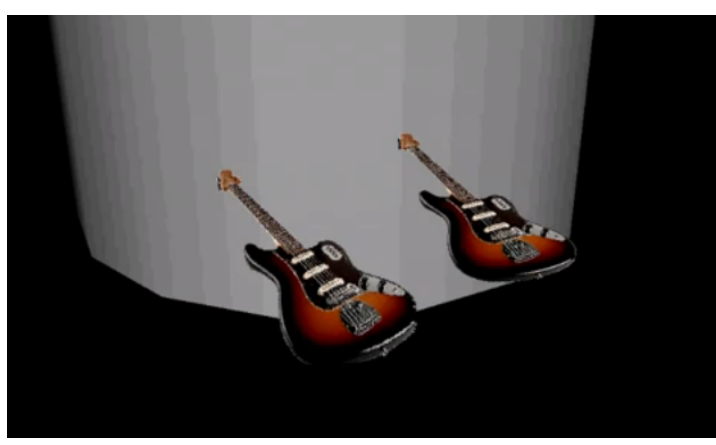

(a) Renderização do contra baixo eletrônico.

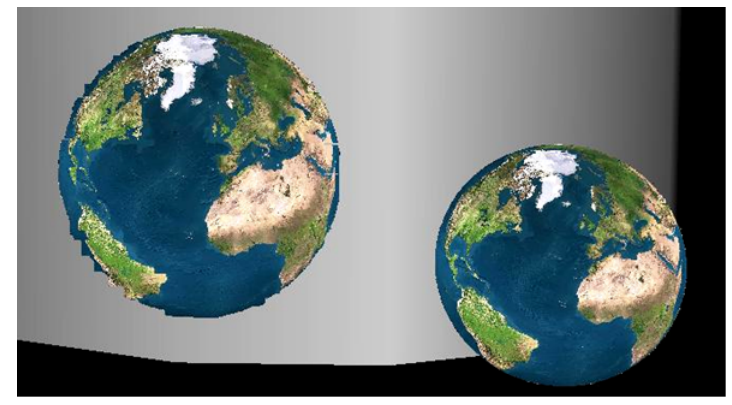

(b) Renderização do globo terrestre.

Figura 6.1: Renderização por microfacet billboarding à direita e à esquerda, imagem plana renderizada por um billboard para comparação

\subsubsection{Visualização: Vídeo-Based}

A segunda prova de conceito criada, foi a implementação da base conceitual da técnica VBMB apresentada na seção 5.1.1. Nessa implementação, a captura de mapa de alturas pela câmera câmera especial de captura 3D Zcam (GVILI et al., 2003), foi utilizada para a obtenção das informações tridimensionais. Para efeito de testes, vídeos pré-gravados foram utilizados como ambiente de teste controlável. Porém o algoritmo de renderização em si é implementado em tempo-real, de forma a possibilitar a reconstrução dos vídeo-avatares.

Já, para a remoção de fundo dessas cenas, a técnica proposta por Bergh e Lalioti (1999) foi utilizada. Para possibilitar uma comparação, a reconstrução por mapas de alturas e deformação de malhas triangulares também foi implementada. A figura 6.2 compara o resultado obtido da reconstrução de um vaso de planta utilizando-se a técnica de VBMB 6.2(a) e a reconstrução por deformação de malhas triangulares (Mesh rendering) 6.2(b).

Através dessa comparação é possível verificar que, na reconstrução por deformação de maIhas triangulares, os detalhes como as pequenas flores e folhas são deformados, enquanto que na reconstrução por VBMB os detalhes são mantidos. Isso oferece indícios de que a hipótese inicial, ou seja, a técnica de VBMB consegue representar detalhes do objeto reconstruído, é verdadeira.

A técnica de VBMB também foi aplicada à reconstrução de um participante dentro de um ambiente virtual. A figura 6.3 apresenta esse resultado da reconstrução no mesmo instante e em diferentes ângulos. Através dessa reconstrução foi possível ver que, para objetos com superfícies sem ruídos e com poucos detalhes, a reconstrução por VBMB não provê grandes diferenças em relação a reconstrução por mapa de alturas e deformação de malhas triangulares. Porém, para renderização de participantes com muitos detalhes, como nos cabelos, ou em 


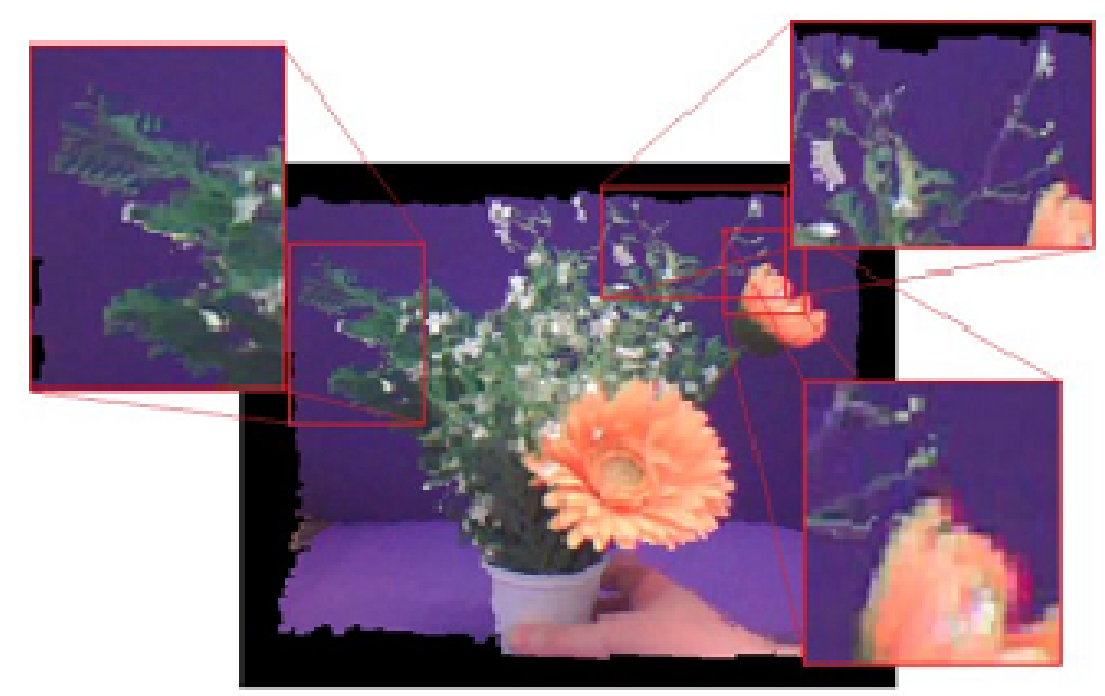

(a) Reconstrução e renderização da planta utilizando-se a técnica de VBMB.

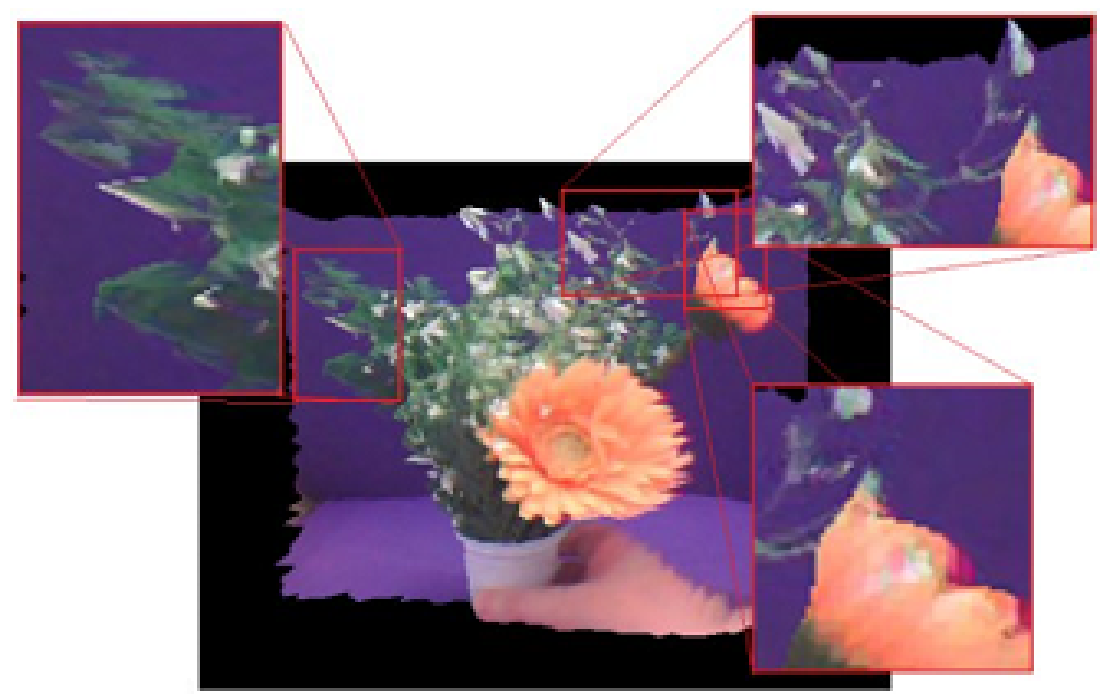

(b) Reconstrução e renderização da planta utilizando-se a renderização por mesh rendering.

Figura 6.2: Comparação das reconstruções por VBMB e deformação de malhas triangulares

casos em que há uma informação importante contida nesses detalhes, como pequenos gestos, a reconstrução por VBMB ainda se mostra uma boa opção.

\subsubsection{Coerência de Iluminação}

A seguir, a coerência do sombreamento da reconstrução com a iluminação virtual, apresentada na seção 5.2, foi implementada. A figura 6.3 apresenta a reconstrução de uma pessoa em diferentes ângulos no mesmo instante, com e sem a coerência com a iluminação dentro de um ambiente virtual. A figura 6.4, por sua vez, apresenta o avatar na mesma posição e com posições de iluminação diferentes. 

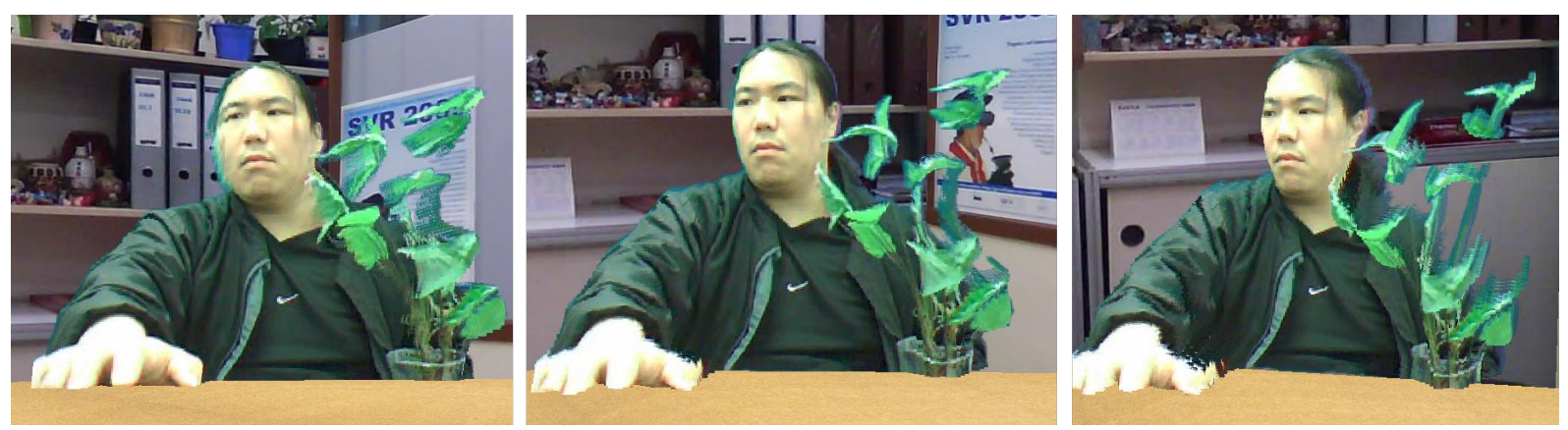

(a) Sem coerência com a iluminação virtual.
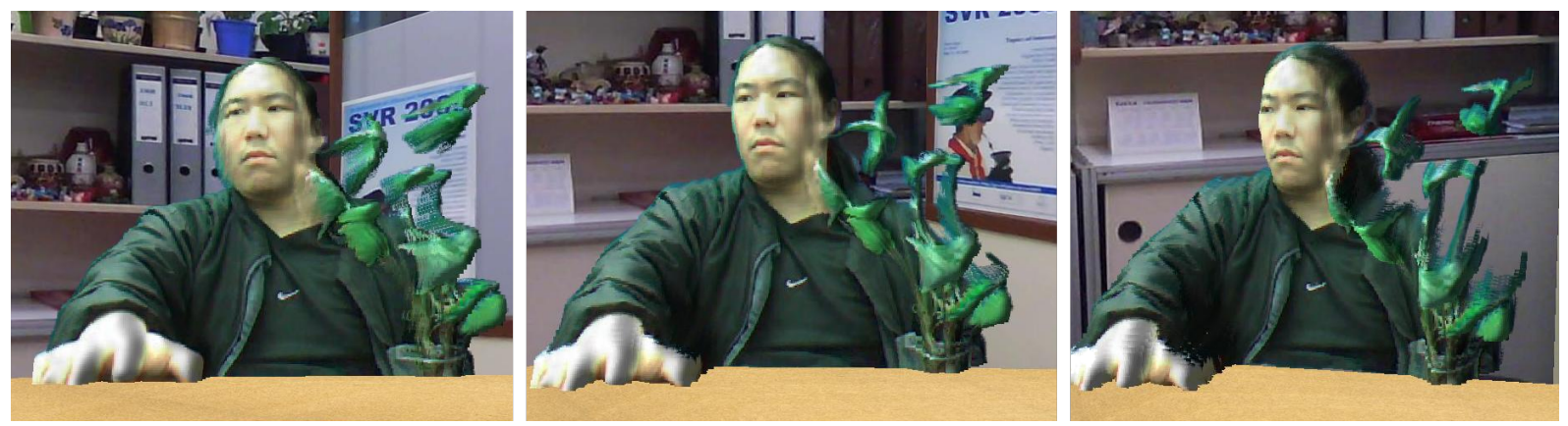

(b) Com coerência com a iluminação virtual.

Figura 6.3: Vídeo-avatar dentro de um ambiente virtual
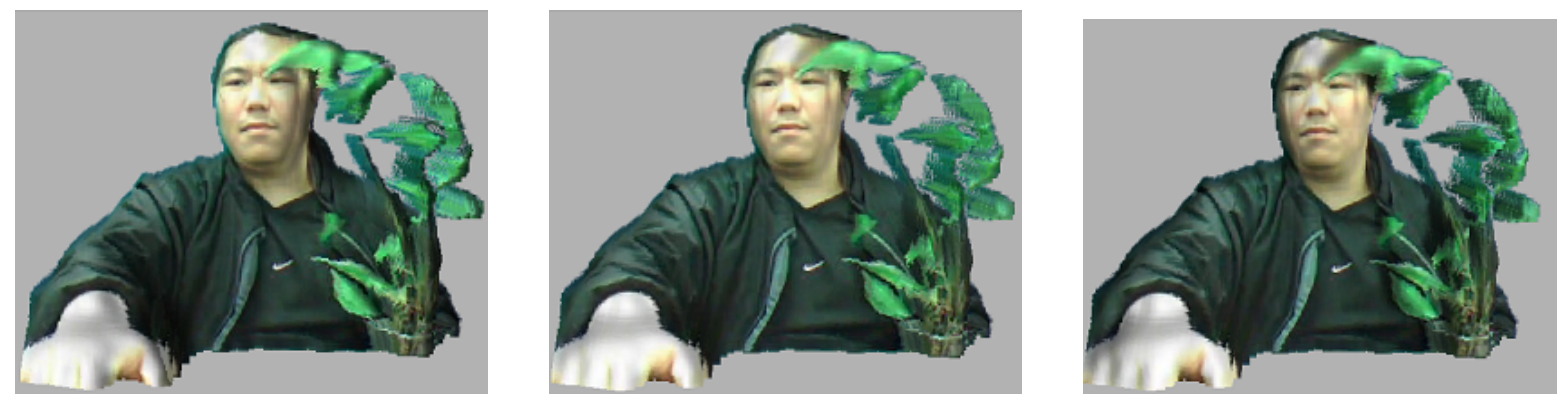

Figura 6.4: Vídeo-avatar com iluminação em diferentes posições

Como aplicação para teste, uma função que rastreia cores vermelhas que o usuário visualizador segura foi implementada. Nessa aplicação a iluminação virtual é posicionada conforme a posição do objeto vermelho rastreado na cena real. Dessa forma, o usuário visualizador do avatar tem a ilusão de estar iluminando o avatar com esse objeto vermelho. A figura 6.5 apresenta essa aplicação. Através dessas aplicações foi possível se ter indícios de que a coerência com a iluminação virtual do avatar é um importante fator para aumentar a integração do avatar dentro do ambiente virtual. 

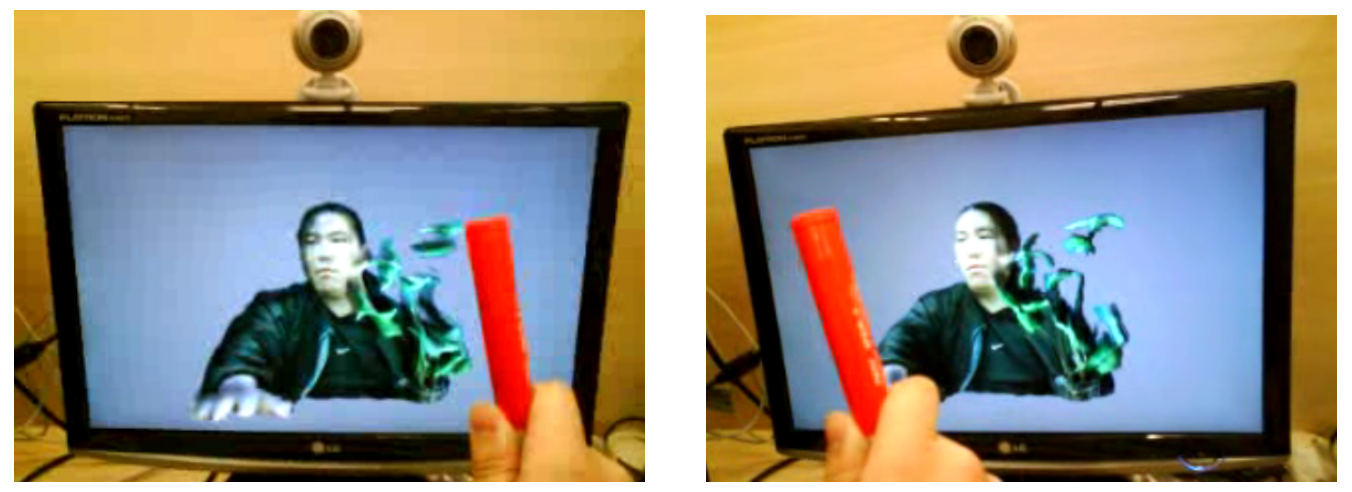

Figura 6.5: Aplicação de iluminação tangível

\subsubsection{Non-photorealistic Vídeo-Avatar}

O próximo passo deste trabalho foi a implementação do conceito de non-photorealistic videoavatar, apresentado na seção 5.2, sobre a técnica de VBMB. Como ambiente de testes foi implementada uma aplicação que possibilita o carregamento, através de um arquivo XML, e visualização de diferentes objetos virtuais e vídeo-avatares com e sem o estilo não fotorrealístico. Esse ambiente permite diferentes testes de usuários, tais como os que foram aplicadas neste trabalho e outro que podem ser aplicadas futuramente. É importante notar que, uma vez que o ambiente criado permite carregar ao mesmo tempo objetos com e sem o estilo não fotorrealístico, esse ambiente permite os testes de experiência de usuário utilizando-se o estilo não fotorrealístico como nova foma de apresentação de objetos virtuais em aplicações de realidade aumentada, como propostos por Fischer, Haller e Thomas (2008).

A figura 6.6 apresenta os resultados obtidos com essa aplicação. A figura 6.6(a) e 6.6(b) apresenta o vídeo-avatar com o estilo "sombrio", já a figura 6.6(c) apresenta um outro ambiente renderizado com um outro estilo.

As figuras em 6.7 apresentam imagens no mesmo instante, em diferentes ângulos e em diferentes estilos. A figura 6.7(a) apresenta o vídeo-avatar realista dentro de um ambiente virtual renderizado com algoritmos de OpenGL ${ }^{2}$ convencionais. Através dessa imagem pode-se verificar que o avatar se destaca da cena por ter um nível de realismo maior que os objetos virtuais.

Já a figura 6.7(b) apresenta o vídeo-avatar realista dentro de um ambiente não fotorrealístico. Essa figura nos evidencía que, quando, por motivos de design, um estilo não fotorrealístico é requisitado, o avatar convencional se destaca ainda mais, não se integrando à cena. Por fim, a figura 6.7 (c) apresenta o non-photorealistic video-avatar dentro de um ambiente não fotorre-

\footnotetext{
${ }^{2}$ http://www.opengl.org/
} 


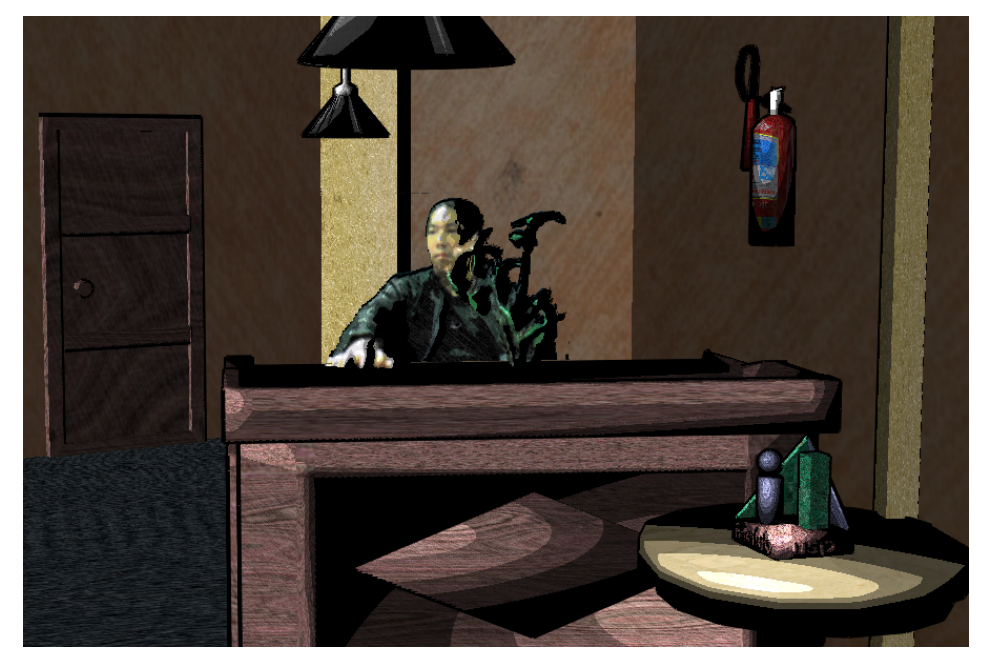

(a) non-photorealistic video-avatar dentro de um corredor visto por longe

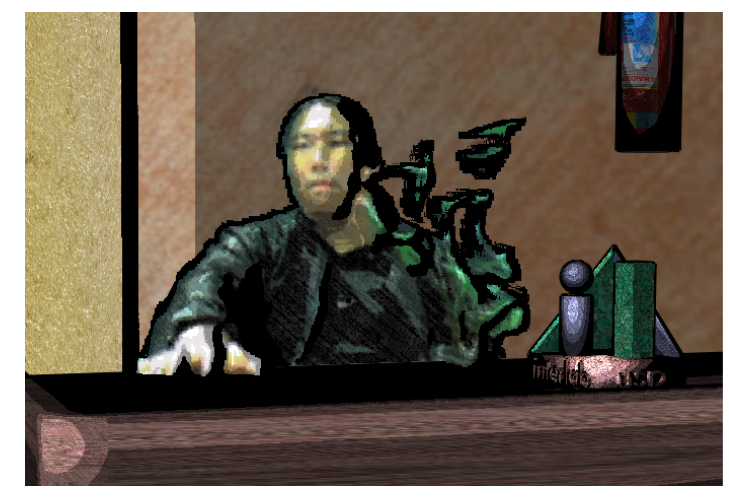

(b) non-photorealistic video-avatar dentro de um corredor visto por perto

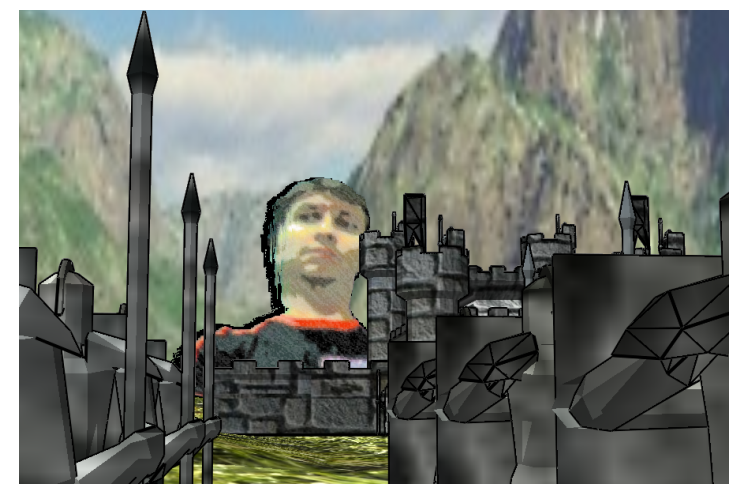

(c) non-photorealistic video-avatar em um outro ambiente com um estilo diferente

Figura 6.6: non-photorealistic video-avatar em ambientes virtuais

alístico. Comparando as diferentes figuras, pode se notar que o non-photorealistic video-avatar se integra mais a cena que nos outros casos, dando evidências que a hipótese inicial é válida.

\subsubsection{Splats + VBMB}

Outra prova de conceito criada foi a implementação da proposta de splats, apresentada na seção 5.1.4, sobre o VBMB. Essa prova de conceito não implementa completamente o conceito de splats, uma vez que essa implementação não é válida para a visualização do avatar em qualquer ângulo. Porém, com essa implementação, é possível de se visualizar o potencial dessa proposta. A figura 6.8 apresenta esse resultado.

A figura 6.9 apresenta parte da renderização do vídeo-avatar na mesma posição e com o mesmo valor de subdivisão de imagem, com e sem a técnica de splats aplicada à técnica VBMB. Através dessa comparação é possível se verificar que o problema das quinas é amenizado, 

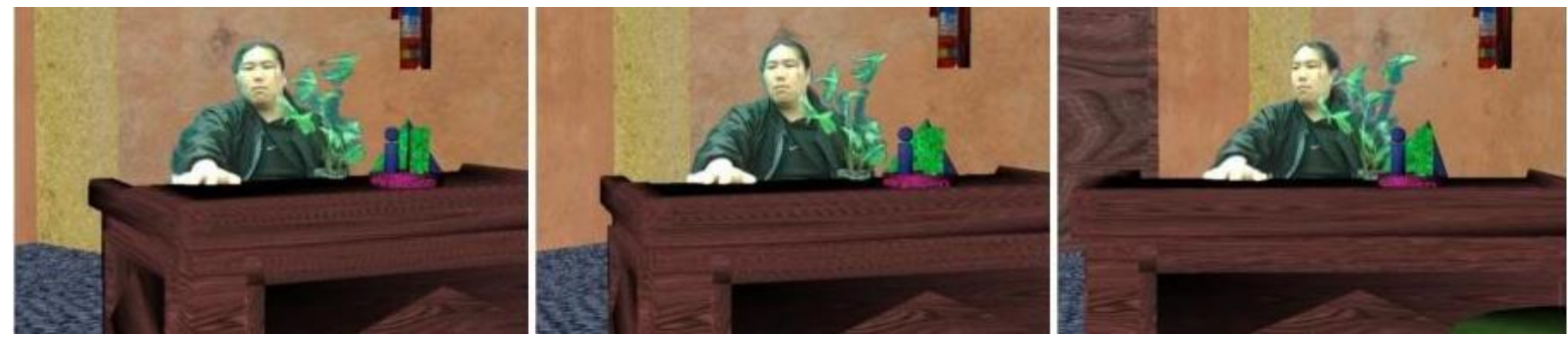

(a) vídeo-avatar realista dentro de um ambiente renderizado com algoritmos convencionais de OpenGL
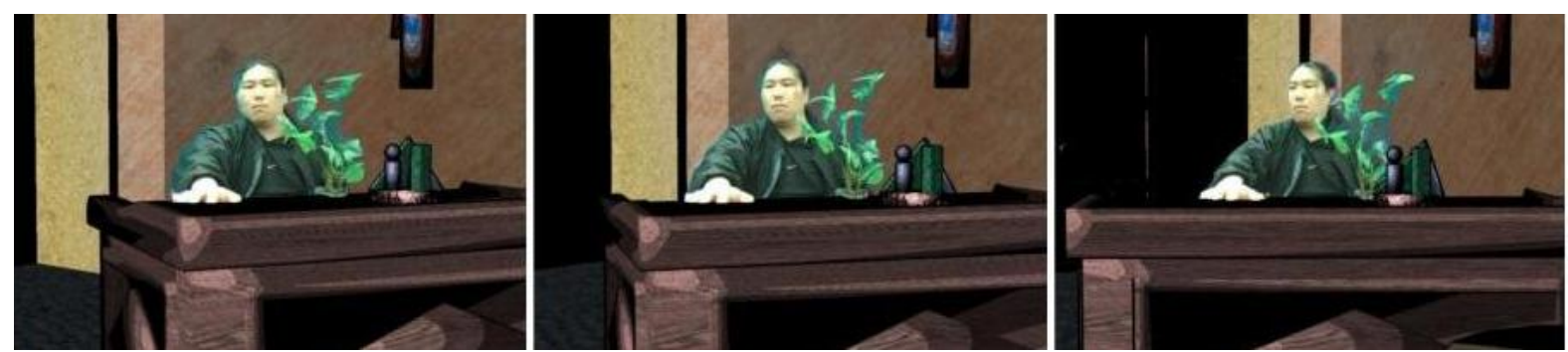

(b) vídeo-avatar realista dentro de um ambiente não fotorealista.
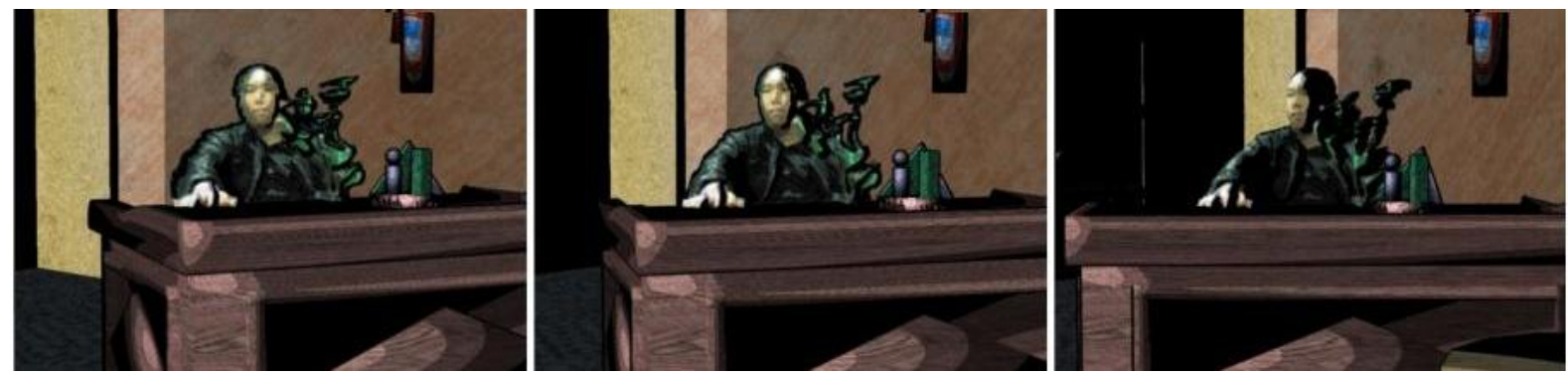

(c) non-photorealistic video-avatar dentro de um ambiente não fotorealista

Figura 6.7: Comparação entre o non-photorealsitic video-avatar e o vídeo-avatar realista em ambientes realistas e não fotorealistas

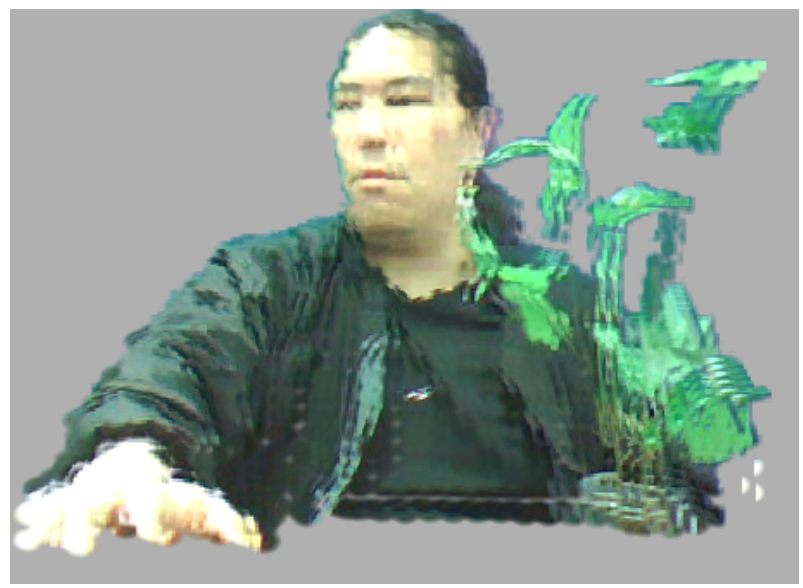

Figura 6.8: Resultado da renderização utilizando-se a técnica de splats sobre o VBMB.

mostrando que a proposta do uso do conceito de splats sobre VBMB é válida. 

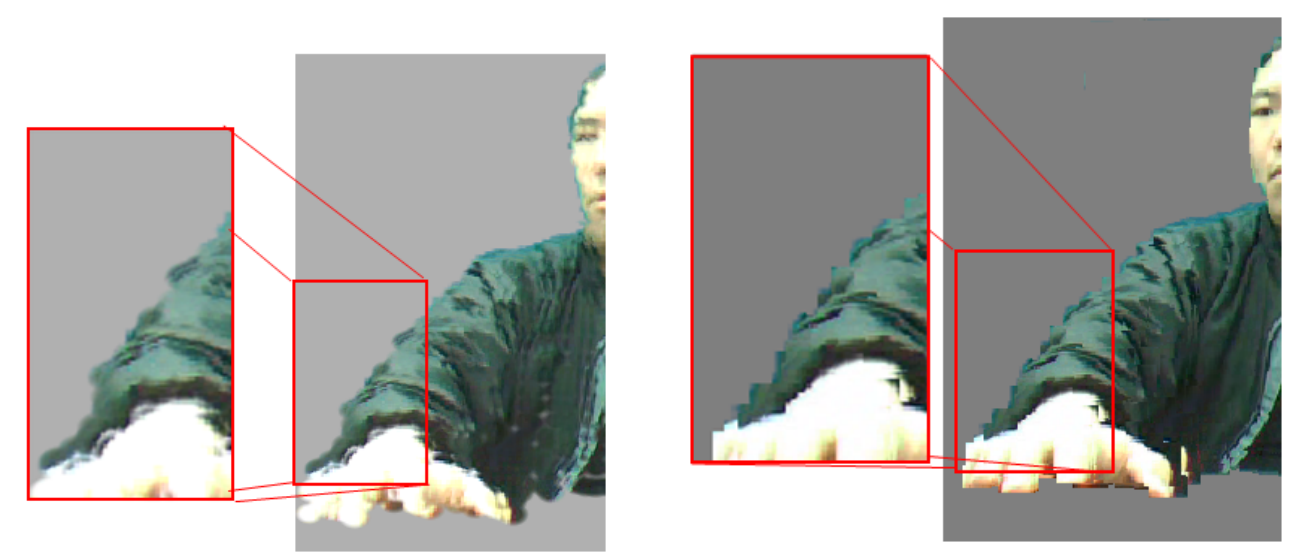

(a) parte do vídeo-avatar renderizado (b) parte do vídeo-avatar renderizado utilizando-se a técnica de splats sobre a utilizando-se a técnica de VBMB técnica de VBMB

Figura 6.9: Comparação entre o a técnica de splats+VBMB e VBMB convencional

\subsubsection{Big Head}

A última prova de conceito desenvolvida neste trabalho foi a implementação de um simples algoritmo para gerar avatares caricaturados. Esse algoritmo rastreia a cabeça do participante e aumenta o tamanho desse dentro da imagem, gerando um efeito simples de caricatura. Essa função pode ser aplicada na técnica non-photorealistic video-avatar junto com o processamento de imagem para se gerar o estilo "sombrio", gerando uma prova do conceito de caricatured video-avatar, conceito proposto nesse trabalho na seção 5.2.3. A figura 6.10 apresenta as imagens obtidas utilizando-se essa função.
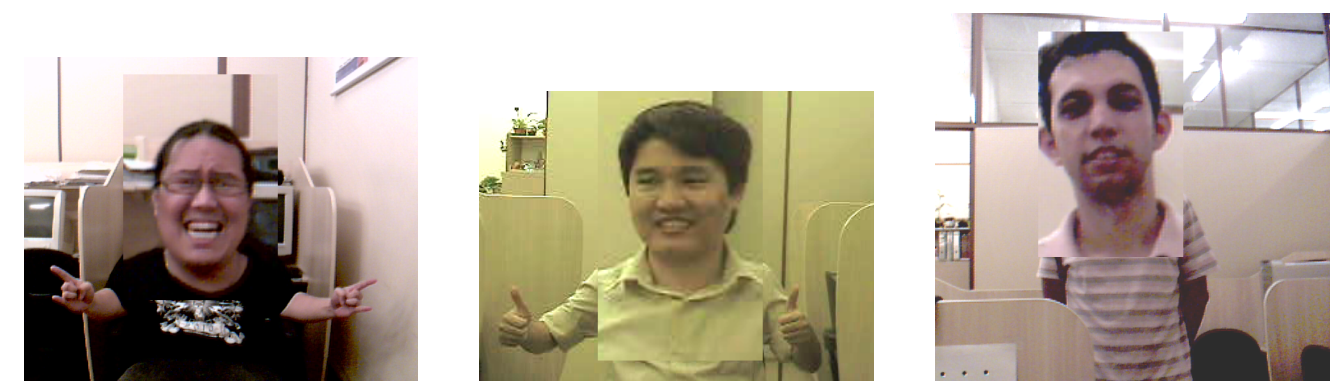

Figura 6.10: Função "Big Head", que pode ser utiliza para se gerar o caricatured video-avatar

\subsection{Testes e Análise}

Esta seção apresenta os testes aplicados sobre as implementações e conceitos propostos neste trabalho. Inicialmente, testes de desempenho das implementações foram exercidos (subseção 
6.2.1). Depois, testes iniciais com usuários especialistas foram exercidos (subseção 6.2.2), de forma a se obter um direcionamento inicial para se verificar se as hipóteses abordadas neste trabalho são válidas.

\subsubsection{Testes de Desempenho}

Todos os testes de desempenho exercidos nesta seção foram executados em um computador com processador Intel Core 2 Quad com $2.4 \mathrm{GHz}$ de frequência de clock, 4GB de memória RAM e uma placa de vídeo GeForce 8800 Ultra com 756MB de memória. Como teste de desempenho, o valor médio de quadros por segundos (FPS) da renderização de um único vídeo-avatar em diferentes condições foram obtidos. As condições testadas são:

- renderização por VBMB do vídeo-avatar realista;

- renderização por VBMB do non-photorealistic video-avatar;

- renderização por Mesh Render do vídeo-avatar realista;

- renderização por Mesh Render do non-photorealistic video-avatar;

Para cada condição, o valor de $N$, valor de subdivisão da imagem em uma matriz $N \times$ $N$ foi variado. O gráfico 6.11 apresenta o resultados dos testes, variando-se o valor de $N$ entre 10 à 100. Já o gráfico 6.12 apresenta os resultados obtidos variando-se $N$ entre 30 à 300. O aumento de $N$, nessas reconstruções, representam o aumento da qualidade visual da reconstrução. Assim, podemos dizer que os resultados obtidos aqui é a relação entre desempenho e qualidade visual da reconstrução.

Pode-se notar pelos gráficos, que ambos os métodos, VBMB e mesh render, não têm grandes variações até $N=50$. Depois desse valor, pode-se notar que o decaimento do método VBMB é maior que o de mesh render. Isto se deve à replicação de micro-billboards efetuada ao longo da altura, proposta para se evitar a falha da superfície apresentada na seção 5.1.1. Esse valor não se altera antes de $N=50$, uma vez que o tamanho dos billboards são grandes o suficiente para não se necessitar dessa replicação.

Um comportamento similar ocorre com ao desempenho da renderização do non-photorealistic video-avatar, i.e., da mesma forma que a renderização realista, o decaimento da técnica VBMB é maior que a de mesh rendering. $\mathrm{E}$, os valores de desempenho são menores que a renderização realista, pois esse tipo de representação necessita de outros processamentos de imagem para 


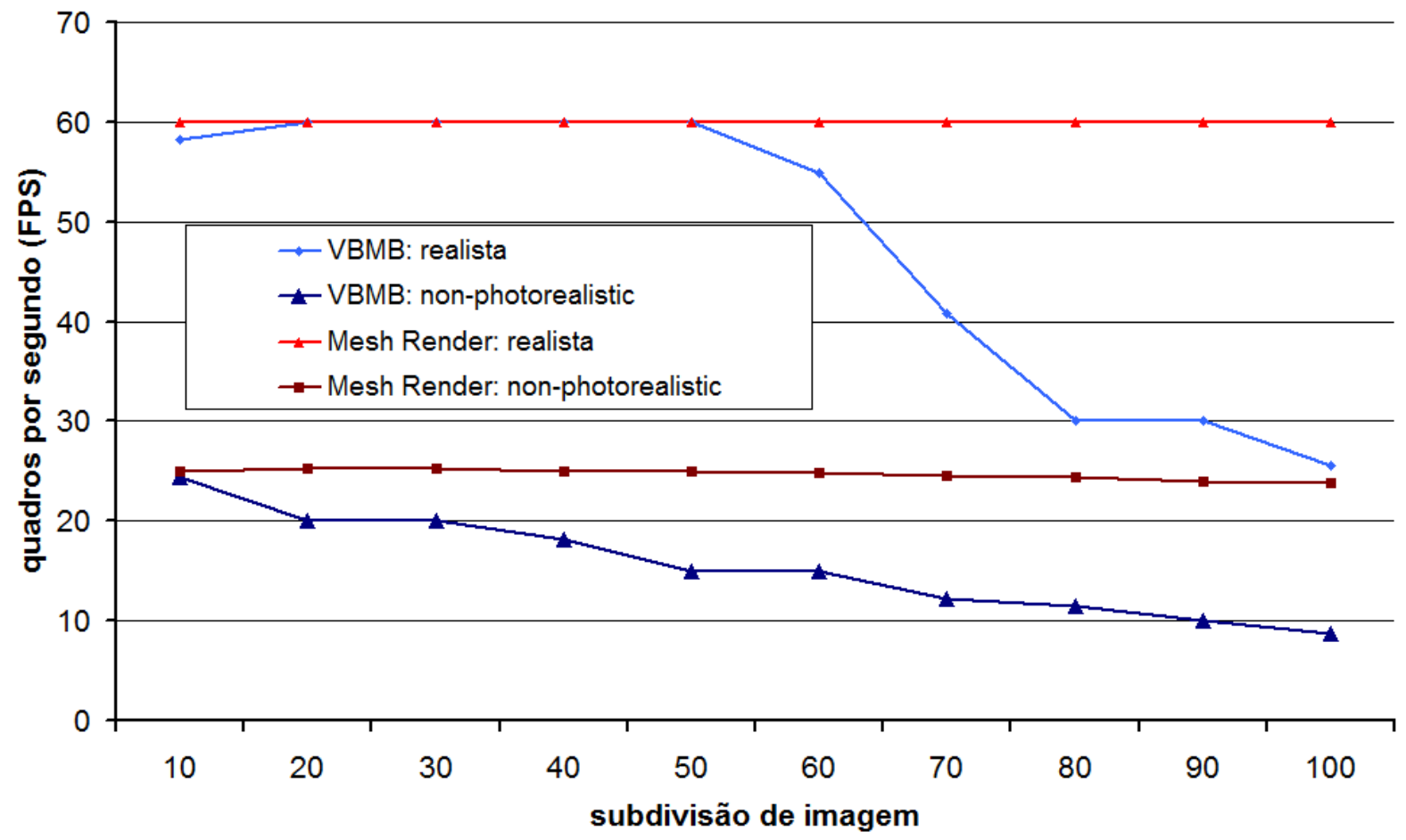

Figura 6.11: Gráfico FPS × Subdivisão de imagem (10 à 100)

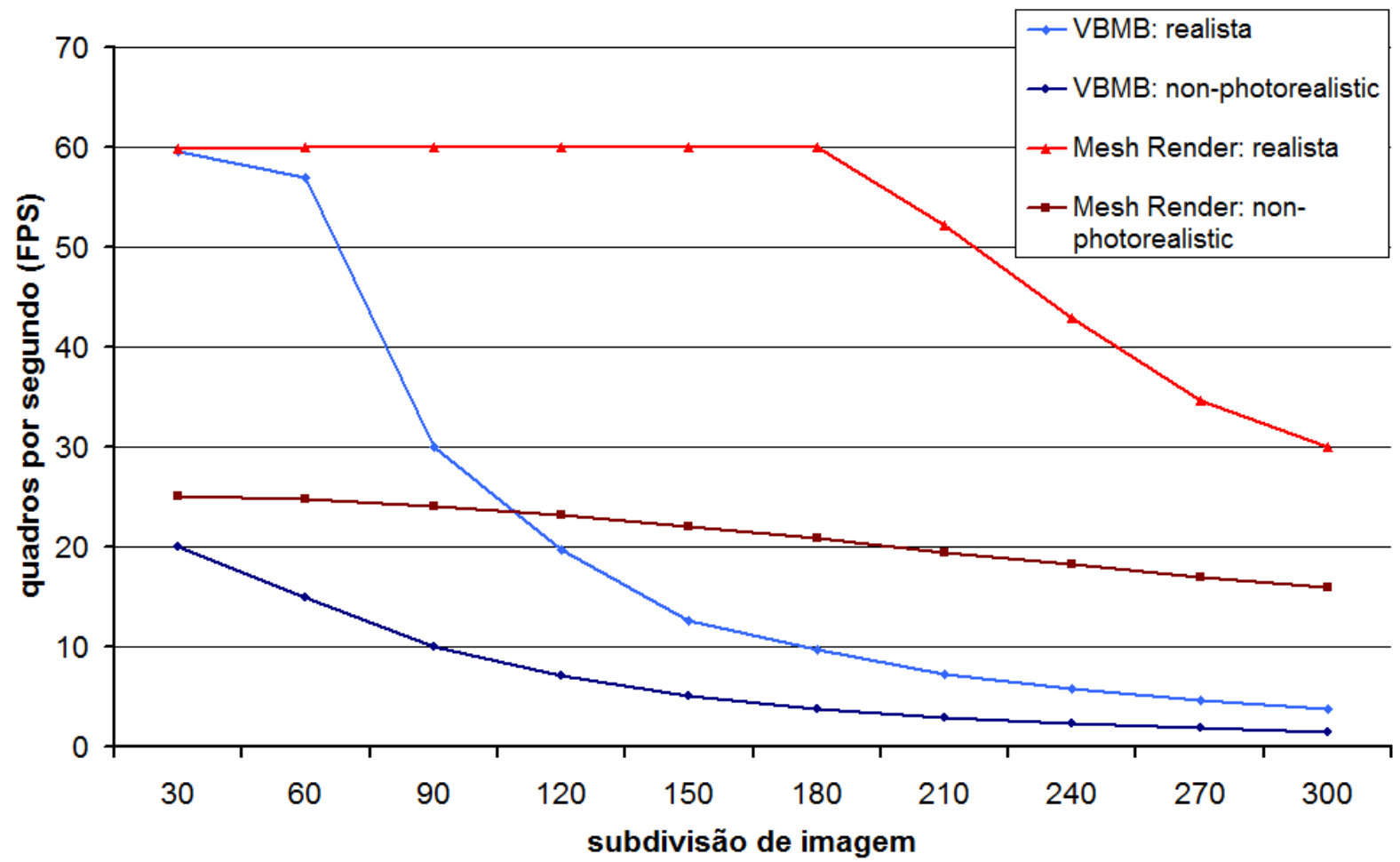

Figura 6.12: Gráfico FPS × Subdivisão de imagem (30 à 300)

se gerar o efeito não fotorrealístico, como o de conversão para HLS e truncar os valores de brilho e geração do mapa de normais. 


\subsubsection{Testes com Usuários}

Para verificar se o vídeo-avatar possui as características "representação de detalhes" e "integração do avatar", testes preliminares com um pequeno número de usuários foram procedidos. Para a execução desses testes, o aplicativo apresentado na seção 6.1.4 foi utilizado. Neste contexto, diferentes objetos reconstruídos em diferentes estados e em diferentes ambientes virtuais foram apresentados para os usuários para que eles consigam comparar e analisar os resultados visuais.

Este teste preliminar com usuários, foi aplicado em 6 usuários entre estudantes de graduação e pós-graduação de engenharia elétrica com enfase em computação e estudantes de graduação do curso de design. Desta forma, pode se afirmar que o nível de conhecimento em relação a computação e computação gráfica é alto neste grupo de usuários. Este grupo foi selecionado para que os usuários se concentrem na análise da técnica, não tendo dificuldades ou falta de conhecimento prévio sobre as áreas de computação e computação gráfica, devido a sua familiaridade com a tecnologia.

\section{Teste aplicado}

Inicialmente, duas reconstruções do vaso de flor, as mesmas reconstruções apresentadas na figura 6.2, foram apresentadas simultaneamente ao usuário, uma reconstruída com a técnica de VBMB e outra com a técnica de mapa de alturas e deformação de malhas triangulares (mesh render). Solicitou-se que o usuário avalia-se qual das reconstruções foi melhor ou se elas foram iguais, em termos de qualidade de reconstrução, deformação e representação de detalhes. Esse teste foi replicado para diferentes valores de subdivisões de imagem, ou seja, diferentes qualidades de reconstruções, como explicado na seção 6.2.1. Através desse teste, visou-se provar que a reconstrução por VBMB permite representar melhor os detalhes dos objetos com muitos detalhes visuais, e por meio disso, obter uma qualidade de reconstrução melhor que a técnica de deformação de malhas triangulares.

O segundo teste realizado foi semelhante ao primeiro teste, porém, no lugar do vaso de flores, a reconstrução de uma pessoa foi apresentada aos usuários. Esse teste visou verificar se a reconstrução por VBMB é melhor que a reconstrução por malhas para reconstruções de vídeo-avatares, que geralmente possuem menos detalhes que o vaso de flor.

A seguir, apresentou-se ao usuário o avatar reconstruído com diferentes valores de subdivisões e, a cada aumento no valor da subdivisão, perguntou-se para o usuário se a qualidade visual do avatar melhorou, piorou ou se ele se manteve igual. Esse teste visou verificar a ten- 
dência de percepção da qualidade do avatar percebida pelos usuários em relação aos valores de subdivisões. A hipótese abordada nesse teste é que, com o aumento das subdivisões, se obterá um aumento da qualidade visual até que não se perceba mais a melhora.

Depois desses testes, foram executados testes para se verificar a integração do avatar com o ambiente virtual. Inicialmente, dois avatares, com e sem a coerência com à iluminação virtual, foram apresentados para o usuário dentro de um ambiente e perguntou-se qual desses avatares estavam mais integrados a cena. Esse teste visa verificar se o vídeo-avatar com a coerência realmente é mais integrado ao ambiente virtual.

O próximo teste visa verificar as hipóteses levantadas na seção 5.2 sobre o non-photorealistic video-avatar. Para tal, foi procedido um teste onde o mesmo ambiente com o mesmo avatar é apresentado para o usuário em diferentes estilos. As cenas apresentadas para os usuários foram:

- Avatar realista em um ambiente renderizado com algoritmos de renderização do OpenGL convencional;

- Avatar realista em um ambiente com o estilo "sombrio";

- Avatar com o estilo "sombrio" em um ambiente renderizado com algoritmos de renderização do OpenGL convencional;

- Avatar e ambiente com o estilo "sombrio";

Foi solicitado a cada usuário que se atribuí-se uma nota de 1 a 4 para cada caso, onde a nota 1 representa que o avatar é muito diferente da cena, e a nota 4 representa que não foi possível de se distinguir qual dos modelo foi reconstruído. Esse teste visa provar que a integração do avatar é maior quando se utiliza um estilo não fotorrealístico único sobre todo o ambiente e avatares, diminuindo a discrepância de realismo entre os objetos virtuais e os reconstruídos.

Por fim, o último teste utiliza do vídeo-avatar com e sem o estilo não fotorrealístico em um possível ambiente de jogo não fotorrealístico para verificar se o avatar não fotorrealístico era mais integrado ao ambiente que o avatar realista. Para esse teste utilizou-se o mesmo ambiente apresentado na figura 6.6(c). Nesse teste também solicitou-se que o usuário atribuise uma nota 1 a 4 da mesma forma que o teste anterior. O questionário completo utilizado nos testes com usuários segue como apêndice I neste trabalho. 


\section{Resultados da Comparação Entre VBMB e Deformação de Malhas Triangulares}

O gráfico 6.13 apresenta o resultado obtido com o primeiro teste. Pode-se verificar, através desse gráfico, que em geral a reconstrução por VBMB obteve resultados melhores que a reconstrução por mesh render. Somente no caso onde os numeros de subdivisões são muito pequeno que os usuários tiveram preferencia pela reconstrução por mesh render, pois a deformação era maior na técnica VBMB. Esse teste também prova a hipótese de que quanto mais se aumenta o valor das subdivisões menos se verifica diferença entre a técnica de VBMB e a de mesh render.

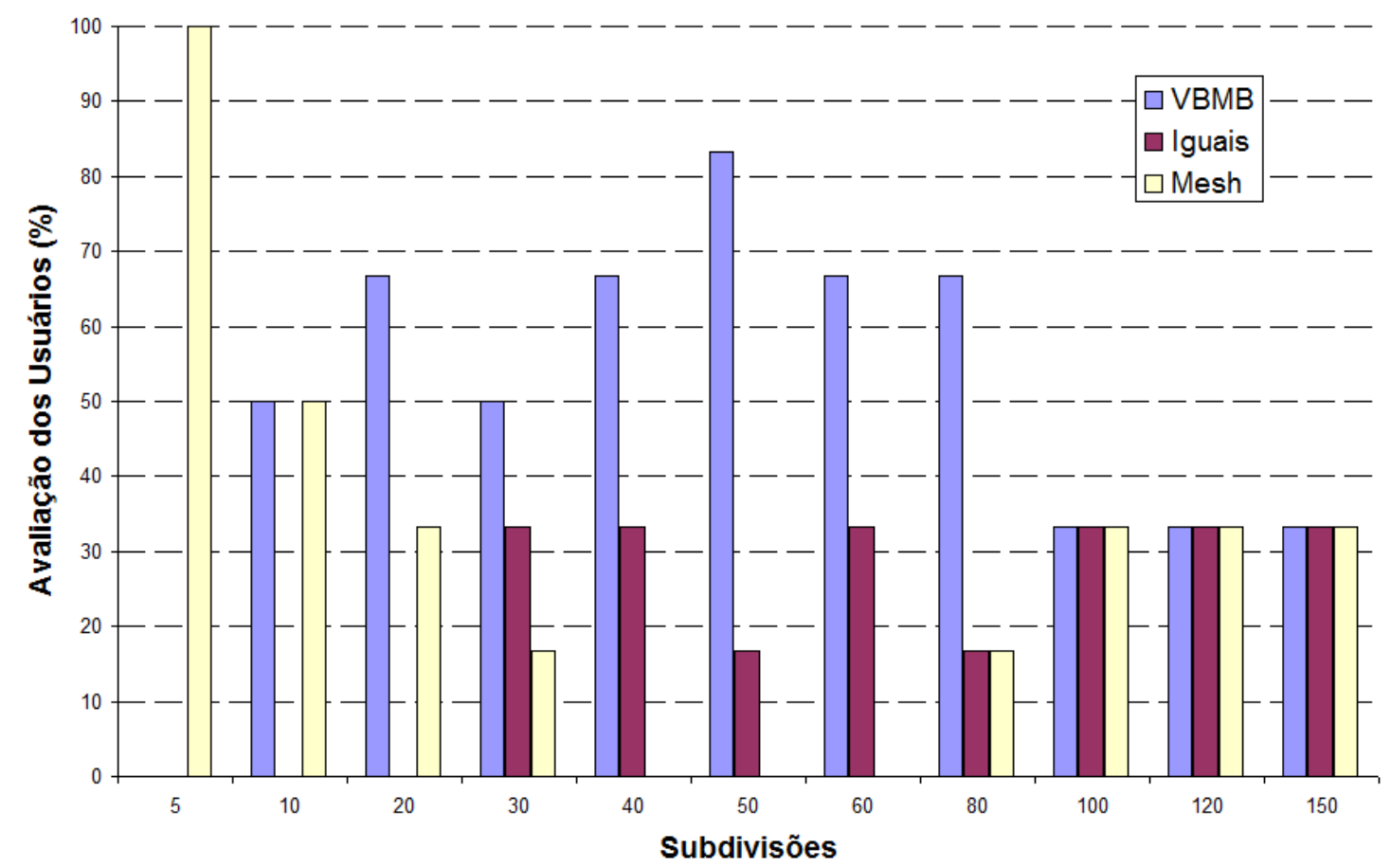

Figura 6.13: Comparação das técnicas VBMB e mesh render na reconstrução de um objeto detalhado

Já o gráfico 6.14 apresenta o resultado do segundo teste. Nesse caso, onde o objeto reconstruído não possui muitos detalhes, os usuários tiveram uma preferência pelo mesh render. Colhendo os comentários dos usuários durante e depois do teste, pode se observar que nesse caso os usuários notavam muito mais os problemas das quinas, apresentado na seção 5.1.4, que na reconstrução do objeto detalhado. Dessa forma, a nota atribuída a reconstrução por VBMB foi muito pior que a reconstrução por mesh render.

Porém esse fato também pode ser interpretado de outra forma, de que, junto do resultado do primeiro teste, realmente a técnica de VBMB consegue ser superior que outros métodos quando há a necessidade de representação de detalhes visuais do objeto reconstruído e que os 
detalhes são melhor representados na técnica VBMB. Dando fortes indícios de que a característica de representação de detalhes, necessitada pelo sistema iLive, é atingida através dessa técnica. Uma forma de se diminuir esse problema das quinas é o uso da proposta de splats apresentada na seção 5.1 .4 e 6.1.5.

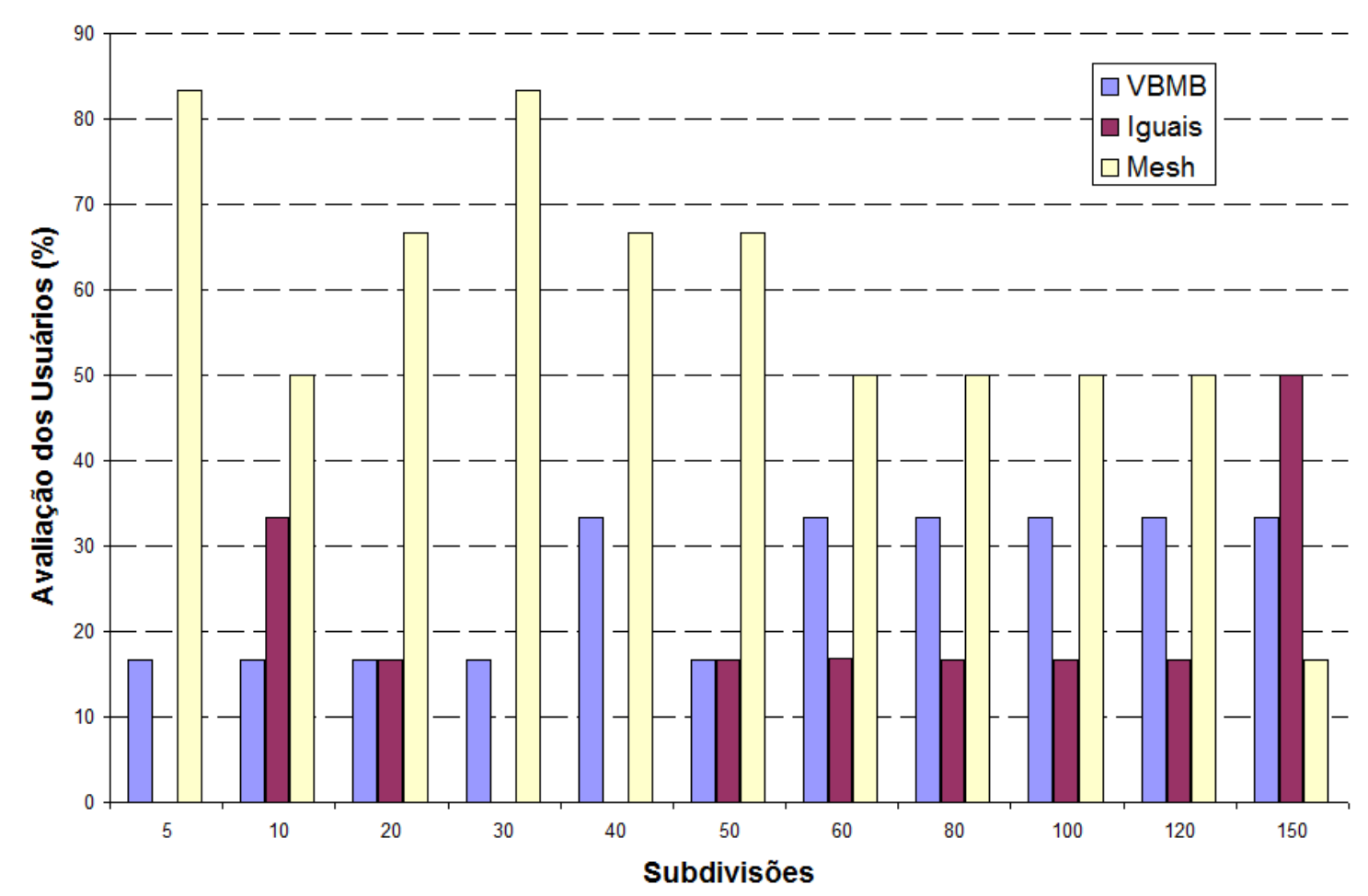

Figura 6.14: Comparação das técnicas VBMB e mesh render na reconstrução de um avatar

\section{Resultado da Percepção da Qualidade Visual do Avatar}

O gráfico 6.15 apresenta os resultados obtidos do teste que visa verificar a percepção da qualidade de reconstrução em relação ao aumento do número de subdivisões do avatar. Para possibilitar a comparação, os valores de cada usuários foram normalizados entre 0 a 1 , onde a nota 0 representa o pior resultado percebido pelo usuário e 1 o melhor resultado. Dessa forma, tornando possível uma análise das tendências de percepção de qualidade de cada usuário, padronizando os resultados entre o melhor e pior resultado percebido por cada usuário.

Pode se verificar que, como na hipótese, a qualidade percebida pelo usuário aumenta com o aumento do número de subdivisões, até um valor no qual, não é mais possível de se visualizar uma melhora, se saturando em um valor. Através desse gráfico e o gráfico 6.11 de performance, podemos ver que o valor de subdivisão $N=50$ é um bom valor onde os usuários julgaram que a qualidade visual atinge um valor bom e ao mesmo tempo a sua performance é boa, sendo igual à renderização por mesh. Já, quando uma qualidade melhor que a de $N=50$ 


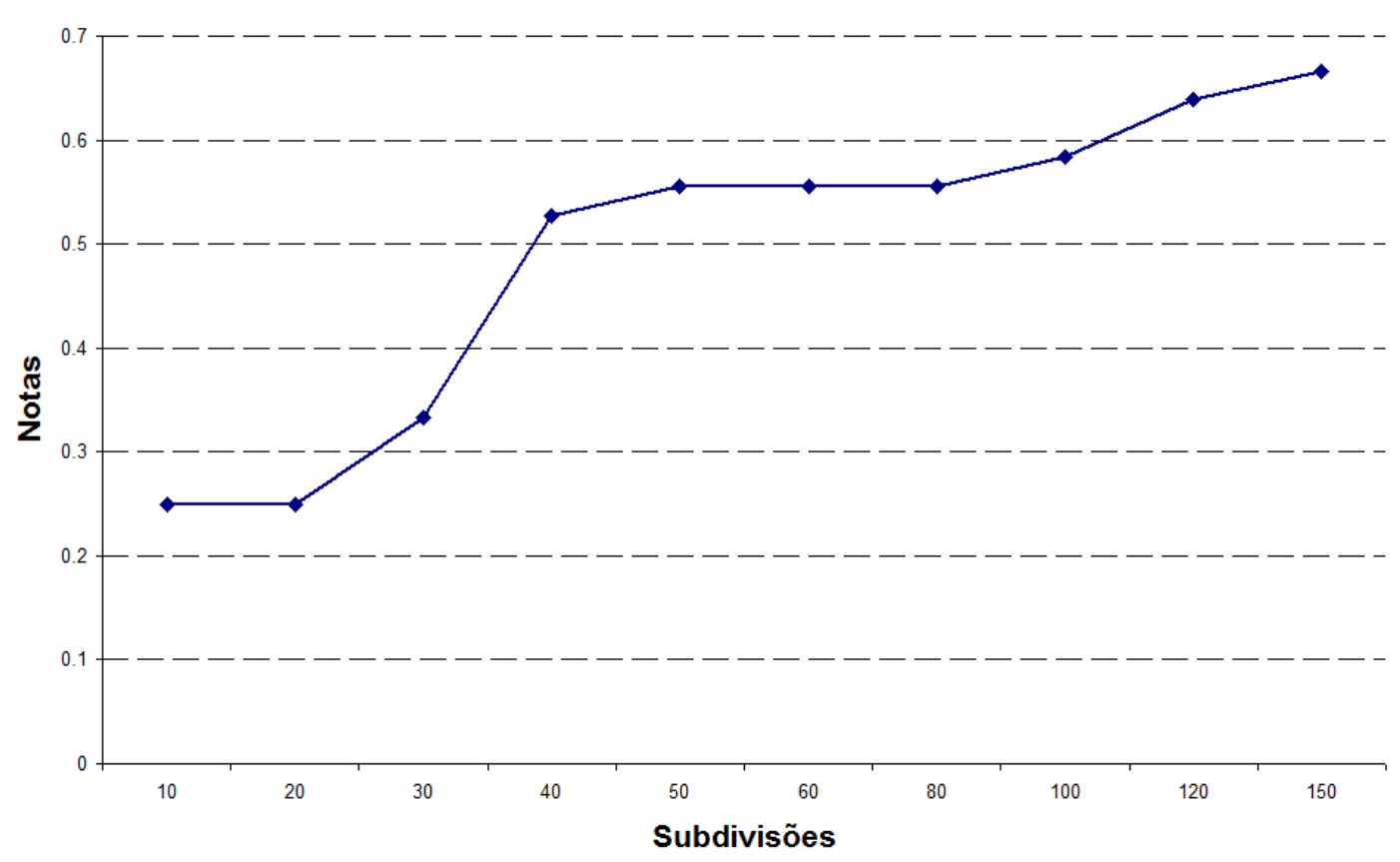

Figura 6.15: Qualidade visual do avatar X Valor de Subdivisões

é necessitada, o valor de $N=100$ é um bom valor, pois a qualidade percebida é maior e sua performance é em torno de 30 quadros por segundo.

\section{Resultado do Teste de Coerência com a Iluminação Virtual}

No teste para se verificar a integração do avatar com ou sem a coerência com a iluminação virtual, $100 \%$ dos usuários responderam que a integração era maior com a coerência com a iluminação. Devido ao pequeno número de usuários que foram submetidos aos testes, não se pode garantir que essa coerência 100\% aumenta a integração do avatar, mas nos da fortes indícios de que realmente essa coerência aumenta a sensação de integração do avatar.

\section{Resultados do Non-photorealistic Video-avatar}

O gráfico 6.16 apresenta os resultados obtidos do teste que visa provar as hipóteses sobre o conceito de non-photorealistic video-avatar. Por esse gráfico podemos notar que a integração do avatar é maior quando o ambiente e avatar são unificados com um único estilo não fotorrealístico, dando indícios que a hipótese de que o non-photorealistic video-avatar traz o aumento da integração do avatar é verdadeira.

Esse teste também dá um outro resultado interessante. Através do resultado, pode se notar que a integração do avatar e ambiente é bem menor quando os estilos não são iguais, i.e. quando existe um desconexo do estilo visual entre os objetos. Esse fato pode ser interpretado de 


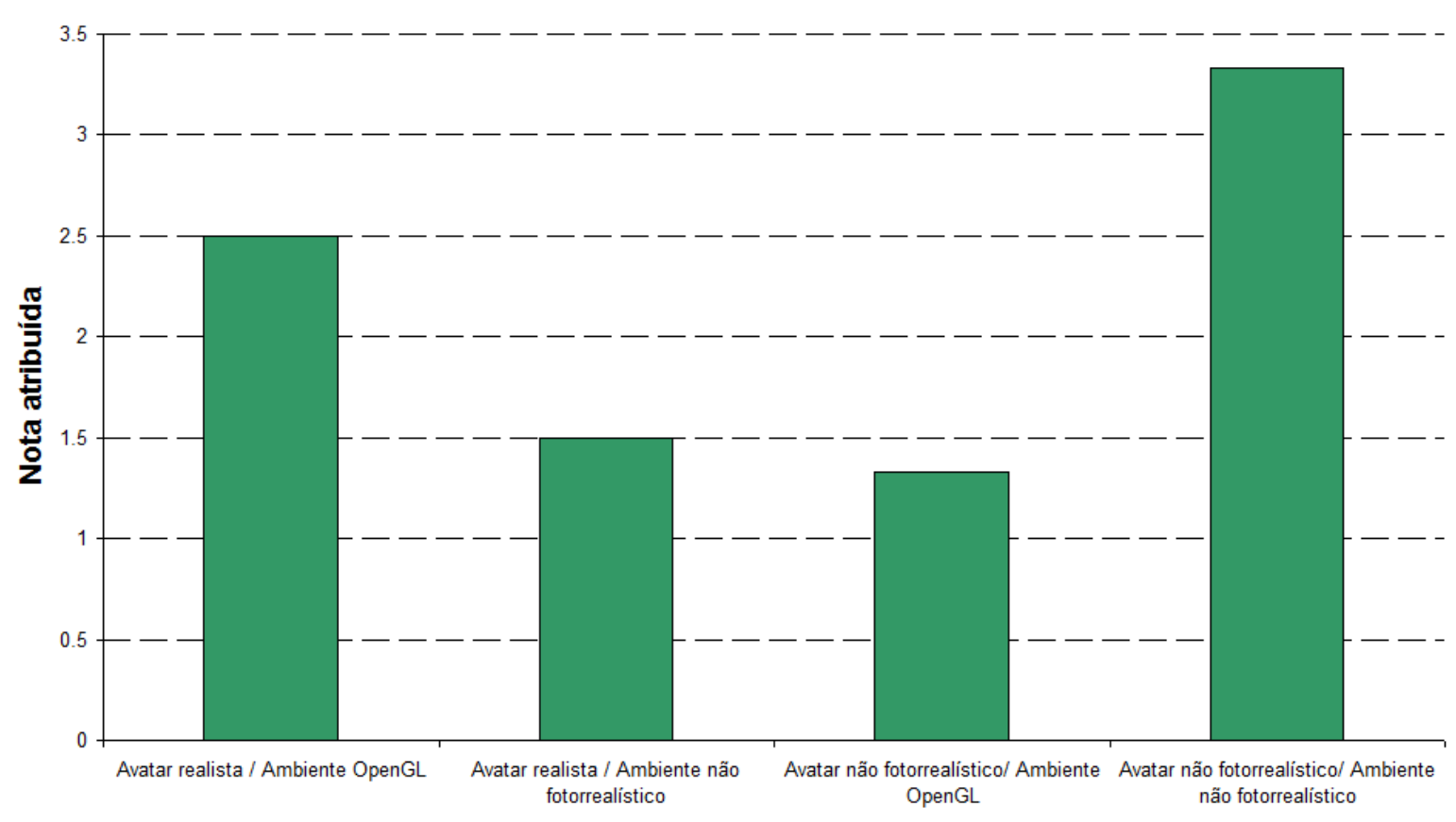

Figura 6.16: Comparação da integração do vídeo-avatar com o ambiente, ambos em diferentes estilos

outra forma, de que, os objetos são mais destacados quando se utiliza um estilo visual diferente do resto da cena. Assim, essa desconexão de estilos pode ser utilizado para a visualização de informações que se deseja destacar do restante da cena ou se deseja obter atenção do usuário. Por exemplo, quando se deseja que usuários imersos em um ambiente virtual prestem atenção em uma informação ou objeto importante, essa informação/objeto pode ser estilizado com um estilo diferente do restante da cena, se destacando visualmente e por sua vez aumentando a atenção dos usuários, como proposto no trabalho de Fischer, Haller e Thomas (2008). Assim, esse teste com usuários dá indícios de que a proposta de Fishcer é válida na prática.

Um último resultado obtido é apresentado no gráfico 6.17. Esse gráfico apresenta o resultado obtido com o último teste, que visa verificar a integração do avatar dentro de um ambiente de jogo. Nesse teste também o avatar com um mesmo estilo que o ambiente foi melhor avaliado que o avatar que não possui um mesmo estilo que o ambiente. Dessa forma, dando indícios que, quando um estilo não fotorrealístico é necessitado pelo jogo por motivos de design, o uso do non-photorealistic video-avatar traz mais integração do objeto reconstruído que o uso direto de técnicas de reconstrução geométricas convencionais. 


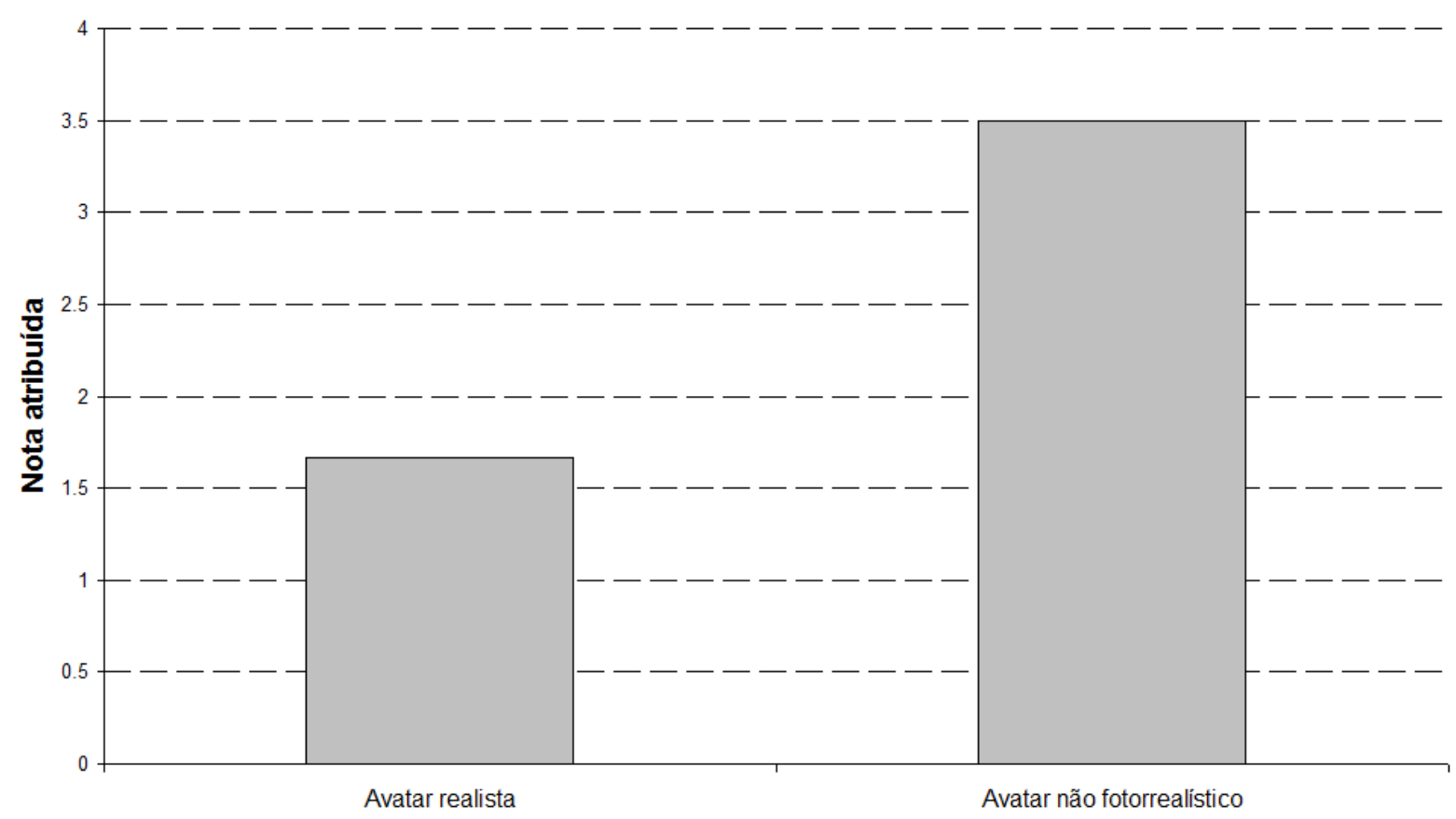

Figura 6.17: Comparação da integração do vídeo-avatar em um ambiente de jogo, com ou sem o estilo do ambiente.

\subsection{Integração com o Sistema iLive}

Um último resultado obtido neste trabalho foi a integração da técnica de reconstrução VBMB e da proposta de non-photorealistic video-avatar dentro do sistema de telecomunicação imersiva iLive, desenvolvida pelo Interlab. O sistema desenvolvido possui uma arquitetura como ilustrada pela figura 6.18 .

Nessa arquitetura, a captura das informações necessárias para a reconstrução são processados isoladamente da modelagem e renderização por motivos de paralelização dos processos e configurações físicas. Uma vez que a implementação da técnica VBMB também segue o modelo teórico proposto no capítulo 4 , os módulos de captura, modelagem e renderização são isolados em nível de código. Dessa forma, a integração da técnica VBMB foi procedida simplesmente pela inserção do módulo de captura da reconstrução no pacote "Video Capture" do sistema, e os módulos de modelagem e renderização no pacote "Avatar". 


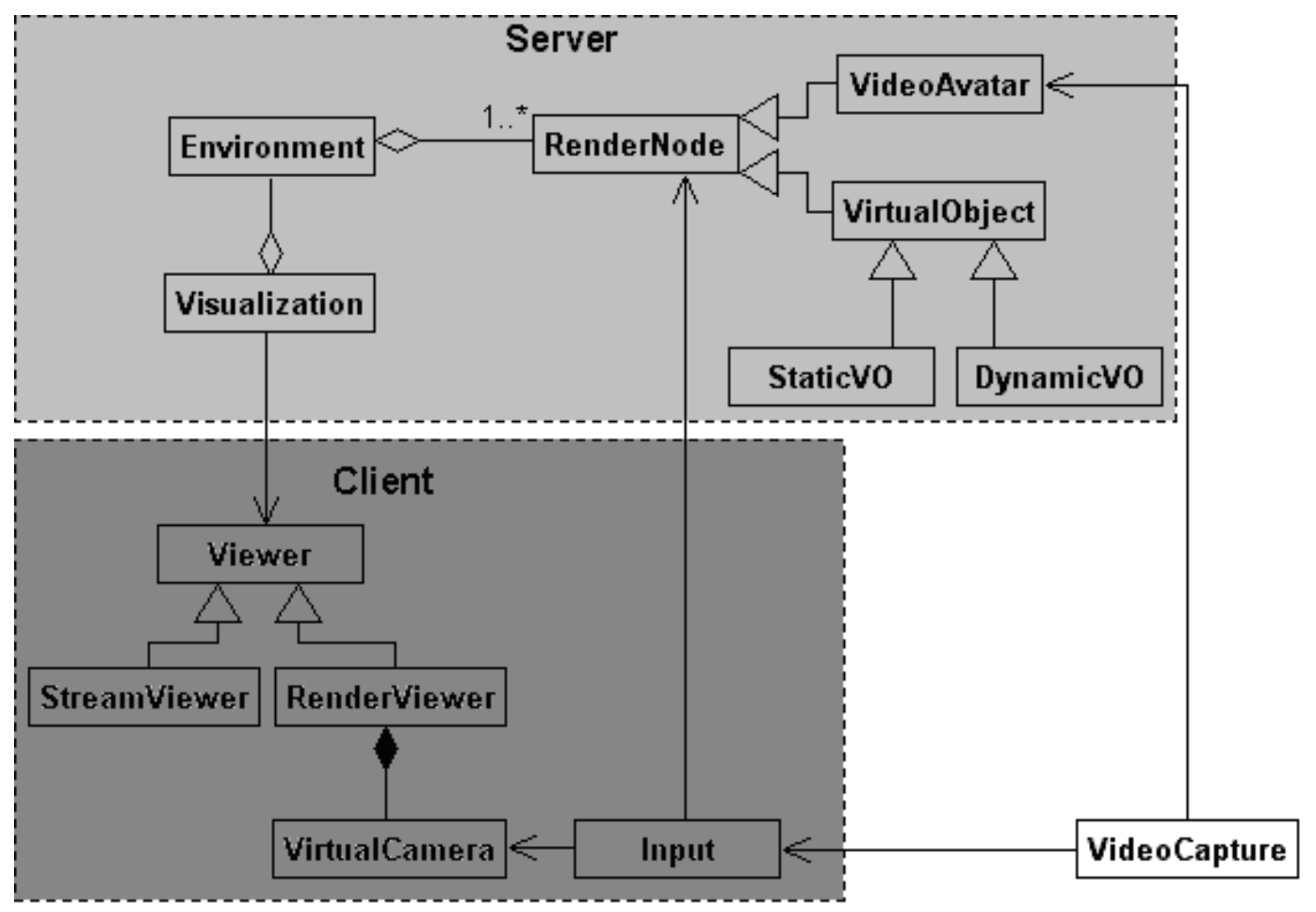

Figura 6.18: Arquitetura do sistema iLive

\subsection{Considerações Finais}

Este capítulo apresentou e discutiu os resultados obtidos neste trabalho. As provas de conceito das sub-seções 6.1 .1 e 6.1.2 deram indícios de que o vídeo-avatar reconstruído com as técnicas apresentados neste trabalho consegue representar detalhes do participante. A prova de conceito 6.1 .4 oferece evidências de que o conceito de non-photorealistic video-avatar consegue aumentar a integração do objeto reconstruído. Junto com o resultado obtido pela prova de conceito da seção 6.1 .3 pôde-se dizer que o vídeo-avatar possui boas chances de se integrar a cena virtual. Essas hipóteses são reforçadas pelos resultados obtidos com os testes de usuários da seção 6.2.2.

A partir destes resultados é possível dizer que as técnicas propostas neste trabalho podem criar um vídeo-avatar que possui as três características necessárias para o sistema iLive, uma vez que essas técnicas permitem o uso em tempo-real e os testes nos dão indícios de que o vídeo-avatar reconstruído pode representar detalhes e é integrado ao ambiente virtual.

O próximo capítulo apresenta a conclusão deste trabalho como um todo, apresentando discussões finais sobre a pesquisa, discussões sobre o uso dessas técnicas em jogos e os possíveis trabalhos futuros para se dar continuidade a este trabalho. 


\section{CONCLUSÃO}

Neste trabalho novas técnicas de reconstrução geométrica e renderização foram propostas. Estabeleceu-se que essa reconstrução e renderização deve possuir três características (temporeal, representação de detalhes e integração com o ambiente tridimensional) para a implementação do sistema de telecomunicação imersiva iLive desenvolvido pelo Interlab (Laboratório de Tecnologias Interativas da Escola Politécnica da Universidade de São Paulo).

Este capítulo apresenta discussões sobre o trabalho como um todo, tais como resultados obtidos, características e restrições. Também são feitas discussões sobre o uso de vídeoavatar dentro de jogos eletrônicos, apresentando os seus potenciais e problemas. Por fim, são apresentadas propostas de trabalhos futuros, para se dar continuidade à este trabalho.

\subsection{Discussões Sobre o Trabalho}

Este trabalho teve como base o iLive, projeto de telecomunicação imersiva desenvolvido pelo Interlab. Esse projeto visa o uso de tais sistemas em aplicações de educação e jogos eletrônicos. Através do estudo das possíveis aplicações do iLive, foram listadas três principais características que a representação visual do participante deveria possuir. São elas: tempo-real, para possibilitar uma aula interativa ao viva; representação de detalhes, para permitir a troca de informação entre participantes; e integração com o ambiente virtual, visando aumentar a imersão dos usuários em geral (BIOCCA, 1997).

\section{Desenvolvimento Teórico}

Inicialmente foi desenvolvida uma pesquisa das técnicas de reconstrução geométrica e renderização existentes, tais como visual hull (MATUSIK; BUEHLER; MCMILLAN, 2001), representação bidimensional (SISCOUTTO; TORI, 2004) e microfacet billboarding (YAMAZAKI et al., 2002), entre outras a fim de se analisar as possibilidades de geração do vídeo-avatar com essas características. Porém, nem uma das técnicas existentes atendiam todos os requisitos. Para 
se obter uma técnica que tenha todas essas características, inicialmente um modelo teórico para se modularizar os processos de reconstruções foi proposto, visando facilitar a visualização do fluxo de informações desses métodos, possibilitando assim a visualização de possíveis concatenações entre as técnicas de reconstrução.

Esse modelo se baseia na definição de image-based rendering e video-based rendering proposta por Magnor (2005), que considera que as reconstruções geométricas são constituídos por análise e síntese de imagem. Nesse modelo, a reconstrução é separada em três módulos: captura de dados, modelagem geométrica e renderização do modelo. Três etapas que fazem parte do processo de análise (captura e modelagem) e síntese (renderização) de imagem.

Sobre esse modelo, se procedeu uma nova análise das técnicas pesquisadas. Por meio dessa reanálise, criou-se a base da técnica de video-based microfacet billboarding (VBMB) que é uma concatenação da técnica de reconstrução microfacet bilboarding (YAMAZAKI et al., 2002) e da reconstrução por mapa de alturas e deformação de malha triangulares (OGI et al., 2003). Dessa forma, pode-se afirmar que a técnica de VBMB é um resultado direto desse modelo.

\section{Técnicas}

A técnica de VBMB é uma técnica de reconstrução e renderização em tempo-real que possibilita a representação visual de detalhes, como cabelos do participante, e possui baixa complexidade de configuração física. A coerência de sombreamento em relação à iluminação virtual também foi adicionada, através da técnica de mapeamento de normais (KRISHNAMURTHY; LEVOY, 1996), à técnica para se aumentar a integração do avatar ao ambiente virtual.

Neste trabalho, o conceito de non-photorealistic video-avatar também foi proposto. Essa proposta tem como objetivo melhorar a integração do avatar reconstruído através da aplicação de um estilo não fotorrealístico, diminuindo-se a diferença de níveis de realismo entre o avatar e o ambiente virtual. Essa proposta também pode ser utilizada em aplicações que dependam de um estilo não fotorrealístico por motivos de design, como em jogos eletrônicos, adequando o design visual do avatar com o ambiente.

A partir dos resultados visuais obtidos por implementação e testes preliminares com usuários pôde-se obter indícios de que o vídeo-avatar reconstruído possui as três características levantadas como necessárias para o sistema iLive.

A característica de tempo-real é atingida através da própria técnica de VBMB que pode ser aplicada em tempo-real. Já a característica de representação de detalhes pode ser atingida 
pela renderização por microfacet billboarding. Os resultados obtidos pela implementação e os gráficos de testes de usuários dão evidências que essa característica foi obtida. Por fim, acredita-se que a característica da integração com o ambiente virtual é atingida com a coerência à iluminação virtual e o conceito de non-photorealsitic video-avatar. Essa hipótese também é reforçada pelos resultados de implementação e dos testes preliminares de usuários.

\section{Demais Considerações}

Testes que usam dados de referência acurados como base poderiam ser aplicados de forma a comprovar algumas características, como a representação os detalhes. Porém, para se comprovar perfeitamente que todas essas características são atingidas na prática, principalmente características subjetivas, como a integração do avatar, o vídeo-avatar deve ser utilizado em diferentes aplicações de situações reais. Através dessas aplicações, deve-se observar se essas características são atingidas nas diferentes situações. A aplicação das propostas deste trabalho bem como a análise dos resultados são os próximos desafios deste trabalho e do sistema iLive.

Por fim, a técnica de VBMB, apesar de ser a única técnica de reconstrução e renderização que aparenta atender a todos os requisitos estabelecidos e ter baixa complexidade de configuração física, pode não ser adequada para ambientes onde uma reconstrução completa do participante é necessitada. Para tal reconstrução e renderização, o modelo teórico proposto neste trabalho pode ser utilizado. Para se obter essa reconstrução e renderização completa, a técnica de switching depth model pode ser utilizada no lugar da reconstrução por mapa de alturas dentro do VBMB, como parte da captura e modelagem. Porém não se deve esquecer que essas técnicas de reconstrução completa também têm o problema de possuir alta complexidade de configuração física, não sendo apropriadas para o uso em larga escala para usuários não especialistas. Essa criação de diferentes técnicas para o sistema iLive utilizando o modelo teórico proposto, não só enriquece o sistema, mas também valida ainda mais o modelo.

\subsection{Vídeo-Avatar e Jogos Eletrônicos}

Esta seção se dedica a discussões sobre o uso de vídeo-avatares emjogos eletrônico, discutindose mais profundamente as possibilidades de uso, restrições, características, questões de imersão, entre outros assuntos. 


\section{Imersão}

Pode-se inferir que criar uma imersão total do jogador dentro do ambiente virtual é um dos pontos almejados em diversos jogos, como apresentado em diversas narrativas de ficção cientificas como o estilo de jogo do futuro (LISBERGER, 1982; WACHOWSKI; WACHOWSKI, 1999; OSHII; SHIROW, 1995; OSHII, 2001) e estudados em diversos trabalhos científicos (OGI et al., 2003; PRINCE et al., 2002; HAUBER et al., 2005; BIOCCA, 1997). Uma forma de se atingir esse ponto de imersão pode ser pelo do uso do vídeo-avatar como meio de se inserir o usuário dentro do ambiente virtual.

Porém deve-se esclarecer que a técnica de vídeo-avatar não permite diretamente a imersão total do próprio jogador. Isto se deve ao fato de que o vídeo-avatar é uma representação visual do usuário, e em ambientes imersivos o participante não deve visualizar a sua própria imagem em terceira pessoa. Assim, fica a questão de como essa técnica pode aumentar a imersão ou pode ajudar na criação de jogos imersivos como os idealizados por diferentes artistas.

Apesar de o vídeo-avatar não poder gerar diretamente a imersão total da própria pessoa, ele permite que outros participantes sejam apresentados para o jogador com a mesma forma que eles aparentam. Dessa forma, essa técnica consegue montar um ambiente compartilhado onde há a ilusão de que todos os outros participantes são integrados no ambiente virtual, gerando a sensação de que esses estão imersos no ambiente.

Uma forma de se medir a imersão do usuário é através da sensação de presença. Biocca (1997) define três diferentes tipos de sensação de presença, a presença física - sensação de estar imerso em um ambiente, presença social - a sensação de estar com alguém e autopresença - a sensação de pertencer ao corpo. Através dessa definição de presença e uso dessa como métrica para a avaliação do nível de imersão, podo-se dizer que o vídeo-avatar pode prover o aumento da presença social, uma vez que os outros participantes são representados como eles são na vida real. E esse aumento de presença provoca, por sua vez, o aumento da imersão do jogador.

Existem também pesquisas estudando os efeitos exercidos à sensação de presença onde o usuário visualiza a sua representação visual, utilizando-se a sua própria imagem, como o trabalho de Perottoni et al. (2008), ou utilizando-se modelos tridimensionais que não condizem diretamente com a sua imagem, como o trabalho de Strepparava et al. (2007). Apesar de que essa linha de pesquisa é muito nova, não possuindo resultados suficientes para se tirar conclusões definitivas, muitos desses trabalhos apresentam indícios de que ocorre o aumento da imersão do usuário mesmo com a visão da própria representação em terceira pessoa. Nes- 
ses casos o vídeo-avatar também pode ser utilizado para a representação visual do jogador, contribuindo com o aumento da imersão do usuário.

\section{Realismo}

Um problema do uso de vídeo-avatares em jogos é o contraste de seu alto nível de realismo em relação ao ambiente virtual sintético, como apresentado na seção 5.2. Em jogos que tentam replicar a realidade ou possuem como ambientação cenas do dia a dia, como jogos de xadrez ou jogos de cartas, esse realismo não afeta a integração do avatar. Porém, o vídeo-avatar pode ser muito realista para jogos que possuem um design diferenciado, quebrando a integração desse com o ambiente em sua volta. Uma forma de se diminuir esse desnível de realismo é através do uso de non-photorealistic video-avatar e caricatured video-avatar, como proposto na seção 5.2 .

Contudo, mesmo com o uso dessas técnicas, não se pode garantir que o vídeo-avatar irá se integrar por completo com o ambiente em jogos com narrativas e design muito distantes da realidade atual, por exemplo jogos que se passam em idades medievais. Isto se deve ao fato de que o avatar reconstruído representa o usuário da forma que ele se encontra no momento da captura, não sendo possível de se garantir que suas vestimentas vão condizer com o design do jogo. Uma forma de se contornar esse problema seria a renderização somente da cabeça do participante sobre um modelo tridimensional pré-modelado, como proposto no trabalho de (OGI et al., 2003). Porém essa renderização envolve outras técnicas além do uso de vídeo-avatar. Assim, essa discussão não irá ser abordada neste trabalho.

\section{Troca de Informações e Interações}

Mesmo com todas as restrições anteriormente apontadas, uma grande vantagem no uso de vídeo-avatares em jogos está na possibilidade da troca de informações visuais através de expressões faciais e gestos. Através dessa troca de informações, novos designs de jogos podem ser gerados.

Um bom exemplo de estilo de jogo que pode utilizar bem essa troca de informação são jogos de cartas, do tipo poker. Nesse jogo de cartas, a análise do oponente através de expressões faciais e gestos é um importante fator dentro da própria mecânica do jogo em ambiente reais. Porém, esse aspecto não é explorado em implementações computacionais desse jogo. Com o uso da técnica de vídeo-avatares esse problema pode ser resolvido, provendo um design de jogo mais rico. A figura 7.1 apresenta uma imagem conceito, gerada utilizando-se o sistema 
de visualização de avatares apresentado na seção 6.1.4, de uma possível implementação do jogo utilizando-se vídeo-avatares.

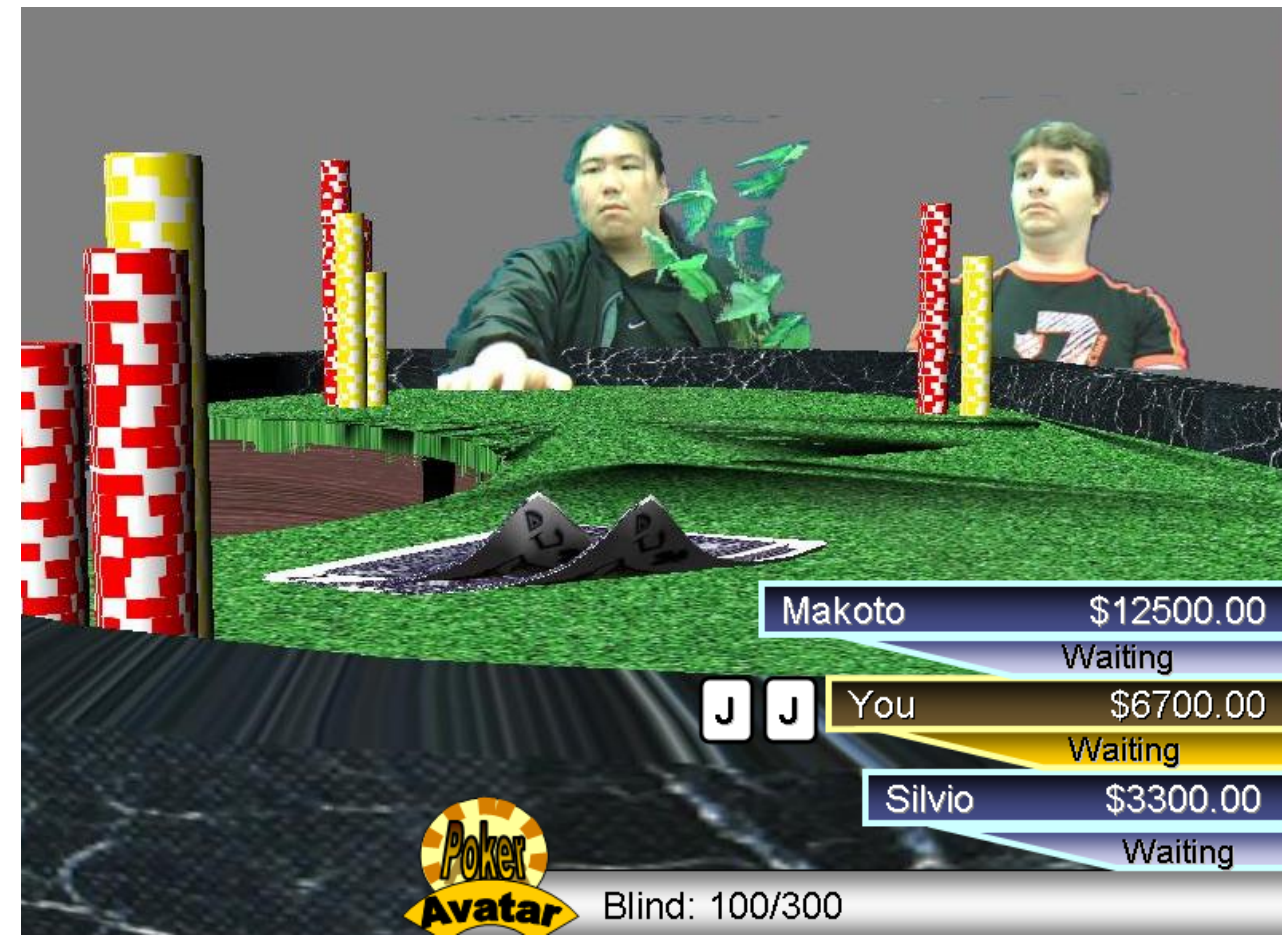

Figura 7.1: Imagem conceito de um jogo de poker utilizando vídeo-avatares.

Por fim, a integração de métodos de interações diretas com as mãos, como colisão, gestos ou outros métodos apresentados no trabalho de Bowman et al. (2004), também é um outro fator que pode aumentar a imersão do jogador. Tori et al. (2009) propõem em seu trabalho que a manipulação direta dos objetos virtuais pode aumentar a imersão do usuário através do aumento da autopresença. Dessa forma, podemos ter indícios de que a interação direta do avatar com o ambiente pode aumentar a imersão do participante.

Outro fator importante no uso de interações com o vídeo-avatar está no efeito visual apresentado aos outros visualizadores. Uma vez que essas interações de mão livre são exercidas com uma coerência visual da reconstrução, pois todos os movimentos do usuário real serão replicados ao vídeo-avatar, a ilusão passada para os outros visualizadores é que o jogador esteja interagindo diretamente com o objeto virtual. Assim, para os outros visualizadores, há um aumento da sensação de integração desse jogador dentro do ambiente virtual, aumentando também a sensação de presença social desses visualizadores. A figura 1.1 apresentada no início deste trabalho apresenta uma imagem conceito dessa interação do vídeo-avatar com o ambiente virtual. 


\subsection{Trabalhos futuros}

Diversas linhas podem ser levantadas como trabalhos futuros, para se dar continuidade a este trabalho. Uma linha seriam as implementações de melhorias da técnica VBMB, como a implementação completa da proposta de splats na técnica VBMB, para se melhorar a qualidade visual da técnica.

Outra linha seria a criação de novas técnicas utilizando-se o modelo teórico proposto, como a concatenação de técnicas como visual hull ou switching depth model e microfacet billboarding, possibilitando a reconstrução completa. A análise de outras técnicas sobre o modelo proposto também é um possível trabalho, provando-se, com isso, a aderência do modelo a diferentes técnicas e através disso possibilitar a visualização de mais concatenações.

Testes formais de larga escala com usuários e, por meio desses testes, provar as hipóteses abordas neste trabalho é um outro importante trabalho futuro. Os testes exercidos neste trabalho são de pequena escala e com usuários especialistas, não sendo o suficiente para se provar as hipóteses abordadas aqui. Principalmente, testes envolvendo o conceito de nonphotorealistic video-avatar são importantes, pois esse é novo conceito, não havendo resultados concretos que comprovem as hipóteses aqui levantadas.

Implementação e análise do conceito de caricatured video-avatar, extensão da proposta de non-photorealsitic video-avatar, é um outro trabalho futuro, concretizando-se essa proposta e provando-se, através de testes com usuários, que essa proposta é válida para se aumentar a integração do avatar no ambiente virtual.

Também, como levantado na seção 7.1, é necessária a criação de diferentes aplicações para se utilizar na prática o sistema iLive e através dessas aplicações, fazer um estudo de imersão, usabilidade e exercer testes de usuários para se comprovar as hipóteses levantadas neste trabalho na prática.

Por fim, a criação de jogos com o vídeo-avatar é uma última, mas não menos importante, linha de trabalhos futuros. Testar o vídeo-avatar como nova interface para jogos eletrônicos e testar as hipóteses abordadas na seção 7.2 é uma importante linha a se dar continuidade. Isso porque essas interfaces de interação, imersão dos participantes e compartilhamento de ambientes virtuais ainda não foram largamente exploradas, sendo uma linha que permite abrir novas possibilidades na área de jogos eletrônicos. 


\section{REFERÊNCIAS BIBLIOGRÁFICAS}

AKENINE-MöLLER, T.; HAINES, E.; HOFFMAN, N. Real-Time Rendering 3rd Edition. Natick, MA, USA: A. K. Peters, Ltd., 2008. 1045 p. ISBN 987-1-56881-424-7.

AZUMA, R. A survey of augmented reality. Azuma, R. T. A survey of augmented reality. In Computer Graphics (SIGGRAPH '95 Proceedings, Course Notes 9: Developing Advanced Virtual Reality Applications) (Aug. 1995), pp. 1-38. [s.n.], 1995. Disponível em: <citeseer.ist.psu.edu/azuma95survey.html > .

BARRON, J. L.; FLEET, D. J.; BEAUCHEMIN, S. S. Performance of optical flow techniques. International Journal of Computer Vision. [S.I.: s.n.], 1994. v. 12, p. 43-77.

BERGH, F. van den; LALIOTI, V. Software chroma keying in an immersive virtual environment. South African Computer Journal. [s.n.], 1999. v. 24, p. 155-162. Disponível em: <citeseer.ist.psu.edu/vandenbergh99software.html>.

BIOCCA, F. The cyborg's dilemma: Embodiment in virtual environments. CT '97:

Proceedings of the 2nd International Conference on Cognitive Technology (CT '97). Washington, DC, USA: IEEE Computer Society, 1997. p. 12. ISBN 0-8186-8084-9.

BLANZ, V.; VETTER, T. A morphable model for the synthesis of 3d faces. SIGGRAPH '99: Proceedings of the 26th annual conference on Computer graphics and interactive techniques. New York, NY, USA: ACM Press/Addison-Wesley Publishing Co., 1999. p. 187-194. ISBN 0-201-48560-5.

BLESER, G.; WUEST, H.; STRICKER, D. Online camera pose estimation in partially known and dynamic scenes. ISMAR '06: Proceedings of the 2006 Fifth IEEE and ACM International Symposium on Mixed and Augmented Reality (ISMAR'06). Washington, DC, USA: IEEE Computer Society, 2006. p. 56-65. ISBN 1-4244-0650-1.

BOWMAN, D. A.; KRUIJFF, E.; LAVIOLA, J. J.; POUPYREV, I. 3D User Interfaces: Theory and Practice. Redwood City, CA, USA: Addison Wesley Longman Publishing Co., Inc., 2004. ISBN 0201758679.

BOYKOV, Y.; JOLLY, M.-P. Interactive graph cuts for optimal boundary \& region segmentation of objects in n-d images. Computer Vision, 2001. ICCV 2001.

Proceedings. Eighth IEEE International Conference on. [S.I.: s.n.], 2001. v. 1, p. 105-112 vol.1.

CANNY, J. A computational approach to edge detection. IEEE Trans. Pattern Anal. Mach. Intell. Washington, DC, USA: IEEE Computer Society, 1986. v. 8, n. 6, p. 679-698. ISSN 0162-8828.

CANTONI, V.; CELLARIO, M.; PORTA, M. Perspectives and challenges in e-learning: towards natural interaction paradigms. Journal of Visual Languages and Computing. 
[s.n.], 2004. v. 15, n. 5, p. 333 - 345. ISSN 1045-926X. Image Understanding and Retrieval. Disponível em: <http://www.sciencedirect.com/science/article/B6WMM-4CJVC5G1/2/c1b0405e36d7d67b1922c62b8c11b3da $>$.

CHEN WEN-HUNG LIAO, P.-Y. C. Y.-L. Generation of 3d caricature by fusing caricature images. Systems, Man and Cybernetics, 2006. SMC '06. IEEE International Conference on. [S.I.: s.n.], 2006. v. 1, p. $866-871$.

CHOI, Y.-S.; LEE, I.-K.; KOO, B.-K. Painterly caricature maker. SIGGRAPH '09: SIGGRAPH '09: Posters. New York, NY, USA: ACM, 2009. p. 1-1.

COLLOMOSSE, J. P.; HALL, P. M. Video motion analysis for the synthesis of dynamic cues and futurist art. Graph. Models. San Diego, CA, USA: Academic Press Professional, Inc., 2006. v. 68, n. 5, p. 402-414. ISSN 1524-0703.

CRIMINISI, A.; CROSS, G.; BLAKE, A.; KOLMOGOROV, V. Bilayer segmentation of live video. Computer Vision and Pattern Recognition, 2006 IEEE Computer Society Conference on. [S.I.: s.n.], 2006. v. 1, p. 53-60. ISSN 1063-6919.

DECAUDIN, P. Modélisation par Fusion de Formes 3D pour la Synthèse d'Images

- Rendu de Scènes 3D imitant le Style 'Dessin Animé'. Tese (Thèse de doctorat)

- Université de Technologie de Compiègne, France, dec 1996. Disponível em:

$<$ www.antisphere.com/Research/ThesisPhDecaudin.php $>$.

DORNBACH, P. Implementation Of Bidirectional Ray Tracing Algorithm. 1998.

DRETTAKIS, G.; ROBERT, L.; BOUGNOUX, S. Interactive common illumination for computer augmented reality. Proceedings of the Eurographics Workshop on Rendering Techniques '97. London, UK: Springer-Verlag, 1997. p. 45-56. ISBN 3-211-83001-4.

FISCHER, J.; BARTZ, D. Stylized augmented reality for improved immersion. VR '05:

Proceedings of the 2005 IEEE Conference 2005 on Virtual Reality. Washington, DC, USA: IEEE Computer Society, 2005. p. 195-202, 325. ISBN 0-7803-8929-8.

FISCHER, J.; HALLER, M.; THOMAS, B. Stylized Depiction in Mixed Reality. International Journal of Virtual Reality. [S.I.: s.n.], 2008. v. 7, n. 4, p. 71-79.

GORAL, C. M.; TORRANCE, K. E.; GREENBERG, D. P.; BATTAILE, B. Modeling the interaction of light between diffuse surfaces. SIGGRAPH Comput. Graph. New York, NY, USA: ACM, 1984. v. 18, n. 3, p. 213-222. ISSN 0097-8930.

GREENE, N.; HECKBERT, P. Creating raster omnimax images from multiple perspective views using the elliptical weighted average filter. Computer Graphics and Applications, IEEE. [S.I.: s.n.], 1986. v. 6, n. 6, p. 21-27. ISSN 0272-1716.

GROSCH, T. Differential photon mapping: Consistent augmentation of photographs with correction of all light paths. Eurographics 2005 Short Papers, Trinity College, Dublin, Ireland. [S.I.: s.n.], 2005.

GROSS, M.; WüRMLIN, S.; NAEF, M.; LAMBORAY, E.; SPAGNO, C.; KUNZ, A.; KOLLER-MEIER, E.; SVOBODA, T.; GOOL, L. V.; LANG, S.; STREHLKE, K.; MOERE, A. $V$.; STAADT, O. blue-c: a spatially immersive display and $3 \mathrm{~d}$ video portal for telepresence. 
SIGGRAPH '03: ACM SIGGRAPH 2003 Papers. New York, NY, USA: ACM, 2003. p. 819-827. ISBN 1-58113-709-5.

GVILI, R.; KAPLAN, A.; OFEK, E.; YAHAV, G. Depth keying. SPIE Elec. Imaging. [S.I.: s.n.], 2003. v. 5006, p. 554-563.

HAUBER, J.; REGENBRECHT, H.; HILLS, A.; COCKBURN, A.; BILLINGHURST, M. Social presence in two- and three-dimensional videoconferencing. PRESENCE 2005: The 8th Annual International Workshop on Presence. [S.I.: s.n.], 2005.

HIRSCH, M.; LANMAN, D.; HOLTZMAN, H.; RASKAR, R. BiDi screen: A thin, depth-sensing LCD for 3D interaction using lights fields. ACM Trans. Graph. [S.I.]: ACM, 2009. v. 28, n. 5.

INSLEY, J.; SANDIN, D.; DEFANTI, T. Using video to create avatars in virtual reality. Visual Proceedings of the 1997 SIGGRAPH Conference. [S.I.: s.n.], 1997. p. 128.

ISHII, H. Tangible bits: beyond pixels. TEI '08: Proceedings of the 2nd international conference on Tangible and embedded interaction. New York, NY, USA: ACM, 2008. p. $x v-x x v$. ISBN 978-1-60558-004-3.

JENSEN, H. W. Importance driven path tracing using the photon map. in Eurographics Rendering Workshop. [S.I.]: Springer-Verlag, 1995. p. 326-335.

KANADE, T.; NARAYANAN, P. J. Virtualized reality: Perspectives on 4d digitization of dynamic events. IEEE Comput. Graph. Appl. Los Alamitos, CA, USA: IEEE Computer Society Press, 2007. v. 27, n. 3, p. 32-40. ISSN 0272-1716.

KANEKO, T.; TAKAHEI, T.; INAMI, M.; KAWAKAMI, N.; YANAGIDA, Y.; MAEDA, T.; TACHI, S. Detailed shape representation with parallax mapping. In Proceedings of the ICAT 2001. [S.I.: s.n.], 2001. p. 205-208.

KELTON, A. Second life: Reaching into the virtual world for real-world learning. ECAR research bulletin. [s.n.], 2007. v. 2007, n. 17. Disponível em: <http://www.educause.edu/ECAR/SecondLifeReachingintotheVirtu/161863>.

KIRNER, T. G.; KIRNER, C.; KAWAMOTO, A. L. S.; CANT aO, J.; PINTO, A.; WAZLAWICK, R. S. Development of a collaborative virtual environment for educational applications. Web3D '01: Proceedings of the sixth international conference on 3D Web technology. New York, NY, USA: ACM, 2001. p. 61-68. ISBN 1-58113-339-1.

KLEIN, G.; MURRAY, D. Compositing for small cameras. ISMAR '08: Proceedings of the 7th IEEE/ACM International Symposium on Mixed and Augmented Reality. Washington, DC, USA: IEEE Computer Society, 2008. p. 57-60. ISBN 978-1-4244-2840-3.

KOLSCH, M.; TURK, M.; HOLLERER, T. Vision-based interfaces for mobility. Mobile and Ubiquitous Systems: Networking and Services, 2004. MOBIQUITOUS 2004. The First Annual International Conference on. [S.I.: s.n.], 2004. p. 86-94.

KRISHNAMURTHY, V.; LEVOY, M. Fitting smooth surfaces to dense polygon meshes. SIGGRAPH '96: Proceedings of the 23rd annual conference on Computer graphics and interactive techniques. New York, NY, USA: ACM, 1996. p. 313-324. ISBN 0-89791-746-4. 
KUMAR, M.; TORR, P.; ZISSERMAN, A. Learning layered motion segmentations of video. Computer Vision, 2005. ICCV 2005. Tenth IEEE International Conference on. [S.I.: s.n.], 2005. v. 1, p. 33-40 Vol. 1. ISSN 1550-5499.

LAURENTINI, A. The visual hull concept for silhouette-based image understanding. IEEE Trans. Pattern Anal. Mach. Intell. Washington, DC, USA: IEEE Computer Society, 1994. v. 16, n. 2, p. 150-162. ISSN 0162-8828.

LEE, S.-Y.; KIM, I.-J.; AHN, S. C.; LIM, M.-T.; KIM, H.-G. Toward immersive telecommunication: 3d video avatar with physical interaction. ICAT '05: Proceedings of the 2005 international conference on Augmented tele-existence. New York, NY, USA: ACM, 2005. p. 56-61. ISBN 0-473-10657-4.

LI, M.; SCHIRMACHER, H.; MAGNOR, M.; SIEDEL, H.-P. Combining stereo and visual hull information for on-line reconstruction and rendering of dynamic scenes. Multimedia Signal Processing, 2002 IEEE Workshop on. [S.I.: s.n.], 2002. p. 9-12.

LIM FEDOROV, A. S.-D. K. Y.-K. 3d caricature generation system on the mobile handset using a single photograph. Parallel Processing Workshops, 2007. ICPPW 2007.

International Conference on. [S.I.: s.n.], 2007. p. $37-37$.

LISBERGER, S. TRON. USA: Groucho II Film Partnershipy, 1982. 1 filme (96 min), son., color.

MAGNOR, M. Video-Based Rendering. [S.I.]: A K Peters, 2005.

MATUSIK, W.; BUEHLER, C.; MCMILLAN, L. Polyhedral visual hulls for real-time rendering. Proceedings of the 12th Eurographics Workshop on Rendering Techniques. London, UK: Springer-Verlag, 2001. p. 115-126. ISBN 3-211-83709-4.

MATUSIK, W.; BUEHLER, C.; RASKAR, R.; GORTLER, S.; MCMILLAN, L. Image-based visual hulls. in Proceedings of ACM SIGGRAPH 2000. [S.I.: s.n.], 2000. p. 369-374.

MATUSIK, W.; PFISTER, H.; NGAN, A.; BEARDSLEY, P.; ZIEGLER, R.; MCMILLAN, L. Image-based 3d photography using opacity hulls. ACM Trans. Graph. New York, NY, USA: ACM, 2002. v. 21, n. 3, p. 427-437. ISSN 0730-0301.

MILGRAM, P.; TAKEMURA, H.; UTSUMI, A.; KISHINO, F. Augmented reality: A class of displays on the reality-virtuality continuum. Proceedings of the SPIE Conference on Telemanipulator and Telepresence Technologies. Boston, Massachusetts, USA: [s.n.], 1994. (Proceedings of SPIE, v. 2351), p. 282-292.

NAEF, M.; STAADT, O.; GROSS, M. Spatialized Audio Rendering for Immersive Virtual Environments. 2002.

NAEF, M.; STAADT, O.; GROSS, M. blue-c api: a multimedia and 3d video enhanced toolkit for collaborative $\mathrm{vr}$ and telepresence. VRCAI '04: Proceedings of the 2004 ACM SIGGRAPH international conference on Virtual Reality continuum and its applications in industry. New York, NY, USA: ACM, 2004. p. 11-18. ISBN 1-58113-884-9.

NAKAMURA, R. Vídeo Avatar com detecção de colisão para Realidade Aumentada e Jogos. Tese (Doutorado) — Escola Politénica cda Universidade de São Paulo, 2008. 
NAKAMURA, R.; TORI, R. Improving collision detection for real-time video avatar interaction. SVR '08: Proceedings of $\mathbf{X}$ Symposium on Virtual Reality. [S.I.: s.n.], 2008. p. 105-114.

OGI, T.; YAMADA, T.; KURITA, Y.; HATTORI, Y. Y.; HIROSE, M. Usage of video avatar technology for immersive communication. ACL 2003 Co-located Workshop: First International Workshop on Language Understanding and Agents for Real World Interaction. [S.I.: s.n.], 2003.

OGI, T.; YAMADA, T.; TAMAGAWA, K.; KANO, M.; HIROSE, M. Immersive telecommunication using stereo video avatar. VR '01: Proceedings of the Virtual Reality 2001 Conference (VR'01). Washington, DC, USA: IEEE Computer Society, 2001. p. 45. ISBN 0-7695-0948-7.

OLIVEIRA, M. M.; BISHOP, G.; MCALLISTER, D. Relief texture mapping. SIGGRAPH '00: Proceedings of the 27th annual conference on Computer graphics and interactive techniques. New York, NY, USA: ACM Press/Addison-Wesley Publishing Co., 2000. p. 359-368. ISBN 1-58113-208-5.

OSHII, M. Avalon. Japan: Deiz Production, 2001. 1 filme (107 min), son., color.

OSHII, M.; SHIROW, M. Ghost in the Shell. Japan: Bandai Visual Company, 1995. 1 filme (82 $\mathrm{min})$, son., color.

PAMPlonA, V. F.; OlIVEIRA, M. M.; NEDEL., L. P. Game Programming Gems VII. Hingham, Massachusetts: Charles River Media, Inc., 2008. 401-412. p.

PEROTTONI, A. J.; ROSADO, F. Y.; Ribeiro Jr, J. R.; COSTA, L. M. da. Desenvolvimento de um Sistema de Imersão em Realidade Aumentada. 2008. (Trabalho de conclusão de curso) - Escola Politécnica da Universidade de São Paulo, 2008.

PETIT, B.; LESAGE, J.-D.; BOYER, E.; RAFFIN, B. Virtualization gate. SIGGRAPH '09: ACM SIGGRAPH 2009 Emerging Technologies. New York, NY, USA: ACM, 2009. p. 1-1. ISBN 978-1-60558-833-9.

PRAUN, E.; HOPPE, H.; WEBB, M.; FINKELSTEIN, A. Real-time hatching. In Proceedings of SIGGRAPH 2001. [S.I.]: ACM Press, 2001. p. 579-584.

PRINCE, S.; CHEOK, A.; FARBIZ, F.; WILLIAMSON, T.; JOHNSON, N.; BILLINGHURST, M.; KATO, H. 3d live: real time captured content for mixed reality. Mixed and Augmented Reality, 2002. ISMAR 2002. Proceedings. International Symposium on. [S.I.: s.n.], 2002. p. 7-317.

QIAN, R.; SEZAN, M. Video background replacement without a blue screen. Image Processing, 1999. ICIP 99. Proceedings. 1999 International Conference on. [S.I.: s.n.], 1999. v. 4, p. 143-146 vol.4.

RASKAR, R.; NII, H.; DEDECKER, B.; HASHIMOTO, Y.; SUMMET, J.; MOORE, D.; ZHAO, Y.; WESTHUES, J.; DIETZ, P.; BARNWELL, J.; NAYAR, S.; INAMI, M.; BEKAERT, P.; NOLAND, M.; BRANZOI, V.; BRUNS, E. Prakash: lighting aware motion capture using photosensing markers and multiplexed illuminators. SIGGRAPH '07: ACM SIGGRAPH 2007 papers. New York, NY, USA: ACM, 2007. p. 36. 
REN, L.; PFISTER, H.; ZWICKER, M. Object space ewa surface splatting: A hardware accelerated approach to high quality point rendering. Computer Graphics Forum. [S.I.: s.n.], 2002. p. 461-470.

SAITO, T.; TAKAHASHI, T. Comprehensible rendering of 3-d shapes. SIGGRAPH Comput. Graph. New York, NY, USA: ACM, 1990. v. 24, n. 4, p. 197-206. ISSN 0097-8930.

SANCHES, S. R. R. A Utilização da Técnica de Chromakey na Composição de Cenas em Ambientes de Realidade Misturada. Dissertação (Mestrado) - Centro Universitário Euripedes de Marília, UNIVEM, 2007.

SANCHES, S. R. R.; SEMENTILLE, A. C.; TORI, R. Método para segmentação de vídeo em tempo-real para aplicações em teleimersão. SVR 2009: Proceedings of XI Symposium on Virtual ans Augmented Reality. Porto Alegre, RS, Brasil: Sociedade Brasileira de Computação, 2009. p. 175-186.

SHUM, H.-Y.; CHAN, S.-C.; KANG, S. B. Image-Based Rendering. Secaucus, NJ, USA: Springer-Verlag New York, Inc., 2006. ISBN 0387211136.

SHUM, H. yeung; KANG, S. B. A survey of image-based rendering techniques. In Videometrics, SPIE. [S.I.: s.n.], 1999. p. 2-16.

SISCOUTTO, R.; TORI, R. Augmented virtuality tele-conferencing. SVR '04: Proceedings of VII Symposium on Virtual Reality. [S.I.: s.n.], 2004. p. 124-136.

SISCOUTTO, R. A. Proposta de Arquitetura para Teleconferência Baseada na Integração de Vídeo Avatar Estereoscópico em Ambiente Virtual Tridimensional. Tese (Doutorado) Escola Politénica cda Universidade de São Paulo, 2003.

SMITH, A. R.; BLINN, J. F. Blue screen matting. SIGGRAPH '96: Proceedings of the 23rd annual conference on Computer graphics and interactive techniques. New York, NY, USA: ACM, 1996. p. 259-268. ISBN 0-89791-746-4.

STREPPARAVA, M. G.; HARB, M. O.; RUSSO, S.; ZORZI, F.; RIZZI, A. Individual differences in virtual environments. an experimental research on emotions, behaviour and sense of presence in second life. PRESENCE 2007: Proceedings of the The 10th Annual International Workshop on Presence. [S.I.: s.n.], 2007. p. 191-194. ISBN 0-9792217-1-4.

TAMAGAWA, K.; YAMADA, T.; OGI, T.; HIROSE, M. Developing a 2.5-d video avatar. Signal Processing Magazine, IEEE. [S.I.: s.n.], 2001. v. 18, n. 3, p. $35-42$. ISSN 1053-5888.

TOMOYOSE, A. N.; SANCHES, S. R. R.; TORI, R. Integração da estereoscopia à mecânica dos jogos. SBGames 20009 - VIII Simpósio Brasileiro de Jogos e Entretenimento Digital. [S.I.: s.n.], 2009. p. 1-8.

TORI, R. Educação sem Distância: as tecnologias interativas na redução de distâncias em ensino e aprendizagem. [S.I.]: Editora Senac São Paulo, 2010.

TORI, R.; NUNES, F.; NAKAMURA, R.; BERNARDES, J.; CORRêA, C.; TOKUNAGA, D. Design de interação para um atlas virtual de anatomia usando realidade aumentada e gestos. Interaction 09 | South America. [S.I.: s.n.], 2009. 
TRIAS, L.; TORI, R. Janela3d: a visual telecommunication tool sensible to user's viewpoint. SVR 2009: Proceedings of XI Symposium on Virtual ans Augmented Reality. Porto Alegre, RS, Brasil: Sociedade Brasileira de Computação, 2009. p. 69-78.

WACHOWSKI, A.; WACHOWSKI, L. The Matrix. USA: Groucho II Film Partnershipy, 1999. 1 filme (136 $\mathrm{min})$, son., color.

WATT, A. 3d Computer Graphics. 3rd. ed. [S.I.]: Addison Wesley, 2000. 570 p. ISBN 0-201-39855-9.

WINNEMöLLER, H.; OLSEN, S. C.; GOOCH, B. Real-time video abstraction. ACM Trans. Graph. New York, NY, USA: ACM, 2006. v. 25, n. 3, p. 1221-1226. ISSN 0730-0301.

XIE, J.; CHEN, Y.; LIU, J.; MIAO, C.; GAO, X. Interactive 3d caricature generation based on double sampling. MM '09: Proceedings of the seventeen ACM international conference on Multimedia. New York, NY, USA: ACM, 2009. p. 745-748. ISBN 978-1-60558-608-3.

YAMAZAKI, S.; SAGAWA, R.; KAWASAKI, H.; IKEUCHI, K.; SAKAUCHI, M. Microfacet billboarding. EGRW '02: Proceedings of the 13th Eurographics workshop on Rendering. Aire-la-Ville, Switzerland, Switzerland: Eurographics Association, 2002. p. 169-180. ISBN 1-58113-534-3.

ZWICKER, M.; PFISTER, H.; BAAR, J. van; GROSS, M. Surface splatting. SIGGRAPH '01: Proceedings of the 28th annual conference on Computer graphics and interactive techniques. New York, NY, USA: ACM, 2001. p. 371-378. ISBN 1-58113-374-X. 
Apêndice I - TESTE COM USUÁRIOS 


\section{Vídeo Avatar - Teste com Usuários}

Compare as duas imagens e as avalie quanto à qualidade, deformação e, principalmente, ao nível de detalhamento e assinale a melhor das duas (Imagens de uma flor):

\begin{tabular}{|l|l|l|l|}
\hline & I1 & Iguais & I2 \\
\hline 5 & & & \\
\hline 10 & & & \\
\hline 20 & & & \\
\hline 30 & & & \\
\hline 40 & & & \\
\hline 50 & & & \\
\hline 60 & & & \\
\hline 80 & & & \\
\hline 100 & & & \\
\hline 120 & & & \\
\hline 150 & & & \\
\hline
\end{tabular}

Compare as duas imagens e as avalie quanto à qualidade, deformação e, principalmente, ao nível de detalhamento e assinale a melhor das duas (Imagens de uma pessoa):

\begin{tabular}{|l|l|l|l|}
\hline & I1 & Iguais & I2 \\
\hline 5 & & & \\
\hline 10 & & & \\
\hline 20 & & & \\
\hline 30 & & & \\
\hline 40 & & & \\
\hline 50 & & & \\
\hline 60 & & & \\
\hline 80 & & & \\
\hline 100 & & & \\
\hline 120 & & & \\
\hline 150 & & & \\
\hline
\end{tabular}

Comente as diferenças entre as duas imagens: 
Compare as imagens:

Faça a comparação da imagem atual àquela imediatamente anterior a ela

\begin{tabular}{|l|l|l|l|}
\hline & Pior & Igual & Melhor \\
\hline 10 & & & \\
\hline 20 & & & \\
\hline 30 & & & \\
\hline 40 & & & \\
\hline 50 & & & \\
\hline 60 & & & \\
\hline 80 & & & \\
\hline 100 & & & \\
\hline 120 & & & \\
\hline 150 & & & \\
\hline
\end{tabular}

Comente suas impressões:

Indique qual dos dois avatares encontra-se mais integrado ao ambiente:

- Com Sombra

- Iguais

- Sem Sombra

Comente suas impressões: 
Avalie o quão integrado o avatar encontra-se em relação ao ambiente:

\begin{tabular}{|l|l|l|l|l|}
\hline & $\begin{array}{c}\text { O Avatar é muito } \\
\text { diferente do modelo } \\
\text { sintetizado (1) }\end{array}$ & & (2) & $\begin{array}{c}\text { Não é possível } \\
\text { distinguir qual dos } \\
\text { modelos foi } \\
\text { reconstruído (4) }\end{array}$ \\
\hline $\begin{array}{l}\text { PhotoRealistic } \\
\text { Avatar / Standard } \\
\text { OpenGL Rendered } \\
\text { Scene }\end{array}$ & & & & \\
\hline $\begin{array}{l}\text { PhotoRealistic } \\
\text { Avatar / } \\
\text { NonPhotoRealistic } \\
\text { Scene }\end{array}$ & & & & \\
\hline $\begin{array}{l}\text { NonPhotoRealistic } \\
\text { Avatar / Standard } \\
\text { OpenGL Rendered } \\
\text { Scene }\end{array}$ & & & & \\
\hline $\begin{array}{l}\text { NonPhotoRealistic } \\
\text { Avatar / } \\
\text { NonPhotoRealistic } \\
\text { Scene }\end{array}$ & & & & \\
\hline
\end{tabular}

\section{Comente suas impressões:}

Avalie o quão integrado o avatar encontra-se em relação ao ambiente: Avalie a imersão provocada pelo jogo

\begin{tabular}{|c|c|c|c|c|}
\hline & $\begin{array}{l}\text { O Avatar destrói a } \\
\text { imersão no } \\
\text { ambiente de jogo } \\
\text { (1) }\end{array}$ & (2) & (3) & $\begin{array}{c}\text { O Avatar se integra } \\
\text { perfeitamente ao } \\
\text { jogo (4) }\end{array}$ \\
\hline $\begin{array}{l}\text { PhotoRealistic } \\
\text { Avatar / Ambiente } \\
\text { de Jogo }\end{array}$ & & & & \\
\hline $\begin{array}{l}\text { NonPhotoRealistic } \\
\text { Avatar / Ambiente } \\
\text { de Jogo }\end{array}$ & & & & \\
\hline
\end{tabular}

\section{Comente suas impressões:}

